The copyright of this thesis vests in the author. No quotation from it or information derived from it is to be published without full acknowledgement of the source. The thesis is to be used for private study or noncommercial research purposes only.

Published by the University of Cape Town (UCT) in terms of the non-exclusive license granted to UCT by the author. 


\section{Large cell lymphoma: \\ Correlation of HIV status and prognosis with differentiation profiles assessed by immunophenotyping}

by

Student: SUGESHNEE PATHER

Student number: PTHSUG001

\section{SUBMITTED TO THE UNIVERSITY OF CAPE TOWN}

In (partial if the degree was by coursework AND dissertation) fulfilment of the requirements for the degree

Master of Medicine degree AnatomPathol 3

Faculty of Health Sciences

UNIVERSITY OF CAPE TOWN

Date of submission: $15^{\text {th }}$ August 2011

Supervisor: DR K Pillay

Name of Department and University: Anatomical Pathology

University of Cape Town 


\section{DECLARATION}

I, Sugeshnee Pather, hereby declare that the work on which this dissertation/thesis is based is my original work (except where acknowledgements indicate otherwise) and that neither the whole work nor any part of it has been, is being, or is to be submitted for another degree in this or any other university.

I empower the university to reproduce for the purpose of research either the whole or any portion of the contents in any manner whatsoever.

\section{Signed by candidate}

Signature:

Date: $28^{\text {th }}$ October 2011

\section{DEDICATION AND ACKNOWLEDGEMENTS}

From the depth of the chambers of my heart I dedicate this dissertation to Satguru Babaji Gurinder Singh in gratitude of copious blessings of grace, love, inspiration and bounty.

I wholeheartedly thank my loving and nurturing mother, Amaravathee Naick, for always providing unyielding support and encouragement.

I warmly thank Dr Komala Pillay for being a consistently inspiring, supportive and encouraging supervisor.

Thank you to Professor Dhirendra Govender for sharing invaluable knowledge and selflessly investing time and effort in teaching of registrars. Thank you for inspiring the initiation and completion of this dissertation.

I sincerely thank Mrs Heather McLeod for always assisting in a dedicated and competent manner. Your remarkably pleasant demeanour and high standard of professionalism have long been inspirational to all with whom you have worked.

Thank you to Dr Zainab Mohamed, senior specialist, department of radiation oncology, Groote Schuur Hospital, for providing invaluable contributions to this research project. Your dedicated nature and high standard of clinical practice are most noble, admirable and inspiring attributes. 


\section{TABLE OF CONTENTS}

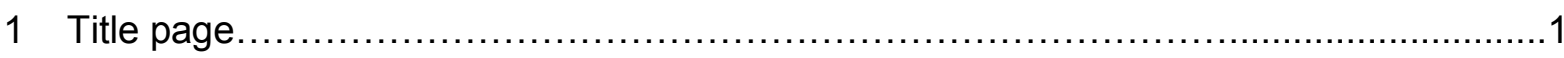

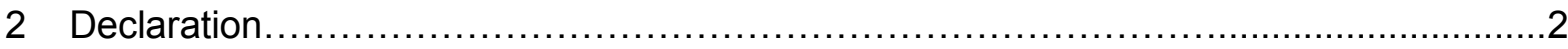

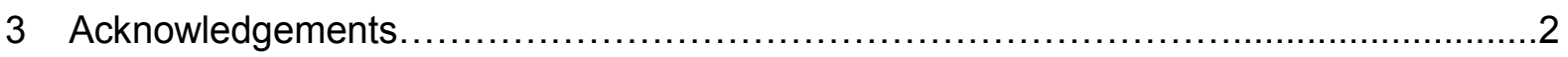

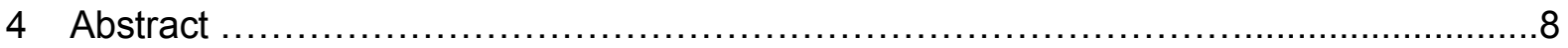

5 Review of the literature

5.1 Concise history of lymphoma classifications and evolution of diffuse large B cell lymphoma and plasmablastic lymphoma................................

5.2 Diffuse large B-cell lymphomas in relation to B-lymphocyte

differentiation. .16

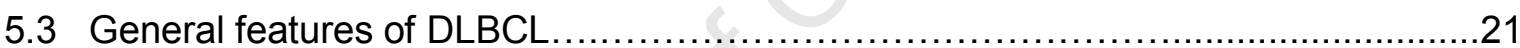

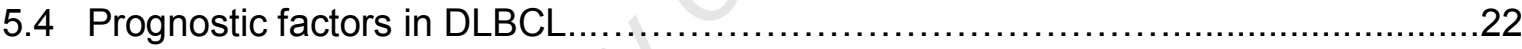

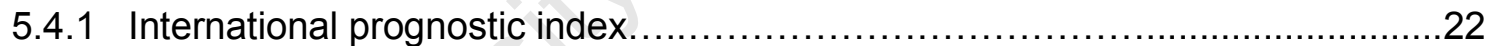

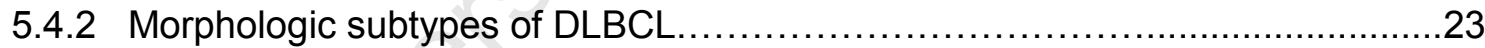

5.4.3 Subdivisions of DLBCL based on immunohistochemistry and

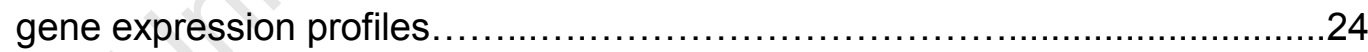

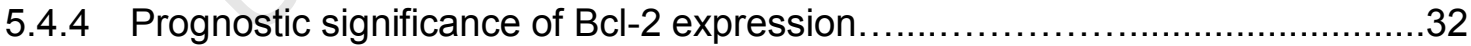

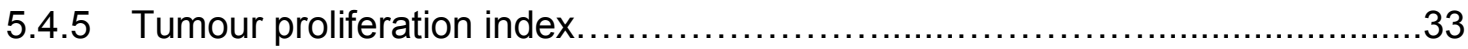

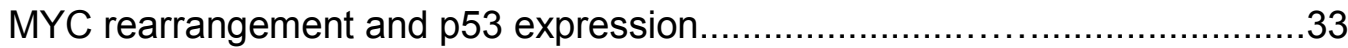

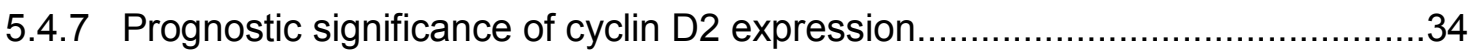

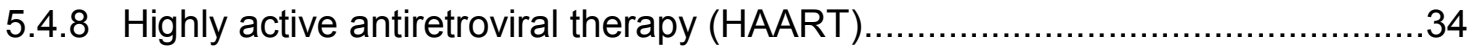

5.5 South African National Antiretroviral Treatment Guidelines...................................35

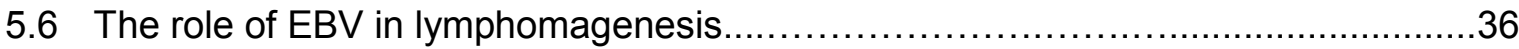

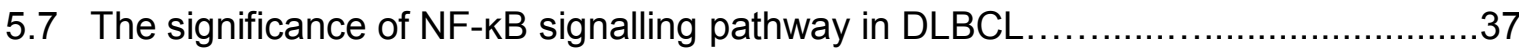




\subsection{Plasmablastic lymphoma}

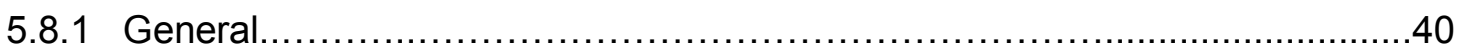

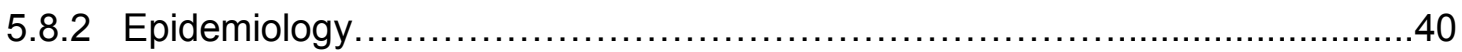

\subsubsection{Aetiology}

5.8.3(a) Immunosuppression...................................................

$5.8 .3(b)$ Epstein-Barr virus................................................. 41

5.8.3(c) Human herpesvirus-8 (HHV-8) .......................................42

5.8.4 Clinical features of plasmablastic lymphoma.....................................43

5.8.5 Morphologic features of plasmablastic lymphoma.................................44

5.8.6 Immunohistochemical features of plasmablastic lymphoma..........................44

5.8.7 Molecular findings in plasmablastic lymphoma....................................45

5.8.8 Outcome of plasmablastic lymphoma................................................

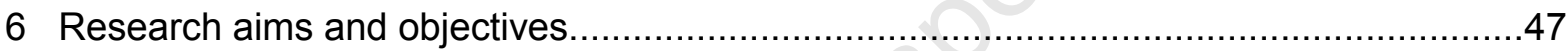

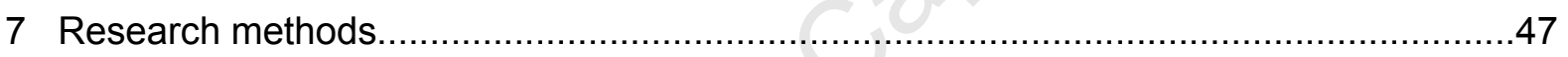

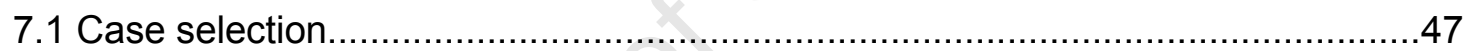

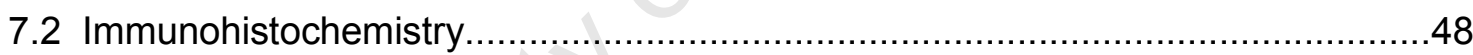

8 Results

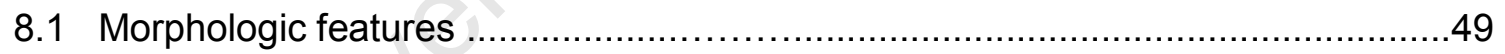

8.2 Immunoprofiles /scoring of immunohistochemistry...................................53

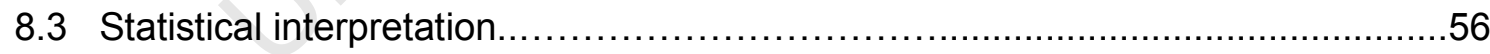

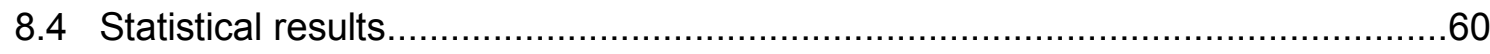

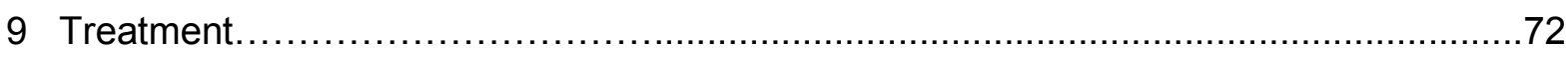

9.1 Co-morbidities occurring during the course of the study....................................72

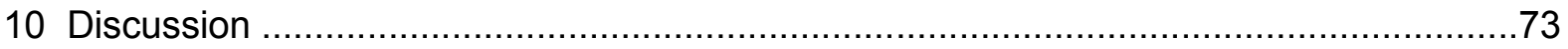

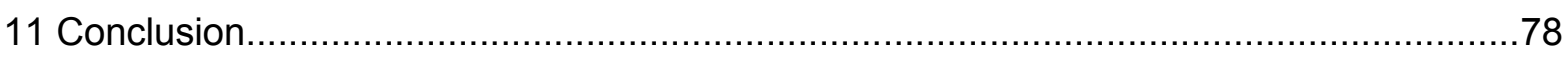

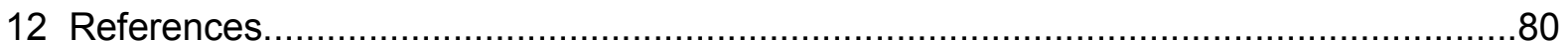

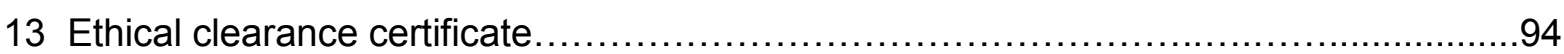




\section{$\underline{\text { ABBREVIATIONS }}$}

ABC DLBCL Activated B-cell-like diffuse large B cell lymphoma

AIDS Acquired immunodeficiency syndrome

ARV Antiretroviral therapy

Bcl-2 / $6 \quad$ B-cell leukaemia/lymphoma 2 / 6

CD Cluster differentiation

cDNA Complementary deoxyribonucleic acid

CHOP Cyclophosphamide, doxorubicin, vincristine and prednisone

DLBCL / DLBL Diffuse large B cell lymphoma

EBV Epstein Barr virus

EBV LMP1 Epstein Barr virus associated latent membrane protein 1

EBER ISH EBV-encoded ribonucleic acid in situ hybridisation

FOXP1 Forkhead box-P1

GCB DLBCL Germinal center B-cell-like DLBCL

GCET1 Germinal center B-cell expressed transcript 1

HAART Highly active antiretroviral therapy

HIV Human immunodeficiency virus

IgVH Immunoglobulin heavy chain variable region

IPI International Prognostic Index

IRF Interferon regulatory factor

MTA3 Metastasis associated gene 3

MUM1/IRF4 Multiple myeloma oncogene1/ interferon regulatory factor 4

Non-GC Non-germinal centre

$\mathrm{NHL} \quad$ Non Hodgkin's lymphoma

NF-kB Nuclear factor kappa B

OS Overall survival

PBL Plasmablastic lymphoma

$\mathrm{PCR} \quad$ Polymerase chain reaction

$\mathrm{R} \quad$ Rituximab

R-CHOP Rituximab + Cyclophosphamide, doxorubicin, vincristine prednisone

TMA Tissue microarray

WHO World Health Organisation

\section{LIST OF TABLES}

Table 1: Original Rappaport classification of 1956

Table 2: Original Lukes' and Collins classification of 1974 B cell types

Table 3: Original Kiel classification of 1974

Table 4 (a) and (b): Working Formulation 
Table 5: Updated Kiel classification of non-Hodgkin's lymphoma

Table 6: Investigating groups and cut-off levels defining positive staining

Table 7: Antibodies used in the study

Table 8: IHC scoring system

Table 9: Scoring of Ki67

Table 10: Data sheet $(A)$

Table 11: Data sheet $(B)$

Table 12: Predictive value of individual and combined immunohistochemical markers in DLBCL

Table 13: PBL and DLBCL expressing EBV LMP1

\section{LIST OF FIGURES}

Figure 1: International Prognostic Index and prognostic groups

Figure 2: Hans' algorithmic subdivision of DLBCL

Figure 3: Amen's algorithmic subdivision of DLBCL

Figure 4: Muris' algorithmic subdivision of DLBCL

Figure 5: 2004 Criteria for ART initiation in adults and adolescents

Figure 6: 2010 Standardised national eligibility criteria for starting ART regimens in adults and adolescents

Figure 7: H\&E stained section of DLBCL displaying mixed centroblastic (longer arrow) and immunoblastic (shorter arrow) features (X200 magnification)

Figure 8: H\&E stained section of DLBCL with immunoblastic morphology (X200 magnification)

Figure 9 H\&E stained section (100X magnification) depicting plasmablastic lymphoma with a starry-sky appearance imparted by interspersed tingible body macrophages (arrows)

Figure 10 H\&E stained section (400X magnification) of plasmablastic lymphoma with distinct blastic morphology 
Figure 11 H\&E stained section (200X magnification) of plasmablastic lymphoma depicting greater degree of plasmacytic differentiation.

Figure A: $D L B C L$ with membrane immunoreactivity for $C D 20$

Figure B: $D L B C L$ with EBV LMP1 immunoreactivity.

This tumour displayed immunoblastic morphologic features.

Figure C: $D L B C L$ with diffuse CD38 immunoreactivity

Figure D: High proliferation index in DLBCL demonstrated by Ki-67 immunohistochemistry

Figure E: PBL displaying diffuse nuclear immunoreactivity for MUM1

Figure F: PBL displaying an absence of CD20 immunoreactivity

\section{LIST OF GRAPHS}

Graph 1: Kaplan Meier curves for overall survival for DLBCL occurring in HIV negative and HIV positive patients

Graph 2: Kaplan Meier curves for overall survival of patients with plasmablastic lymphoma and DLBCL

Graph 3: Kaplan Meier curves for overall survival in GCB and Non GCB DLBCL using Hans' algorithm

Graph 4: Kaplan Meier curves for overall survival in Group 1 and Group 2 patients using Muris' decision algorithm

Graph 5: Kaplan Meier curves for overall survival in HIV negative and positive patients using CD10 expression in DLBCL

Graph 6: Kaplan Meier curves for overall survival in DLBCL using Bcl-6

Graph 7: Kaplan Meier curves for overall survival in DLBCL using MUM 1

Graph 8: Kaplan Meier curves for overall survival in DLBCL when Bcl-2 Expression occurred in the (Hans defined) GCB group

Graph 9: Kaplan Meier curves for overall survival with low risk and high risk IPI scores

Graph 10: Kaplan Meier curves for overall survival in DLBCL using Ki67 $<4$ and $\geq 4$ 


\section{ABSTRACT}

Diffuse large B cell lymphoma (DLBCL) and plasmablastic lymphoma (PBL) represent aggressive non-Hodgkin's large cell lymphomas, particularly in the setting of HIV infection. Due to significant clinical, morphologic, immunophenotypic and molecular heterogeneity, remissions may be achieved in only $40 \%$ of DLBCL, despite multidrug chemotherapeutic regimens. Since the introduction of highly active antiretroviral therapy (HAART), recent studies have documented improved survival outcome in patients with AIDS-related lymphomas.

Aims: The study aimed to contribute a South African perspective by correlating the HIV status and prognosis of DLBCL and PBL with differentiation profiles assessed by immunophenotyping.

Methods: A prospective study was conducted, based on the morphologic, immunophenotypic and clinicopathologic analysis of 61 cases of large cell lymphomas, comprising 52 DLBCL and 9 de novo PBL. All cases were diagnosed between January 2004 and December 2007 in the histopathology department, division of Anatomical Pathology, National Health Laboratory Service, Groote Schuur hospital, Cape Town, South Africa.

Results: The overall survival of patients with PBL was significantly poorer than that of DLBCL (log-rank $p$ value 0.002). Despite HAART, the overall survival of patients with DLBCL associated with HIV infection was poorer than DLBCL occurring in HIV negative patients ( $p$ value $<0.0001$ ). In the HIV positive group, profound immunosuppression was evident as the mean CD4 count at the time of lymphoma diagnosis was $151 \mathrm{cell} / \mathrm{s} / \mathrm{mm}^{3}$ in patients with DLBCL and $61 \mathrm{cells} / \mathrm{mm}^{3}$ in patients with PBL. In addition, HIV positive patients were found to be of significantly younger age at presentation with greater likelihood of extranodal lymphoma relative to HIV negative patients. When the International Prognostic Index (IPI) was assessed, the overall survival of patients with low to intermediate risk IPI scores (0-2) was better than those with intermediate to high risk IPI scores (3-5). However, this difference was not statistically significant ( $p$ value 0.794$)$. When Hans' algorithm was used to prognostically stratify DLBCL, the overall survival of patients with germinal centersubtype DLBCL was better than that of non-germinal center subtypes. However, the difference in survival was not statistically significant ( $p$ value was 0.188 ). Similarly, when Muris' algorithm was used to stratify subtypes of DLBCL, the overall survival of patients with group 1-type DLBCL was better than that of group 2-type DLBCL. However, once again, no statistical significance was demonstrated ( $p$ value was 0.399 ). No statistical significance was found when Bcl-2 expression was assessed independently of the IPI score, CD10, Bcl-6 and MUM1 expression ( $p$ value 0.371). However, when Bcl-2 expression occurred in germinal center-type DLBCL, using Hans' algorithmic stratification, improved survival was conferred by the germinal center phenotype ( $p$ value 0.007 ).

Conclusion: The study confirmed that diffuse large B cell lymphoma and plasmablastic lymphoma are high-grade tumours with significant potential for aggressive behaviour and poor outcome in the setting of profound immunosuppression due to HIV infection. Recent amendment of the South African National Antiretroviral Treatment Guidelines has created 
the potential for improved survival in patients with AIDS-related malignancies. Further studies are required to assess the effect of these amendments, in combination with the role of targeted-immunotherapy (Rituximab) on survival, in patients with AIDS-related nonHodgkin's lymphomas.

\section{REVIEW OF THE LITERATURE}

\subsection{A concise history of lymphoma classifications, focusing on the} evolution of diffuse large B cell lymphoma and plasmablastic lymphoma.

In 1832, the first form of lymphoma was described by Thomas Hodgkin which later became well known as Hodgkin's lymphoma. Characteristic neoplastic binucleate or multinucleate cells were independently described by Carl Sternberg and Dorothy Reed in 1898 and 1902, respectively. These cells became known as ReedSternberg cells. ${ }^{1}$

Several decades later, in 1963 Robert J Lukes proposed the first classification for Hodgkin's lymphoma. Other forms of lymphoma were subsequently recognised and described, constituting a large group of different cancers requiring further classification. In 1956, Henry Rappaport proposed the Rappaport classification (Table 1) which became the first widely used and accepted classification of lymphomas other than Hodgkin's lymphoma. The classification was submitted for publication as a fascicle of the Armed Forces Institute of Pathology in 1959 and was published in 1966. This classification emphasised the architecture and patterns of lymphomas , specifically nodular and diffuse subtypes of each cytological form, other than Hodgkin's lymphoma. Although the Rappaport classification lacked precision in terminology and lineage, it was found to be clinically and prognostically useful. As such, this classification persisted for nearly twenty years. ${ }^{2,3}$

In 1974, the immunologically orientated Lukes and Collins classification (Table 2) introduced new terminology such as follicle center cell, cleaved and non-cleaved. The classification was based on cell lineages and morphological alterations associated with the suggestion that antigenic stimuli induced lymphocyte transformation. $2-4$ 


\section{Malignant lymphoma}

Nodular

Diffuse

1. Lymphocytic type, well differentiated

2. Lymphocytic type, poorly differentiated

3. Mixed type (lymphocytic and reticulum cell)

4. Reticulum cell type

5. Hodgkin's

Table 1: Original Rappaport classification of $1956^{2,3}$

\section{B cell types}

Small lymphocyte (chronic lymphocytic leukaemia; CLL)

Plasmacytoid lymphocyte

Follicular center cell (FCC) types (follicular, diffuse and sclerotic)

Small cleaved

Large cleaved

Small non-cleaved

Large non-cleaved

Immunoblastic sarcoma (of B cells)

Table 2: Original Lukes and Collins classification of 1974 (B cell types) ${ }^{2,3}$

In 1974, the Kiel classification (Table 3) was formulated by Karl Lennert and members of the European Lymphoma Club. The central tenet of this classification 
was that the cytology of lymphoma cells could be used as a grading system to predict clinical behavior. In addition, the nodular lymphomas proposed by Rappaport were considered the neoplastic equivalent of germinal center B cells. New terminology for follicle center B cells was proposed as follows:

1) Germinoblasts / Large non cleaved cells / Centroblasts

2) Germinocytes / Small cleaved cells / $\underline{\text { Centrocytes }}$

\section{Low-grade malignancy}

Malignant lymphoma - lymphocytic (CLL and others)

Malignant lymphoma - lymphoplasmacytoid (immunocytic)

Malignant lymphoma - centrocytic

Malignant lymphoma - centroblastic-centrocytic-follicular; follicular and diffuse; diffuse; with and without sclerosis

High grade malignancy

Malignant lymphoma - centroblastic

Malignant lymphoma - lymphoblastic

Burkitt type

Convoluted-cell type

Others

Malignant lymphoma - immunoblastic

Table 3: Original Kiel classification of $1974^{5}$ 
During the 1960's and 1970's the existence of several distinct lymphocyte lineages ( $\mathrm{T}, \mathrm{B}$, and NK) was established. It was accepted that it was not possible to reliably predict the lineage by morphologic assessment alone. ${ }^{5,6,7}$

Lymphoid cells were found to have surface antigens or receptors which could allow for identification of the lineage of both normal and neoplastic cells. ${ }^{8,9}$ These observations led to the recognition that lymphomas were tumours of the immune system.

In the 1970's four additional classification systems were also in use:

The Dorfman classification, World Health Organisation (WHO), the Updated Rappaport classification and the British National Lymphoma Investigation classification.

The various classifications contained different terminology and different criteria for diagnosis which resulted in confusion and diagnostic difficulty.

Subsequently, in 1982, the Working Formulation (Table 4a) was published by the National Cancer Institute sponsored Lymphoma Classification Project. It was essentially based on concepts and terms of the Rappaport, Lukes-Collins and Kiel classifications. ${ }^{10}$ It encompassed reproducible morphologic appearances which included architectural and cytological features as well as the neoplastic cell size. The term non-Hodgkin's lymphoma (NHL) was created and three grades of lymphoma (Table 4b) were clinically defined as low, intermediate and high grade. The Working Formulation became the standard classification for this group of lymphomas. However, this classification was criticised as being biologically imprecise ${ }^{11}$ In 1988, Stansfield and colleagues proposed the updated/revised Kiel classification (Table 5) introducing clear delineation of B \& T cell lymphoma entities. Intended for nodal lymphomas, little attention was given to extranodal disease. This classification was criticised for its complexity. It was also found to lack clinical relevance and was considered poorly reproducible. 2, 9, 11 
- Malignant Lymphoma, small lymphocytic (chronic lymphocytic leukaemia)

- Malignant Lymphoma, follicular, predominantly small cleaved cell

- Malignant Lymphoma, follicular, mixed (small cleaved and large cell)

- Malignant Lymphoma, follicular, predominantly large cell

- Malignant Lymphoma, diffuse, small cleaved cells

- Malignant Lymphoma, diffuse, mixed (small and large cells)

- Malignant Lymphoma, diffuse large cells

- Malignant Lymphoma, large cell, immunoblastic

- Malignant Lymphoma, lymphoblastic

- Malignant Lymphoma, small non-cleaved cells (Burkitt's lymphoma)

- Composite

- Mycosis fungoides

- Histiocytic

- Extramedullary plasmacytoma

- Unclassifiable

Table 4(a): Working Formulation $^{10}$

Small lymphocytic

Follicular large cell

Large cell immunoblastic

Follicular small-cleaved cell

Diffuse small cleaved cell

Lymphoblastic

Follicular mixed small-cleaved Diffuse mixed small and large cell Small non-cleaved

(Burkitt's/ non-Burkitt's)

Table 4(b): Working Formulation - lymphoma grades ${ }^{10}$ 


\section{B cell}

Low grade

Lymphocytic-chronic lymphocytic and prolymphocytic leukaemia

Hairy cell leukaemia

Lymphoplasmacytic/cytoid

Plasmacytic

Centroblastic/centrocytic

Centrocytic

$\underline{\text { High grade }}$

Centroblastic

Immunoblastic

Large cell anaplastic

Burkitt's Iymphoma

Lymphoblastic

Rare types

Table 5 Updated Kiel classification - B cell non-Hodgkin's lymphoma ${ }^{3,11}$

The divergent use of lymphoma terminology in the United States and Europe lead to difficulties in interpretation of the clinical and haematopathology literature.

Subsequent attempts to identify distinct lymphoma entities with the aim of creating diagnostic reproducibility and acceptable terminology were spearheaded by the International Lymphoma Study Group (ILSG) which comprised 19 expert haematopathologists. All the available information which included clinical features, morphology, immunophenotype and genetic characteristics were used to define the different types of lymphoid tumours. ${ }^{11,14}$

In 1994, the Revised European American Lymphoma (REAL) Classification was established and comprised a list of lymphoid neoplasms considered to be distinctive biological entities which could be reproducibly diagnosed. The REAL classification delineated precursor and peripheral lymphoid neoplasms of both $B \& T$ cell lineages. It included Hodgkin's disease \& plasmacytoma/multiple myeloma. This classification was applicable to nodal and extranodal lymphomas. ${ }^{12}$

However, the REAL classification was criticised because it was not tested for clinical and prognostic value. In addition, at the time of introduction there was no data as to 
how well it could be applied by haematopathologists. These issues were subsequently addressed in the Lymphoma Classification Project.

The Lymphoma Classification Project addressed several salient issues regarding lymphoma classifications by comparing the applicability of the REAL classification with the Working Formulation and Kiel Classification. The Lymphoma Classification Project established that the REAL classification could be applied with a significant degree of accuracy, reproducibility and prognostic significance. It was found that over $95 \%$ of the lymphoma cases with adequate material could be optimally classified. The REAL classification was found to have an interobserver concordance of $85 \%$ for major subtypes and an intraobserver concordance of $94 \%$. Overall, the REAL classification was found to be a good predictor of survival. In addition, immunophenotyping was found to be an essential tool for classification of most lymphomas. In terms of the incidence of non-Hodgkin's lymphoma, diffuse large B cell lymphoma was found to be the commonest lymphoma, followed by follicular lymphoma. The category of diffuse large B cell lymphoma was created by the REAL classification which included cleaved or non-cleaved and immunoblastic lymphoma from the Working Formulation. It also incorporated centroblastic diffuse and immunoblastic B-cell type from the Kiel classification.

The study established an indisputable fact that classification alone was not the only predictor of clinical outcome. It further contributed that patients could be stratified into prognostically significant groups according to the International Prognostic Index (IPI). 13,14 The updated REAL Classification and the data generated by the Lymphoma Classification project have been of great value in formulating the World Health Organisation classification of haematopoietic neoplasms. The most recent WHO classification of 2008 acknowledges the presence of several subtypes of diffuse large B cell lymphoma (DLBCL). These include T cell/histiocyte rich large Bcell lymphoma, CD5-positive DLBCL, primary DLBCL of the CNS, primary cutaneous DLBCL- leg type, EBV-positive DLBCL of the elderly and DLBCL associated with chronic inflammation. Although plasmablastic lymphoma was initially considered to be a variant of DLBCL, it is now recognised as an independent diagnostic entity. ${ }^{15,55}$ 


\subsection{Diffuse large B-cell lymphomas in relation to B-lymphocyte differentiation}

B-cell neoplasms are inclined to mimic stages of normal B-cell differentiation. At the outset of B-cell differentiation within bone marrow precursors, the immunoglobulin $(I g)$ heavy $(H)$ chain variable region is formed by an ordered process of immunoglobulin gene rearrangement resulting in the assembly of distinct variable $(V)$, diversity $(D)$ and joining $(J)$ gene segments. This process is known as VDJ recombination. ${ }^{16}$

Once a functional non-autoreactive antigen receptor is generated, progenitor B-cells and/or B lymphoblasts undergo immunoglobulin gene rearrangements and differentiate into surface immunoglobulin positive $(\lg M+\lg D+)$ naïve $B$ cells which are released into the peripheral B-cell pool. ${ }^{17}$

When an antigen is encountered, the antibody expressed by a naïve B cell may be modified by class-switch recombination and somatic hypermutation, the latter is restricted to $B$ cells proliferating within the environment of the germinal centre. Somatically mutated $V$-region genes are a hallmark of germinal center $B$ cells and their descendants. ${ }^{18}$

The naïve B-cell enters the primary follicle, forming a germinal center (GC), wherein it matures to a CD10 and Bcl-6 expressing centroblast. At the time of transit through the germinal center, B-cells undergo somatically acquired mutations of $\lg V$ (heavy and light chain variable region genes) as well as mutations of the $B C L-6$ gene. Bcl-6 is a DNA-binding zinc-finger transcriptional regulator which is required for germinal center formation. Non-neoplastic germinal center centroblasts do not express Bcl-2 protein. ${ }^{19,23}$

Within the light zone of the germinal centre, the centroblast matures to a centrocyte which re-expresses $\mathrm{Bcl}-2$ protein. Down regulation of $\mathrm{Bcl}-6$ expression follows interaction with the CD23 and CD40 ligand on follicular dendritic cells and T-cells.

IRF4/MUM1 expression occurs in late centrocytic stages and in plasma cells. Within the germinal center, downregulation of Bcl-6, partly by the action of the IRF4/MUM1 protein, is essential for the differentiation of $B$ lymphocytes to plasma cells or memory B-cells. Within the non-neoplastic germinal center B lymphocyte, expression 
of IRF4/MUM1 and Bcl-6 are mutually exclusive. ${ }^{20}$

Histogenetic subdivision of B-cell lymphomas occurs as follows:

(1) Lymphomas derived from pre-germinal center B-cells lacking somatic hypermutation of $\lg V$ and $B C L-6$ genes

(2) Lymphomas closely resembling germinal center B cells associated with somatic $\lg V$ and/or BCL-6 hypermutation and Bcl-6 expression

(3) Lymphomas representing post germinal center B cells associated with somatic IgV and/or BCL-6 hypermutation as well as CD138/syndecan-1 positivity. 18,115

\section{$\underline{\mathrm{Bcl}-6}$}

The BCL-6 gene, located on chromosome $3 q 27$, encodes a zinc finger protein which functions as a transcriptional repressor. Bcl-6 expression is tightly regulated during $B$ cell differentiation and strong nuclear expression is evident preferentially in germinal center B cells. ${ }^{21}$ While Bcl-6 and MUM1 immunoexpression are mutually exclusive in non neoplastic $B$ cells, subsets of activated B cell-like DLBCL may express Bcl-6 in combination with MUM1/IRF4. 58, 66, 116 Approximately 30\% of diffuse large $B$ cell lymphomas show alterations of the $B C L-6$ gene at the $5^{\prime}$ noncoding region by $3 q 27$ chromosomal translocations. ${ }^{22}$ The translocations may result in replacement of the regulatory region of the $B C L-6$ gene by heterologous immunoglobulin (IG) genes. This is the commonest translocation occurring in DLBCL. Deregulation of the BCL-6 gene subsequently occurs as a result of promoter substitution, a process implicated in lymphomagenesis. ${ }^{23}$ The significance of Bcl-6 expression in diffuse large B cell lymphomas will be discussed at length as a prognostic factor. 


\section{Bcl-2}

The $B C L-2$ gene is located on $18 q 21$ and the gene product is an oncoprotein which inhibits apoptosis via the intrinsic mitochondrial pathway. $\mathrm{Bcl}-2$ oncoprotein resides on the cytoplasmic side of the mitochondrial outer membrane, endoplasmic reticulum and nuclear envelope. In non-neoplastic lymphoid tissue, lymphocytes in the mantle region and $\mathrm{T}$ cell region display positive cytoplasmic staining. Very few $\mathrm{T}$ cells within the germinal centers are labelled. ${ }^{24}$

Deregulated expression of $\mathrm{Bcl}-2$ oncoprotein occurs as a result of the $\mathrm{t}(14 ; 18)$ in which the $B C L-2$ gene is juxtaposed to the immunoglobulin $(I g)$ heavy chain locus (14q32). This translocation is present in $20-30 \%$ of diffuse large B cell lymphomas and $85 \%$ of follicular lymphomas. 25,26

\section{$\underline{\text { IRF4/MUM1 }}$}

MUM1 is an interferon regulatory transcription factor and a protein product of the IRF4/MUM1 gene (multiple myeloma oncogene 1) which is located on chromosome 6p25. IRF4 is a possible mediator of nuclear factor $k B$ proliferative responses that is required for proliferation of $B$ and T lymphocytes. ${ }^{27}$

The MUM1p monoclonal antibody used in this study is expressed in the late stages of $B$ cell differentiation. Positive staining occurs within the nuclei and cytoplasm of plasma cells/plasmablasts and "light zone" regions of the germinal center within centrocytes. Approximately $75 \%$ of diffuse large B cell lymphomas strongly express MUM1 protein and there is often co-expression of Bcl-6, unlike mutually exclusive MUM1 and Bcl-6 expression which occurs in non neoplastic germinal center B cells. This finding is suggestive of deregulation of MUM1 and Bcl-6 proteins in diffuse large B cell lymphoma. MUM1 expression may also occur in activated normal and/or neoplastic T lymphocytes often with co-expression of CD30. Positive staining also occurs in the neoplastic cells in Hodgkin's lymphoma. 28, 29

The translocation $\mathrm{t}(6 ; 14)(\mathrm{p} 25 ; \mathrm{q} 32)$ described in multiple myeloma involves juxtaposition of the immunoglobulin heavy chain $(\mathrm{lgH})$ locus to the multiple myeloma oncogene 1 resulting in over expression of the latter and resultant contribution to oncogenic activity. ${ }^{29}$ MUM1 immunoreactivity has also been reported in melanoma. ${ }^{30}$ 


\section{CD38}

CD38 is encoded on chromosome 4 and is recognised as a transmembrane molecule. This molecule plays a role in the synthesis of cyclic ADP-ribose which in turn functions as a second messenger for glucose induced insulin secretion and regulates mobilisation of intracellular calcium ions. ${ }^{31}$ Depending on the cellular enviroment, CD38 functions as a positive and negative regulator of cell activation and proliferation. CD38 is also involved in adhesion between human lymphocytes and endothelial cells and is considered an activation marker. It has been established that CD31 functions as the ligand for CD38. ${ }^{32}$ CD38 been found to deliver potent growth and differentiation signals to lymphoid and myeloid cells.

CD38 immunoexpression has been established in immature $B$ and T lymphocytes lineages, germinal center B cells and Ig-secreting plasma cells.

Positive staining may also occur in monocytes, NK cells, erythroid and myeloid progenitors.

Diagnostic expression occurs in T-cell acute lymphoblastic lymphoma, chronic lymphocytic leukaemia (CLL) / small lymphocytic lymphoma, atypical CLL, transformed CLL, diffuse large B cell lymphoma, follicular lymphoma, lymphoplasmacytic lymphoma, myeloma, plasmablastic lymphoma, plasma cell neoplasms and primary effusion lymphoma. ${ }^{31,38}$

\section{CD138}

CD138 (also known as syndecan-1) is a member of the syndecan family of transmembrane proteoglycans bearing extracellular domains composed of heparin sulphate and chondroitin sulphate. Reiland et al. ${ }^{33}$ found four tyrosine and serine/threonine complexes which serve as phosphorylation sites within the transmembrane and cytoplasmic domains of CD138.

The exact function of CD138 is unknown. However, roles in autocrine and/or paracrine cytokine function have been suggested in association with delaying of apoptosis and increasing viability of leukaemic cells, particularly with regard to expression of CD138 in B-cell chronic lymphocytic leukaemia. ${ }^{34}$ CD138 may play a role in cellular functions such as proliferation, cell-matrix and cell-cell adhesion. Mediation of adhesion of myeloma cells to type I collagen has 
been attributed to CD138. ${ }^{35}$

CD138 expression has been found in the late stages of B-cell differentiation within immunoglobulin producing plasma cells and immunolabelling occurs in myeloma/plasmacytoma, B-CLL and lympoplasmacytic lymphoma. ${ }^{36}$ Expression has also been established in immunoblastic variants of diffuse large B cell lymphoma occurring in HIV infected patients. 37

CD138 expression has also been established in simple and stratified epithelia (including stratified keratinocytes), fibroblasts and endothelial cells. ${ }^{38}$

\section{$\underline{\mathrm{CD} 10}$}

CD10 is a metalloendopeptidase called neprilysin which is involved in the inactivatation of a variety of biologically active peptides. Initially CD10 was identified as the common acute lymphoblastic leukaemia antigen (CALLA). Identification of CD10 has been found on the surface of normal early lymphoid progenitor cells, immature B cells and germinal center B cells. In lymphoid tumours, expression occurs on cells of lymphoblastic lymphoma/leukaemia, Burkitt's lymphoma, follicular germinal center lymphomas (follicular lymphoma and diffuse large B cell lymphoma) and chronic myelocytic leukaemia (CML) in lymphoid blast crisis. ${ }^{39,40}$ The significance of expression of CD10 in diffuse large B cell lymphomas has varied among different studies and will be discussed at length as a prognostic factor. CD10 expression also occurs in various non-lymphoid cells, such as endometrial stromal cells, breast myoepithelial cells, bile canaliculi and fibroblasts. High expression occurs on the brush border of kidney and gut epithelial cells. ${ }^{38}$

\section{$\underline{\mathrm{VS} 38 \mathrm{C}}$}

VS38C is a marker for plasma cells. It is directed towards proteins associated with the endoplasmic reticulum. Labelling includes plasma cells and plasma cell neoplasms such as myeloma, plasmacytoma and plasmablastic lymphoma. Positive staining also occurs in lymphoplasmacytoid lymphoma. In addition, immunoexpression has been reported in neuroendocrine tumours and melanocytic lesions. p63 protein, a transmembrane antigen, is a synonym for the antigen found in both plasma cells and epithelium. 41, 42, 43 
$\underline{\mathrm{Ki} 67}$

The Ki67 antigen is a nuclear protein which is expressed during all active phases of the cell cycle. It is not present in cells which are in the resting phase of the cell cycle $\left(\mathrm{G}_{0}\right)$. During interphase, there is exclusive expression within the nucleus. Interestingly, during mitosis most of the protein is relocated to the surface of chromosomes. As the cell enters a non-proliferative state, the antigen is usually rapidly degraded. There is no known expression of Ki-67 during the process of DNA repair. Ki67 antigen expression occurs in normal and neoplastic cells. ${ }^{44,45,46}$

\subsection{General features of diffuse large B cell lymphoma}

Diffuse large $B$ cell lymphoma (DLBCL) is known to be a malignant neoplasm of large B lymphoid cells representing approximately $20-30 \%$ of non-Hodgkin's lymphomas in Western countries and constituting greater percentages in developing countries. ${ }^{47}$ However, the incidence of DLBCL in Africa is at present unknown. DLBCL is an aggressive malignancy characterised by significant clinical, morphologic and molecular heterogeneity. Despite multidrug chemotherapeutic regimens, remissions may be achieved in only $40 \%$ of cases. ${ }^{48}$

Underlying immunodeficiency is a significant risk factor for the development of DLBCL. Acquired immunodeficiency syndrome (AIDS) -associated lymphomas are defined as those that occur with increased frequency in patients infected with Human immunodeficiency virus (HIV) with low CD4 counts, representing one of the commonest AIDS defining illnesses. ${ }^{49}$ In the United States, Cote et al ${ }^{50}$ demonstrated a 165 -fold increase in the relative risk of developing lymphoma within three years of an AIDS diagnosis compared with patients unaffected by AIDS.

Before the availability of highly active antiretroviral therapy, all subtypes of nonHodgkin's lymphoma were increased up to 200 times in patients infected with HIV. DLBCL represents one of the commonest HIV-associated non-Hodgkin's lymphomas. Other aggressive B-cell lymphomas included in this group are plasmablastic lymphoma, Burkitt's lymphoma and primary effusion lymphoma. ${ }^{51}$ 


\subsection{Prognostic factors}

Various prognostic factors have been proposed to predict the outcome of aggressive non-Hodgkin's lymphomas. ${ }^{52}$

\section{$\underline{5.4 .1 \text { International Prognostic Index }}$}

The International Prognostic Index (IPI) is an important clinical prognostic tool which encompasses clinical parameters such as age (>60 years), performance status, advanced Ann Abor stage (III or IV), extranodal involvement and abnormal serum lactate dehydrogenase. These parameters are used to stratify patients into (low, intermediate and high risk) prognostic groups based on the relative prognostic index. $53,55,56,58$

Figure 1 - International Prognostic Index and prognostic groups 


\section{$\underline{5.4 .2}$ Morphologic subtypes of DLBCL}

At a morphological level, the definition of a large B cell is that in which the nuclear size is equal to or exceeds the size of a normal macrophage nucleus or more than twice the size of a normal lymphocyte. ${ }^{47}$ The large B cell displays a mean diameter which is equal to or greater than $20 u m .{ }^{53}$

The common morphologic variants of DLBCL include centroblastic, immunoblastic and anaplastic variants.

Centroblastic variant - characterised by medium to large lymphoid cells with vesicular nuclei in which there are two to four nucleoli occurring in close proximity to the nuclear membrane. The cytoplasm may be sparse with an amphophilic to basophilic hue.

Immunoblastic variant - characterised by greater than $90 \%$ of tumour cells displaying a centrally located single nucleolus and significant amount of basophilic cytoplasm.

Anaplastic variant of DLBCL contains large round or polygonal cells displaying significant nuclear pleomorphism and bizarre cytomorphologic features. This variant may mimic poorly differentiated carcinomas and melanoma. 53,54

The prognostic significance of centroblastic and immunoblastic morphologic subtypes of diffuse large B cell lymphoma is controversial. Some studies have demonstrated better prognostic outcome in centroblastic DLBCL compared with immunoblastic DLBCL. However, the clinical significance of the morphologic features of the tumour, in the absence of the immunophenotype and molecular signature, is of doubtful significance due to interobserver variability and variable/mixed morphologic appearances occurring among individual cells within the same tumour. 54,55

DLBCL which occurs in HIV infected patients may also be composed of centroblasts and/or immunoblasts. Approximately $25-30 \%$ of these tumours are composed of 
centroblasts predominantly, with scattered intermixed immunoblasts.

This morphologic appearance is similar to that occurring in the HIV-negative population. Evidence of Epstein Barr virus (EBV) infection is demonstrable in $30 \%$ of these tumours by the use of EBER in situ hybridisation.

The immunoblastic morphologic subtype of DLBCL exhibiting plasmacytoid features accounts for approximately $10 \%$ of cases occurring in HIV positive patients and is thought to be more characteristic of HIV infection. EBV infection is demonstrable in $90 \%$ of these cases by means of EBV LMP1 (latent membrane protein 1) immunohistochemistry, unlike the centroblastic subtype which lacks EBV LMP1 immunoexpression. ${ }^{56,57}$

$\underline{5.4 .3}$ Subdivisions of DLBCL based on immunohistochemistry and gene expression profiles

At immunohistochemical and molecular levels there have been several salient subdivisions of DLBCL.

Hans et al ${ }^{58}$ stratified 152 cases of de novo DLBCL into prognostically significant subgroups with germinal center B-cell-like (GCB), activated B-cell-like (ABC) and type 3 gene expression profiles. This subdivision was based on tumour cell expression of Bcl-6, CD10 and IRF-4/MUM1 as defined by the Hans algorithm (Figure 2). This study correlated the subclassification of DLBCL by gene expression with protein expression using immunohistochemistry. All of the cases had immunohistochemistry, using tissue microarray, combined with previously evaluated cDNA (complementary deoxyribonucleic acid) microarray gene expression data using the Lymphochip cDNA microarray. The combined analysis and interpretation allowed for an optimal prognostically advantageous classification of DLBCL. The tumour cells were considered positive if $30 \%$ or more stained with the various antibodies used. The concordance rate between immunohistochemistry and gene expression profiles was found to be $71 \%$ in GCB-like DLBCL and $88 \%$ in non-GCB DLBCL. This fractional discordance is attributed to the interpretation of Bcl-6 immunoexpression and associated gene expression profiles. Although Bcl-6 is 
primarily a germinal center marker, when Bcl-6 expression occurred in combination with MUM1 expression, the tumour was found to have an $A B C$ gene expression pattern which was associated with inferior survival outcome. This finding would account for discrepancies in outcome prediction of DLBCL when Bcl-6 expression is assessed in isolation of MUM1 expression and gene expression profiles.

Figure 2 - Hans' algorithmic stratification of DLBCL ${ }^{58}$

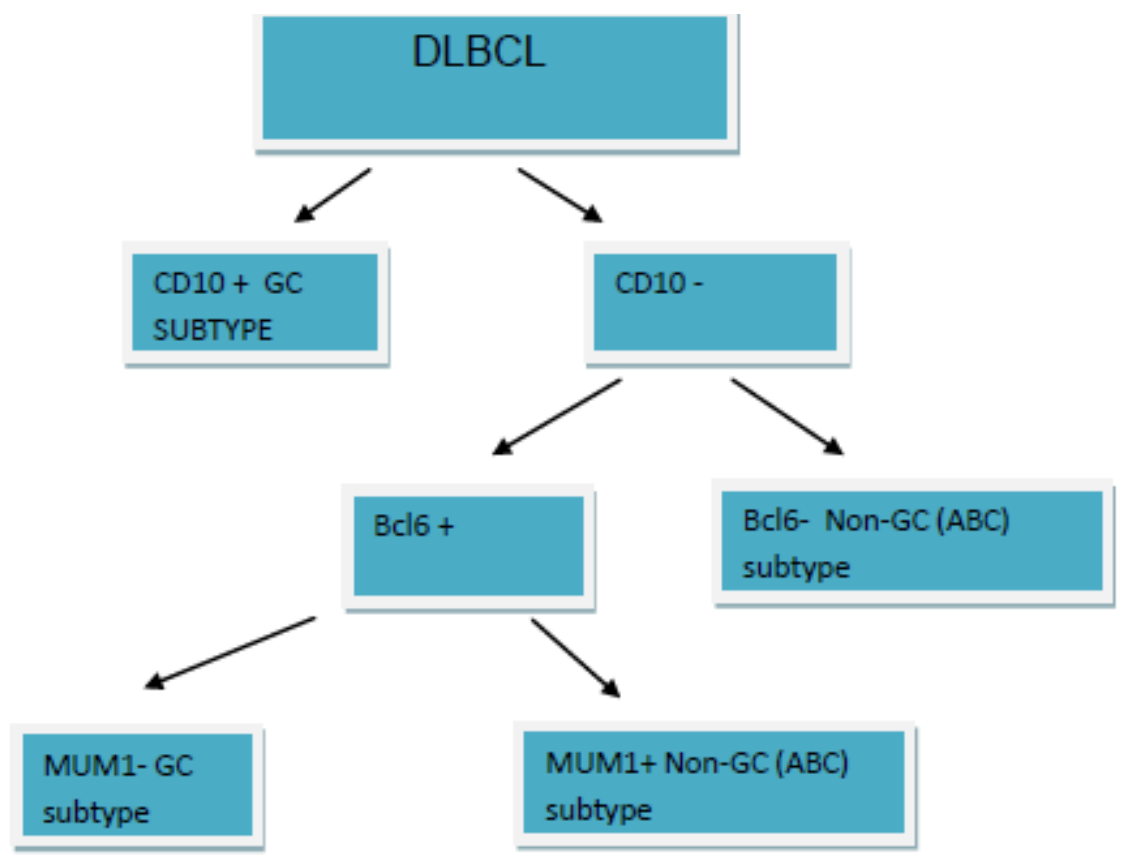

Alizadeh et al. ${ }^{116}$ used DNA microarrays to characterise varying gene expression profiles in DLBCL which allowed for subdivision into germinal center-like diffuse large $B$ cell lymphoma (GC-DLBCL) and activated B cell-like DLBCL (ABC-DLBCL). Congruent with the findings by Hans et al. ${ }^{58}$ the GC-DLBCL was found to be associated with favourable outcome.

In a retrospective study of 42 cases of de novo DLBCL by Chang et al. ${ }^{59}$ similar findings were established in that DLBCL with immunophenotypic expression patterns of GC B-cells had improved overall survival relative to those with expression patterns 
of activated B cells. In this study Bcl-6, CD10, MUM1 and CD138 were assessed with cut-off levels for positive staining set at $20 \%$.

The cases were divided into three patterns of immunohistochemical expression: Pattern A -

GC B-cell pattern expressing CD10 and/or Bcl-6 but not activation markers Pattern B -

activated GC B-cell pattern expressing at least one GC B-cell marker and one activation marker

Pattern C -

activated non-GC B-cell pattern expressing MUM1/IRF4 and/or CD138 but not GC B-cell markers.

Similar to the activated germinal center B-cell (pattern B) subdivision of DLBCL by Chang et al, ${ }^{59}$ Madan et al. ${ }^{60}$ found that the immunophenotype in AIDS-related DLBCL was intermediate between the germinal center and activated B-cell types with frequent co-expression of both germinal center cell antigens (CD10 and Bcl-6) and post-GC cell marker (MUM1).

Carbone et al. ${ }^{61}$ divided AIDS-related DLBCL into two categories. The first included the LMP1 negative, CD138 negative and Bcl-6 positive phenotype, which corresponded to the centroblastic subtype of DLBCL. The LMP-1 positive, CD138 positive and Bcl-6 negative phenotype corresponded to the immunoblastic subtype of DLBCL.

It is noteworthy that in one of few studies to emerge from Africa, specifically Uganda, Tumwine et al. ${ }^{62}$ established that the activated germinal center-type DLBCL, defined as those expressing CD10, Bcl-6, MUM1 and CD138, was found to have the best prognosis relative to other groups of DLBCL in their study.

Using tissue microarrays constructed from 81 cases of DLBCL, Amen et al. ${ }^{63}$ defined the germinal center-subgroup (GC) of DLBCL as that which expressed Bcl-6 or CD10 irrespective of MUM1expression. The GC subgroup was subsequently subdivided into a favourable germinal center subset on the basis of absence of expression of both Bcl-2 and cyclin D2 and an unfavourable germinal centre subset which was positive for either Bcl-2 or cyclin D2 (Figure 3). The absence of both Bcl-6 and CD10 expression defined a non-germinal center subset of DLBCL. 
In this study Bcl-6, CD10, Bcl-2 and MUM1 were considered positive if there was moderate to strong positivity in $30 \%$ of tumour cells. When assessing cyclin-D2, $10 \%$ of cells having moderate to strong staining were considered positive.

Significantly improved event free survival and overall survival were found in the absence of cyclin D2 and Bcl-2 expression. Thus the favourable germinal center subset was defined. A difference is apparent in the definition of germinalcenter subgroups by Hans et al. ${ }^{58}$ and Amen et al. ${ }^{63}$ The former group would classify CD10, Bcl-6 and MUM1 positive DLBCL as GCB subtype due to the presence of concomitant GC gene expression profiles found in similar tumours in their study. In contrast, CD10 negative, Bcl-6 positive and MUM1 positive cases would be classified as non-GC subtype of DLBCL due to the likelihood of an associated ABC gene expression profile. However, both Bcl-6 and CD10 are wellrecognised germinal center markers. Therefore, the latter group of investigators feasibly allowed for further stratification by employing the use of cyclin D2 and Bcl-2 to successfully create favourable and unfavourable GC subgroups.

Figure 3 - Amen's algorithmic subdivision of DLBCL ${ }^{63}$

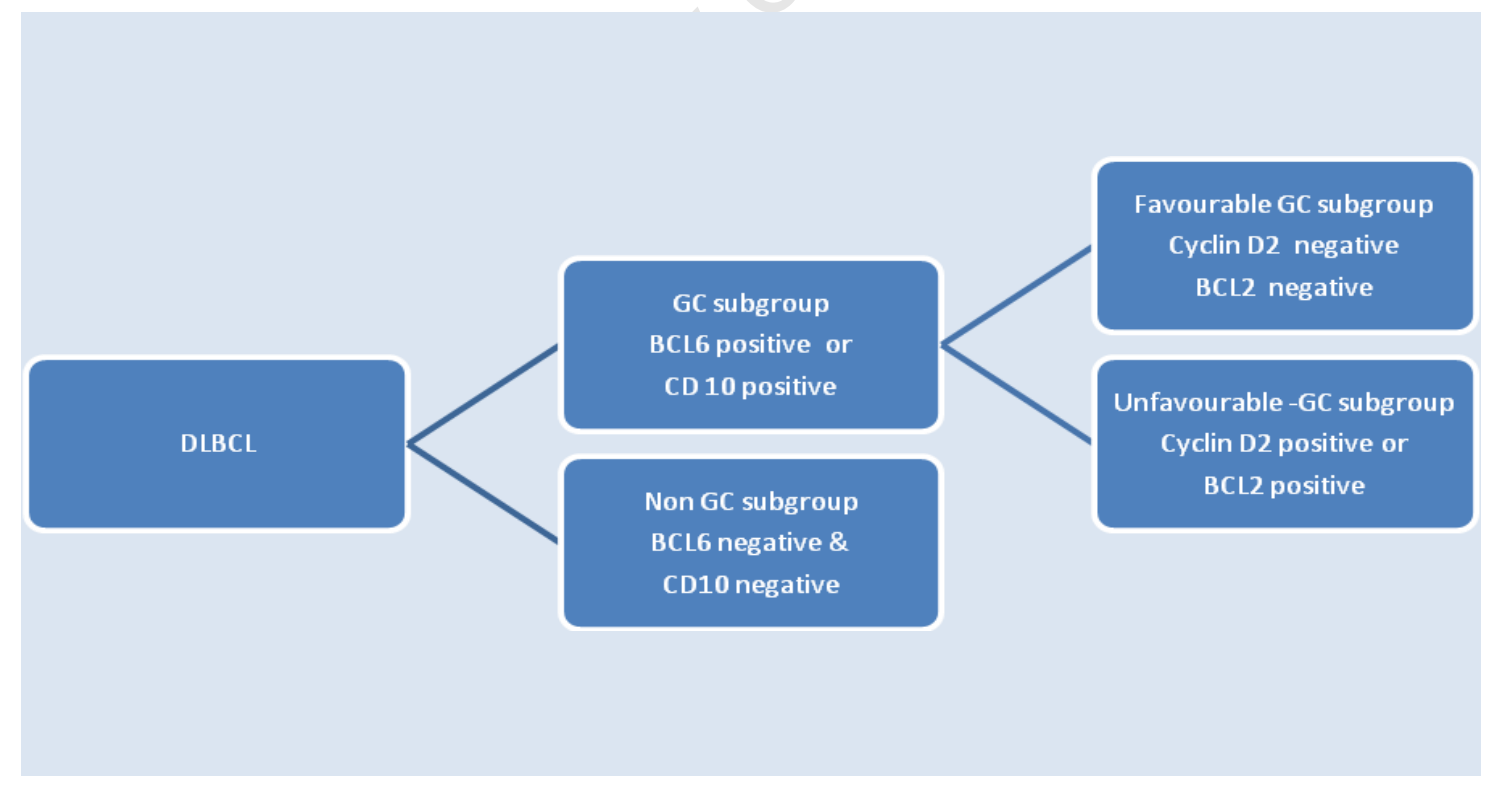

The prognostic significance of Bcl-6 expression was reiterated by Lossos et al. ${ }^{64}$ in that Bcl-6 expression was found to be the single most important factor which was predictive of good prognosis among patients with DLBCL. In diffuse large B cell 
lymphoma, $B C L-6$ gene rearrangement correlates strongly with improved survival outcome. By employing the use of 63 cases of primary DLBCL, Lossos et al. ${ }^{64}$ investigated $B C L-6 m-R N A$ gene expression by real-time quantitative reverse transcription polymerase chain reaction (RT-PCR) analysis and Bcl-6 protein expression by immunohistochemistry. This study established that BCL-6 mRNA gene expression and $\mathrm{Bcl}-6$ protein expression were associated with significantly better overall survival.

Furthermore, Winter et al. ${ }^{65}$ suggested the presence of therapeutic significance when $\mathrm{Bcl}-6$ expression occurred in DLBCL. Importantly, this group established that patients with Bcl-6-negative DLBCL had a survival advantage when Rituximab was added to the CHOP treatment protocol. This survival advantage was not seen in cases of Bcl-6-positive DLBCL.

Muris et al. ${ }^{66}$ established an interesting algorithmic stratification of cases of primary nodal DLBCL into prognostically favourable (group 1 ) and unfavourable groups (group 2) based on assessment of tumour expression of Bcl-2, MUM1 and CD10 (Figure 4). Using 71 cases of primary nodal DLBCL, this algorithmic stratification was found to be most predictive of clinical outcome in patients with intermediate to high IPI scores. In this study, the CD10 expression appeared to be more indicative of germinal-center phenotype than combined CD10 and Bcl-6 expression. This is due to the finding that $\mathrm{Bcl}-6$ expression also occurred frequently in DLBCL cases expressing MUM1 in keeping with an activated B-cell phenotype. Based on statistical analysis, the optimal cut-off point (the threshold with the most discriminative power) was found to be at $30 \%$ for CD10, Bcl-6 and MUM1. The optimal cut-off for $\mathrm{Bcl}-2$ was found to be $50 \%$ positivity within tumour cells. MUM1 expression correlated with $\mathrm{Bcl}-2$ expression in terms of poor outcome. It was interesting to note that when both $\mathrm{Bcl}-2$ and $\mathrm{CD} 10$ expression was assessed, there was improved survival relative to $\mathrm{Bcl}-2$ expression in the absence of CD10 expression.

In further support of the positive prognostic influence associated with CD10 immunoexpression, Berglund et al. ${ }^{80}$ and Ohshima et al. ${ }^{67}$ found that CD10 
expression in DLBCL predicted for improved survival, particularly in patients with low risk IPI scores.

There is corroborative evidence supportive of the understanding that CD10expressing lymphoid cells, both neoplastic and non-neoplastic, are inclined to become increasingly prone to apoptosis. Often there is associated c-myc upregulation within these cells with resultant cellular induction into the cell cycle. ${ }^{68,}$ 69, 70, 71, 72 This process creates the potential for improved response to apoptosisinducing therapy in CD10-expressing DLBCL and may well account for a significant survival advantage.

Figure 4 - Muris' algorithmic subdivision of $D L B C L^{66}$

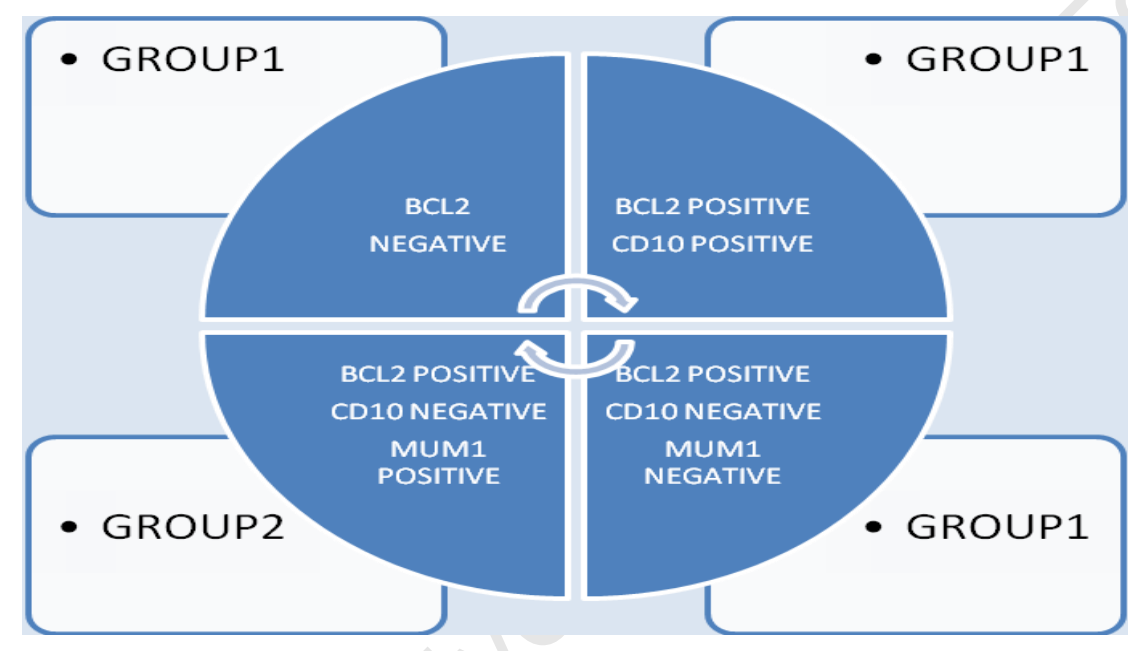

Sjo et al. ${ }^{73}$ examined 108 cases of DLBCL and found that both the Hans algorithm and the Muris algorithm displayed prognostic significance. The cases in this study were scored positive for CD10, Bcl-6, and MUM1 if a minimum of $30 \%$ of the neoplastic cells were labelled, whereas the cut-off levels for $\mathrm{Bcl}-2$ was $50 \%$. It was established that the Hans algorithmic stratification was associated with higher overall survival relative to the Muris algorithmic stratification. 
In contrast to several studies mentioned, the findings of some investigators have not supported the notion of favourable outcome conferred by germinal center-like phenotypes in DLBCL.

Xu et al. ${ }^{74}$ suggested that CD10 and Bcl-2 expression were associated with poor outcome with possible negative impact on treatment response. In support thereof, Uherova et al. ${ }^{75}$ found that CD10 was predictive of inferior survival when combined with Bcl-2 expression. Fabiani et al. ${ }^{76}$ also found that CD10 expression was not associated with statistically significant differences in overall survival in patients with DLBCL. The lack of statistical significance in this study may be attributed low levels of defining CD10 positivity in tumour cells. A cut-off point of $10 \%$ was used to define CD10-positive and CD10-negative cases of DLBCL. This percentage is much lower than that used in other studies in which favourable outcome has been established regarding CD10 expression in DLBCL (Table 6). Chini et al. ${ }^{77}$ found that immunophenotypic subdivision of DLBCL into germinal center and non-germinal center types, using Hans' and Muris' methods of subdivision, failed to predict outcome. In support thereof, Chadburn et al. ${ }^{89}$ found no prognostic significance when cases of AIDS-related DLBCL were stratified into GC and ABC groups using Hans' and Amen's algorithms.

Recently, Choi et al. ${ }^{78}$ created a new algorithmic stratification of DLBCL based on immunohistochemistry (using tissue microarrays) which was found to have good concordance with gene expression profiles (using Lymphochip cDNA microarray ). This algorithm challenged that of Hans et al. ${ }^{58}$ by employing the use of relatively new germinal center markers which showed high germinal center specificity. These markers included germinal center B-cell expressed transcript 1 (GCET1) and metastasis associated gene 3 (MTA3). An additional marker, Forkhead box-P1 (FOXP1), which is highly expressed in activated B-cell-like DLBCL was also employed. However, a particularly high cut-off of $\geq 80 \%$ for FOXP1 was needed to achieve high specificity for the $A B C$ subtype. An equally high cut-off of $80 \%$ was used for GCET1. Concordance between the new algorithm and gene expression profile in this study was $93 \%$. The overall survival using the newly proposed algorithm and gene expression profile-defined GCB and ABC DLBCL was similar to 
the previous studies, in that improved survival was found in the GCB-DLBCL. This algorithmic stratification was found to be more accurate than that proposed by Hans et al. ${ }^{58}$ due to the use of new germinal center-specific markers and the fact that less emphasis was placed on the older germinal center marker Bcl-6. The notable potential drawback is that particularly high cut-off levels for GCET1 and FOXP1 of $80 \%$ were required for positive interpretation.

\begin{tabular}{|c|c|c|c|}
\hline INVESTIGATING GROUP & YEAR & PARAMETER & $\begin{array}{c}\text { \% CUT-OFF FOR INTERPRETATION AS } \\
\text { POSITIVE STAINING IN DLBCL }\end{array}$ \\
\hline
\end{tabular}

$\begin{array}{ll}2004 & \begin{array}{l}\text { Bcl-2, Bcl-6, } \\ \text { CD10 \& MUM 1 } 1\end{array}\end{array}$

Chang et al

2004 Bcl-6, CD10,

$20 \%$

MUM 1, CD138

$30 \%$

Muris et al

2006 CD10, Bcl-6,

MUM1

Bcl-2

$50 \%$

Sjö et al

2007 CD10, Bcl-6

MUM1

$30 \%$

Bcl-2

$50 \%$

Amen et al

2007

Bcl-2, Bcl-6,

$30 \%$

CD10 MUM 1

Choi et al

2009 CD10, Bcl-6

$30 \%$

MUM1

$80 \%$

GCET1 \& FOXP1

$80 \%$

Table 6- Investigating groups and immunophenotypic cut-off levels for positive staining in DLBCL 


\subsubsection{Prognostic significance of Bcl-2 expression}

$\mathrm{Bcl}-2$ expression has been proven in the majority of studies to be an independent adverse prognostic factor in de novo DLBCL with shorter time to relapse occurring with high expression thereof. Kramer et al. ${ }^{79}$ suggested that high $\mathrm{Bcl}-2$ expression in DLBCL is likely to confer resistance to chemotherapy.

It is evident that a variety of defining cut-off levels has been used in various studies for assessment of significant Bcl-2 expression. These cut-off levels range from 10$60 \%$ in tumour cells of DLBCL. ${ }^{80}$

Hans et al. ${ }^{58}$ found that Bcl-2 expression was an adverse predictor in the non-GCB subgroups of DLBCL. In support thereof, Obermann et al. ${ }^{81}$ investigated the significance of $\mathrm{Bcl}-2$ in DLBCL using combined fluorescence in situ hybridisation for $B C L-2$ gene assessment and immunohistochemistry for $\mathrm{Bcl}-2$ protein expression. Non-GC type DLBCL with BCL-2 gene aberrations was found to be associated with significantly worse prognosis which was independent of the IPI score.

Similarly, Hermine et al. ${ }^{82}$ found that high Bcl-2 expression, occurring in greater than $60 \%$ of tumour cells in DLBCL, was associated with reduced overall survival and reduced disease free survival.

Gascoyne et al. ${ }^{83}$ and Barrans et al. ${ }^{84}$ also reported statistically significant correlations between increased Bcl-2 expression and decreased overall survival in patients with DLBCL. The latter group furthermore demonstrated that patients with an intermediate IPI combined with expression of $\mathrm{Bcl}-2$ experienced reduced survival which was similar to the poor survival rates of patients within the IPI high-risk categories. Nyman et al. ${ }^{85}$ further contributed that Bcl-2 expression which occurred in greater than $50 \%$ of tumour cells, continued to be of poor prognostic significance when patients with non-germinal center DLBCL were treated with immunochemotherapy (Rituximab and CHOP).

In contrast, some studies demonstrated that Bcl-2 expression was unassociated with prognostic significance. Kramer et al. ${ }^{79}$ reported no significant correlation between Bcl-2 expression in DLBCL and overall survival. Similarly, in AIDS-related DLBCL, 
Little et al. ${ }^{86}$ and Chadburn et al. ${ }^{89}$ found that Bcl-2 expression did not prognosticate survival.

\section{$\underline{5.4 .5}$ Tumour proliferation index}

The tumour proliferation index in DLBCL is commonly assessed using Ki-67 immunostaining. Studies have shown that diffuse large B cell lymphomas with proliferation indices of greater than $60-80 \%$ are associated with poor prognosis and early death. ${ }^{87,88}$

Conversely, in AIDS-related DLBCL, high proliferation indices (defined as positive staining in $90 \%$ of tumour cells) have been found to be associated with improved survival and better clinical outcome due to targeting of proliferating tumour cells by continuous infusional chemotherapy. ${ }^{89}$

\subsubsection{MYC rearrangement and p53 expression in DLBCL}

Genetic features of DLBCL which adversely influence prognosis include MYC gene rearrangement which is associated with an aggressive clinical course and poor prognosis, appearing independent of the stage of DLBCL and age of the patient. Approximately $5 \%$ of DLBCL harbour a break of the MYC gene. Predictability of the presence of aberrations of the $M Y C$ gene by morphologic and immunohistochemical assessment at present is considered unreliable. MYC gene status can be assessed using fluorescence in situ hybridisation (dual-colour break-apart probes). ${ }^{90}$ Rao et al. ${ }^{91}$ employed the use of comparative genomic hybridisation analysis and reported that $c-M Y C$ amplification was associated with advanced stage disease in patients with DLBCL.

Using immunohistochemistry, Chang et al. ${ }^{92}$ found that co-expression of c-MYC and p53 occurred in 58\% of DLBCL with advanced clinical stage. Co-expression was absent in patients with low clinical stages. In addition, co-expression also occurred more frequently in patients with high or high-intermediate risk IPI than in patients with low or low-intermediate risk. In further support thereof, Sanchez et al. ${ }^{93}$ found 
that the presence of p53 gene mutations in DLBCL was associated with poor prognosis.

\subsubsection{The prognostic significance of cyclin D2 expression in DLBCL}

Cyclin D2 is a cell cycle regulatory protein which is involved in facilitating $\mathrm{G} 1$ to $\mathrm{S}$ phase transition. Using tissue microarrays of 200 cases of de novo DLBCL, Hans et al. ${ }^{156}$ established that patients with DLBCL expressing cyclin D2, defined as expression in $\geq 30 \%$ of tumour cells, were more likely to have B symptoms. By immunohistochemistry, cyclin D2 expression was found to occur in 19\% of DLBCL. Within the context of IPI scores, patients with low IPI scores and cyclin D2 expression by tumour cells were found to have significantly worse overall survival. Cyclin D2 expression was found to predict for worse overall survival and event-free survival in DLBCL and was limited to DLBCL with an activated B-cell-like or unclassified gene expression profile. ${ }^{156}$

\subsubsection{The prognostic significance of highly active antiretroviral therapy (HAART)}

The literature abounds with conflicting findings regarding the prognostic influence of HAART on AIDS-related lymphomas.

In a prospective observational study, Antinori et al. ${ }^{94}$ established that concurrent administration of highly active anti-retroviral therapy (HAART) and chemotherapy could significantly modify the natural history of non-Hodgkin's lymphoma in HIV infected patients. HAART resulted in an increased response rate to chemotherapy and prolonged overall survival. In addition, HAART could possibly increase the tolerability of higher chemotherapy dose intensities. Similarly, Navarro et al. ${ }^{95}$ demonstrated that patients treated with combination CHOP and HAART experienced higher rates of complete remission than those treated only with CHOP. Importantly, Besson et al. ${ }^{96}$ found that the incidence of AIDS-related lymphomas had decreased significantly since the introduction of HAART. Furthermore, patients 
on HAART were found to have higher CD4 counts at the time of lymphoma diagnosis and improved overall survival.

Contrasting findings by Mathews et al. ${ }^{97}$ and Ledergerber et al. ${ }^{98}$ showed that the incidence of $\mathrm{NHL}$ in the era of antiviral therapy was largely unchanged.

\section{$\underline{5.5}$ South African National Antiretroviral Treatment Guidelines}

In 2004, the South African National Antiretroviral Treatment Guidelines stipulated specific criteria for the initiation of antiviral therapy in patients infected with HIV. These criteria included CD4 $<200$ cells $/ \mathrm{mm}^{3}$ irrespective of the WHO-defined disease stage or WHO Stage IV AIDS-defining illness (which included lymphoma) irrespective of the CD4 count. These were accompanied by the essential criterion of patient willingness and readiness to take antiviral therapy adherently (Figure 5). ${ }^{99}$ In 2010, the South African National Guidelines were amended to include initiation of antiretroviral treatment when CD4 counts less than 350 cells $/ \mathrm{mm}^{3}$ occurred in patients with TB/HIV co-infection and in pregnant women. In addition, the criterion of the presence of drug-resistant tuberculosis (MDR/XDR), irrespective of the CD4 count, was included (Figure 6). ${ }^{100}$

Figure 52004 Criteria for ART initiation in adults and adolescents ${ }^{99}$

\section{$\mathrm{CD} 4<200$ cells $/ \mathrm{mm}^{3}$}

\section{WHO stage IV AIDS-defining \\ illness, irrespective of CD4 count}

\section{Patient expresses willingness and} readiness to take ART adherently 
Figure 62010 Standardised national eligibility criteria for starting ART regimens in adults and adolescents ${ }^{100}$
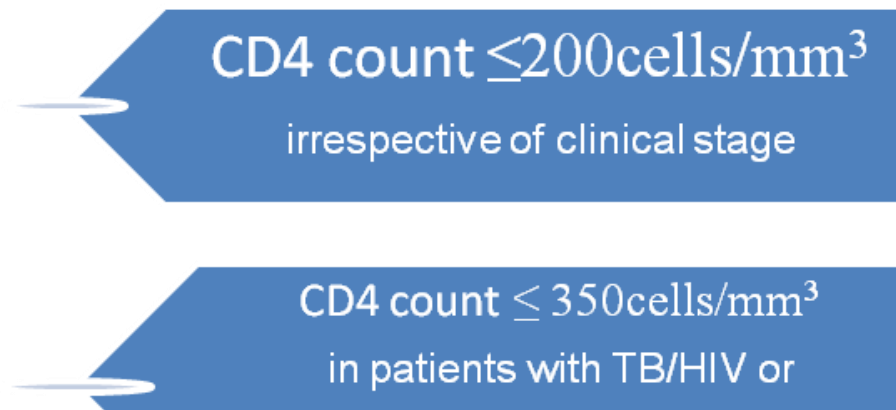

pregnant women

\section{WHO stage IV irrespective of CD4 count OR MDR/XDR irrespective of CD4}

\section{$\underline{5.6}$ The role of Epstein Barr Virus (EBV) in lymphomagenesis}

EBV is a herpes virus which usually infects children, affecting the majority of the world's population. Delayed exposure to EBV occurring in adolescence may result in symptomatic infectious mononucleosis. Control of EBV infection of B lymphocytes involves natural killer cells and cytotoxic T lymphocytes. However, removal of all B cells infected with EBV is not possible and a pool of memory $B$ lymphocytes with latent EBV infection is established. Lifelong carrier status follows primary EBV infection and the establishment of latent EBV infection in B lymphocytes is attributed to unique growth activating viral genes. ${ }^{101}$ Initially EBV infects epithelial cells in the oropharynx and gains access to $B$-lymphocytes via the CD21 receptor. Within the $B$ cell, the linear EBV genome circularises, persisting within the nucleus as an episome. Viral gene expression may occur within lytic or latent cycles. ${ }^{102}$ Maintenance of latent EBV infection is sustained through several interesting mechanisms. During latent cycle infection, EBV gene expression includes nuclear antigens (EBNAs) 1, 2, 3A, 3B, 3C and LP, as well as three latent membrane proteins (LMPs) which are associated with transforming activity. ${ }^{103,104}$ 
LMP1 is an important EBV transforming protein which induces changes associated with B-cell activation. These changes include increased expression of CD23, CD39, CD40 and CD44. Due to the function of LMP1 as an activated member of the tumour necrosis factor receptor super-family, activation of ligandindependent signalling pathways occurs. LMP1 activates the nuclear factor (NF)-kB and JAK/STAT signalling pathways which promote $B$ lymphocytic proliferation and survival. LMP1 also upregulates expression of the anti-apoptotic protein Bcl-2 and stimulates production of cytokines interleukin 6 and interleukin 8. ${ }^{105}$

The nuclear phosphoprotein EBNA-1 promotes maintenance of the EBV episome within the $B$ cell by binding to viral DNA while EBNA-2 functions as a viral transcription factor which induces expression of LMP1. EBNA-2 gene transactivates host genes such as Cyclin $D$ which promotes cell cycle transition of B cells from $\mathrm{G}_{0}$ to $\mathrm{G}_{1}{ }^{106}$

The immortalisation of $B$ lymphocytes by EBV is directly related to mechanisms of apoptosis suppression which includes expression of BHRF1 (an early lytic cycle antigen, member of the Bcl-2 family) in the lytic cycle. In addition, EBV LMP1 upregulates cellular Bcl-2 levels which inhibits apoptosis. ${ }^{107}$

Activation of two EBV immediate-early genes, BZLF1 and BRLF1 allows for the transition from latent to lytic EBV infection. ${ }^{108}$

Patients with primary and secondary immunodeficiencies are particularly prone to develop EBV-associated neoplasms. EBV has a direct role in lymphomagenesis in these patients through mechanisms discussed. In immunocompetent individuals development of EBV-associated neoplasms involves the role of EBV as a cofactor.

\section{$\underline{5.7}$ The significance of NF-KB signalling pathway in DLBCL}

During normal cellular differentiation and immune responses, NF-kB (a transcription factor) is responsible for the integration of several intracellular signalling pathways. 109 
NF-kB transcriptional activity is mediated by dimers of the NF-kB family (p50/105, p52/100, p65/RelA, RelB or c-Rel). In turn, regulation of NF-kB transcriptional activity is controlled by members of the IkB family of inhibitors (particularly $1 \kappa B \alpha$ ) and the associated kinase (IKK) which binds to NF-KB allowing for its retention within the cell cytoplasm. Once phosphorylated, IKBa is prone to degradation via the ubiquitinproteasome pathway, releasing NF-kB dimers which then translocate to the nucleus and activate transcription of target genes. ${ }^{110}$

In B cell development and survival, NF-kB plays a critical role as the heterodimers of NF-KB participate in different stages of $B$ cell differentiation and activation. In $B$ lymphocytes, NF-kB transcriptional function primarily involves heterodimers between one of the transactivating subunits (c-Rel or Rel A) and one of the nontransactivating subunits (p50). Generally in the absence of mitogenic stimuli, mature B cell lines show constitutively low levels of NF-kB (heterodimers p50 and c-Rel activity). ${ }^{111}$

The activation and phosphorylation of NF-kB occurs through pathways involving inflammatory stimuli and pathways triggered by tumour necrosis factor (TNF)-family members. ${ }^{112}$ In order for mature B cells to proliferate and survive in response to mitogenic stimuli, acute increases in NF-kB activity are required. MUM1/IRF4 is a mediator of $B$ lymphocytic proliferative responses, induction of which is caused by binding of c-Rel (a transactivating subunit) to NF-KB. In addition, an optimal increase in the number of $B$ cells following B-cell receptor stimulation involves inhibition of apoptosis in which NF-KB activity has been implicated. Bcl-2, BCL-XL and A1 are members of the anti-apoptotic Bcl-2 family which are targeted by NF-kB. Induction of these anti-apoptotic agents occurs after B-cell receptor stimulation. 113,114 Imbalances in the anti-apoptotic and pro-proliferative functions of NF-kB have been found to contribute to malignant transformation with possible contribution to tumour progression particularly regarding Hodgkin's disease and diffuse large B cell lymphoma. 115

In DLBCL varying gene expression profiles have allowed for subdivision into germinal center B-like diffuse large B cell lymphoma (GC-DLBCL) and activated $B$ cell-like DLBCL (ABC-DLBCL). ${ }^{116}$ Davis et al ${ }^{117}$ established that the activated 
group of DLBCL displayed NF-KB activation due to high levels of IKK activity and IkBa degradation which renders NF-kB readily available for translocation to the nucleus thereby activating transcription of target genes. In ABC DLBCL, certain NFKB target genes are highly expressed. These target genes include cyclin D2, IRF4/MUM1, Bcl-2, c-FLIP and IKBa. Low expression of these genes occurs in GC DLBCL. In addition to Bcl-2, other members of this antiapoptotic family such as $A 1$ and $B C L-X L$ are also NF-KB target genes.

ABC DLBCL showed high constitutive IKK activity and IKB degradation which promotes increased NF-kB DNA binding activity. In contrast, GC DLBCL lacked this form of NF-KB pathway activation.

The constitutive NF-KB activation in ABC DLBCL may be due to derivation from a stage of $B$ cell differentiation at which NF-kB is normally activated. Alternatively, the activation of NF-KB may be an oncogenic event occurring in ABC DLBCL which is unrelated to the physiological role of NF-kB in B cell differentiation.

In ABC DLBCL cell cycle progession requires activity of the NF-kB pathway via expression of Cyclin D2 (a NF-kB targeted gene). During the $\mathrm{G}_{1}$ phase of the cell cycle, cyclin D activates cyclin dependant kinase 4, forming a complex (cyclin DCDK4) which plays a vital role in the phosphorylation of the retinoblastoma susceptibility protein (RB). This protein in turn allows for activation of E2F transcriptional activity facilitating cell cycle progression beyond $\mathrm{G} 1$ and subsequent cellular replication.

Most importantly, inhibition or loss of NF-KB activity has been found to be toxic to $A B C D L B C L$, due to $G 1$ phase cycle arrest. Interestingly, loss of NF-KB function was found to be non-toxic to GCB DLBCL cell lines, thus creating the potential for targeted therapeutic intervention. ${ }^{117}$ 


\subsection{Plasmablastic lymphoma}

\section{$\underline{5.8 .1 \text { General }}$}

In 1978 Banks et al. published a case report of an extramedullary lymphoid neoplasm displaying morphologic features of diffuse large B cell lymphoma of "immunoblastic sarcoma" type. This neoplasm was recognised as unique by the lack of immunohistochemical expression of B-cell surface markers and concomitant cytoplasmic expression of immunoglobulin ( $\mathrm{lgG}$ ) leading to recognition of a malignant lymphoma of plasmablastic identity. ${ }^{118}$

In 1997 the term plasmablastic lymphoma was coined by Delecluse et al ${ }^{119}$, following the description of an acquired immunodeficiency syndrome-associated B-lineage lymphoma with plasmacytic differentiation occurring in the oral cavity region of 16 patients. It was proposed that this lymphoma represented a new subtype of diffuse large B-cell lymphoma. Thereafter, several cases of Human immunodeficiency virus (HIV)-associated plasmablastic lymphomas were reported by Brown et al ${ }^{120}$, Carbone et al ${ }^{121}$, Chetty et al ${ }^{122}$ and Lin et al ${ }^{123}$ (among others) to involve topographic sites such as the oral cavity, jaw and extra-oral regions which included stomach, lung, perianal, nasal, paranasal and cutaneous regions. Subsequently, plasmablastic lymphoma was considered a variant of diffuse large Bcell lymphoma. ${ }^{124}$ Most recently, the 2008 WHO classification recognises plasmablastic lymphoma as a large cell non-Hodgkin's mature B cell lymphoma, having been separated from the DLBCL category. ${ }^{15}$

\subsubsection{Epidemiology}

The plasmablastic lymphoma incidence accounts for approximately $2.6 \%$ of all AIDSassociated non-Hodgkin's lymphoma. ${ }^{125}$

Plasmablastic lymphoma generally occurs in immunocompromised adult patients.

Chabay et al. ${ }^{126}$ and Radhakrishnan et al. ${ }^{127}$ provided rare case reports of plasmablastic lymphoma occurring in paediatric patients with immunodeficiency. There are also rare case reports of plasmablastic lymphoma occurring in 
immunocompetent and/or elderly patients. The topographic sites of involvement include the oral cavity and extra-oral sites. ${ }^{128,129,130}$

The median age at presentation is approximately 30-50 years. However, a broad age range from 7 to 75 years exists. Delecluse et al. ${ }^{119}$ report a $7: 1$ male predominance.

\subsubsection{Aetiology}

\subsection{3 (a) Immunosuppression}

The vast majority of plasmablastic lymphomas occur in HIV-infected patients and represent aggressive malignant tumours with a poor prognosis.

It is now established that other forms of immunodeficiency/immunosuppression including iatrogenic immunosuppression associated with autoimmune disorders, ulcerative colitis and organ transplantation (most frequently renal transplantation) are also risk factors for development of plasmablastic lymphoma. ${ }^{131}$

\subsection{3 (b) Epstein-Barr virus (EBV) infection}

EBV plays an important role in the pathogenesis of plasmablastic lymphoma. EBVpositivity is demonstrable in the vast majority $(60-100 \%)$ of plasmablastic lymphomas involving the oral cavity and extra-oral locations. Several groups (Teruya-Feldstein et al. ${ }^{131}$, Dong et al. ${ }^{133}$ and Tavora el al. ${ }^{132}$ ) have confirmed the presence of EBER (Epstein Barr viral early RNA) by in situ hybridisation. Detection of expression of EBV latency-associated proteins such as latent membrane protein-1 (LMP-1) by immunohistochemistry is very much lower. Chetty et al. ${ }^{122}$ found EBV LMP-1 expression in $10 \%$ of extra-oral plasmablastic lymphomas. Dong et al. ${ }^{133}$ confirmed EBV-EBER positivity in 12 of 14 cases while no LMP-1 immunoexpression was found in 7 of 14 cases tested. ${ }^{133}$

Interestingly, Rochford et al. ${ }^{134}$ observed that EBER positive EBV infection, without detectable LMP-1, was associated with plasmacytic differentiation in EBV-infected B-cell lines. 


\subsection{3 (c) Human herpesvirus- 8 (HHV-8)}

HHV-8 infection is implicated in lymphomagenesis. Plasmablastic lymphoma may arise in the setting of multicentric Castleman's disease in association with HHV-8 infection. Dupin et al. ${ }^{135}$ demonstrated the presence of HHV-8 infection by HHV-8 latent nuclear antigen 1 (LNA) immunohistochemistry in 8 patients within multicentric Castleman's disease. Three of their patients subsequently developed plasmablastic lymphoma. In support thereof, Oksenhendler et al. ${ }^{136}$ confirmed the development of plasmablastic lymphoma in 6 patients with HIV infection and multicentric Castleman's disease. HHV-8 LNA was demonstrated by immunohistochemistry in 3 of these cases.

The demonstration of HHV-8 infection in plasmablastic lymphomas occurring in patients with HIV infection, unassociated with Castleman's disease, has been met with significant controversy. Cioc et al. ${ }^{137}$ initially demonstrated HHV-8 infection by immunohistochemistry and real time in situ PCR in 4 cases of plasmablastic lymphoma occurring within the oral region (oral cavity and oro/nasopharynx). Deloose et al. ${ }^{138}$ confirmed the presence of HHV-8 infection by PCR and immunohistochemistry in 10 of 26 cases of diffuse large B cell lymphoma occurring in HIV infected patients. These cases constituted a distinctive subgroup of DLBCL with immunoblastic/plasmablastic morphology, CD138/syndecan immunoexpression and low/absent expression of B-cell markers such as CD20, PAX5 and CD79a. All of these tumours were located predominantly within the gastrointestinal tract and there was no associated history of multicentric Castleman's disease.

Six of the patients had preceding Kaposi's sarcoma. Due to the high sero-prevalence of HHV-8 infection and frequent association of Kaposi's sarcoma with HIV infection, confirmation of HHV-8 infection of actual lymphoma cells required correlation of HHV-8 PCR findings with HHV8 immunohistochemistry. ${ }^{138}$

Toure et al. ${ }^{139}$ subsequently confirmed the presence of HHV-8 RNA by PCR and immunohistochemistry for HHV-8 protein in one case of plasmablastic lymphoma occurring in the oral cavity of an HIV-infected patient.

However, in several studies which followed, there was no demonstrable evidence of HHV8 infection in plasmablastic lymphoma, unassociated with multicentric 
Castleman's disease. Colomo et al. ${ }^{51}$ showed that 11 cases of plasmablastic lymphoma (of oral mucosa type) lacked evidence of HHV-8 infection.

Although Dong et al. ${ }^{133}$ found low levels of HHV-8 DNA by nested PCR in 6 of 10 cases of plasmablastic lymphoma, immunohistochemistry for HHV-8 latent nuclear antigen was negative in all the tumour cells. Two of the patients included in their study had concomitant Kaposi's sarcoma and tumorous ascites. They concluded that the HHV-8 DNA detected by PCR was most likely due to the presence of infected bystander circulating (non neoplastic) lymphocytes. ${ }^{140}$ The discrepant findings, relative to those of Coic et al. ${ }^{137}$ in which HHV-8 was demonstrated in most of the tumour cells, may be attributed to differences in methodology and the HHV-8 antibody used. Carbone et al. ${ }^{141}$ were subsequently prompted to re-evaluate the possible presence of HHV-8 infection in plasmablastic lymphomas of the oral cavity. No evidence of HHV-8 infection was demonstrated in their study.

Overall, although HHV-8 infection has been reported in some cases of plasmablastic lymphomas (unassociated with multicentric Castleman's disease) occurring within the oral cavity, the majority of studies have not supported this finding.

Thus, at present, the role of HHV8 in the pathogenesis of plasmablastic lymphoma remains uncertain.

\subsubsection{Clinical features of plasmablastic lymphoma}

Plasmablastic lymphoma may occur in oral and extra-oral topographic regions. Most patients present with advanced stage disease as shown by Colomo et al. ${ }^{51}$ Plasmablastic lymphomas present most commonly as primary disease with intermediate to high risk international prognostic indices. Rarely, secondary plasmablastic transformation may occur in pre-existing plasma cell neoplasms as reported by Qing et al. ${ }^{142}$ 


\subsubsection{Morphologic features of plasmablastic lymphoma}

The histopathologic appearance of plasmablastic lymphoma is that of a high grade lymphoma. The tumour displays a morphologic spectrum comprising a diffuse population of large blastic lymphoid cells with a monomorphic cohesive-like quality as well as cells with plasmacytic differentiation. At low power magnification, a starrysky appearance is discernable due to the presence of tingible body macrophages interspersed among tumour cells.

At the blastic end of the spectrum the tumour cells display large round or oval eccentrically displaced nuclei with a single large central nucleolus or several peripherally located nucleoli. The cells contain abundant amphophilic cytoplasm and paranuclear hofs which are morphologically consistent with plasmablasts. Colomo et al. ${ }^{51}$ aptly described the monomorphic features of cells of plasmablastic lymphoma of oral mucosa type as if they were frozen at the same stage of differentiation with minimal plasmacytic differentiation. This morphologic variant tends to occur in association with HIV-infection.

At the plasmacytic end of the spectrum, plasmablastic lymphoma with plasmacytic differentiation comprises plasmablasts and immunoblasts, the latter displaying larger nuclei and larger nucleoli than plasmablasts. Distinct plasmacytic maturation is usually present. Plasmablastic lymphomas with plasmacytic differentiation tend to occur in nodal and extranodal sites other than those of the oral mucosa (gingival, palatal and jaw regions).

Mitotic figures are usually frequent and coagulative tumour necrosis may be present at both ends of the morphologic spectrum. ${ }^{15,52}$

\subsubsection{Immunohistochemical features of plasmablastic lymphoma}

Plasmablastic lymphomas generally lack expression of CD45RB (LCA) and pan B-cell marker CD20. However, Colomo et al. ${ }^{51}$ found weak expression of CD45 in $61 \%$ of plasmablastic lymphomas, oral mucosa type, and in $56 \%$ of plasmablastic lymphomas with plasmacytic differentiation. In this particular study, weak expression of CD20 in 8-13\% of cases of plasmablastic lymphoma was also established. Delecluse et al. ${ }^{119}$ also confirmed weak surface membrane expression of CD20 and LCA, in less than $5 \%$ of tumour cells, in 3 of 8 cases of plasmablastic 
lymphoma. In a case report by Guan et al. ${ }^{130}$ focal LCA expression was also found in plasmablastic lymphoma occurring in the oral cavity of an HIV negative patient.

The tumour cells in plasmablastic lymphoma express plasma cell immunohistochemical markers which include VS38C, CD138, CD38 and IRF4/MUM1. Several groups have demonstrated cytoplasmic expression of immunoglobulins (usually lgG) which occurs in approximately $70 \%$ of cases. EMA expression may occur and there is variable expression of CD79a which ranges from 50 to $80 \%$. 143

CD56 expression is common in myeloma and expression may occur in plasmablastic lymphoma with plasmacytic differentiation. Plasmablastic lymphomas are high grade tumours with significantly high proliferation indices. Ki67, most frequently used to assess the proliferation index, is usually greater than $90 \%$. The vast majority (up to $75 \%$ ) of plasmablastic lymphomas display evidence of EBV infection as demonstrated by EBER in situ hybridisation. Associated EBV LMP1 immunoexpression is very much lower. ${ }^{15,52}$

\subsubsection{Molecular findings in plasmablastic lymphoma}

Valera et al. ${ }^{155}$ identified MYC rearrangements in $49 \%$ of PBL and most of these were partnered by the immunoglobulin (IG) genes. Furthermore, MYC rearrangements were found to be more common in EBV-positive (74\%) than EBVnegative (43\%) plasmablastic lymphomas. No rearrangements of $B C L 2, B C L 6$, MALT1 or PAX5 were detected in this serious of PBL cases.

Similarly, Dawson et al. ${ }^{144}$ reported the association of plasmablastic lymphoma with an IgH/MYC translocation in a patient with HIV infection and haemophilia.

Gaidano et al. ${ }^{145}$ performed sequencing analysis of the immunoglobulin heavy chain variable region $(\mathrm{lgVH})$ gene in 10 cases of plasmablastic lymphoma occurring in patients with HIV infection. Somatic hypermutation was found in four cases. This finding suggested that plasmablastic lymphoma is a molecularly heterogeneous disease derived from post-germinal centre cells or from native B-cells undergoing preterminal differentiation. One of the four cases also showed $B C L-6$ gene mutation implying its derivation from post-germinal centre cells. 
Chang et al. ${ }^{146}$ used array comparative genomic hybridisation to assess the genomic profile of plasmablastic lymphoma. The most frequent segmental gains (> 40\%) in PL included 1p36.11-1p36.33, 1p34.1-1p36.13, 1q21.1-1q23.1, 7q11.27q11.23, 11q12-11q13.2 and 22q12.2-22q13.3.

Segmental gains in $1 \mathrm{p} 35.1-1 \mathrm{p} 36.12,1 \mathrm{q} 21.1-1 \mathrm{q} 23.1,1 \mathrm{p} 36.11-1 \mathrm{p} 36.33$, were found to occur only in PL. Interestingly, segmental gains of 16p12-16p13.2 and 11q14$11 q 14$, occurred more frequently in HIV positive cases suggesting that these lesions may be related to HIV associated malignancies. PLA2 gene has been shown to be activated by HIV envelope glycoproteins and may participate in the fusion of HIV and lymphocytes. Segmental genetic losses were more heterogeneous with frequencies up to $23 \%$. Overall, the genomic aberration pattern appeared to be more similar to that of DLBCL (AIDS-related and non AIDS-related) than myeloma. Gain of 16p13.3 was found to occur in some cases of plasmablastic lymphoma and DLBCL. This alteration was not found in any of the cases of myeloma.

Vega et al. ${ }^{147}$ found that AIDS-related plasmablastic lymphoma had immunophenotypic features and tumour suppressor gene expression profiles which were similar to plasmablastic plasma cell myeloma. Both tumours displayed high Ki67 proliferation indices with overexpression of p53 and loss of expression of p16 as well as p27. However, the tumours differed in that EBV-encoded RNA was positive in all plasmablastic lymphomas and negative in plasma cell myelomas.

In contrast, isolated case reports have challenged the latter finding of Vega et al. ${ }^{147}$ in that EBV infection (EBER) has been documented in a case of submandibular plasmacytoma and in a case of multiple myeloma occurring in a patient with AIDS. 157,158

\subsubsection{Outcome of plasmablastic lymphoma}

Plasmablastic lymphomas are associated with poor outcome despite aggressive therapy which combines systemic chemotherapy and/or radiotherapy and HAART in the setting of HIV infection. Most investigative series have demonstrated median survival of less than 12 months. ${ }^{15,52}$ 


\section{AIMS AND OBJECTIVES}

The aims and objectives were to investigate large cell lymphomas which included diffuse large B cell lymphoma and plasmablastic lymphoma and to correlate the Human Immunodeficiency Virus status and prognosis with differentiation profiles assessed by immunophenotyping.

This study was submitted for review to the Research Ethics Committee of the Health Sciences Faculty at the University of Cape Town and formal ethical approval thereof was obtained (REC reference 209/2006).

\section{METHOD}

\subsection{Case selection}

The researcher retrieved cases of large cell lymphoma comprising diffuse large B cell lymphoma and plasmablastic lymphomas which were diagnosed at the histopathology department, division of Anatomical Pathology, National Health Laboratory Service, Groote Schuur Hospital, Cape Town. The cases were selected from a snomed-based search of the DISA computer system and from the intradepartmental lymphoma database. Random selection of cases from both HIV positive and negative patients was made. Cases of DLBCL with Burkitt-like features were omitted from the study. Tissue samples which were limited by paucity of diagnostic tissue were also excluded from the study.

In total 61 cases were included in this study. Of these, 27 cases were diagnosed in HIV positive patients. These comprised 9 de novo plasmablastic lymphomas and 18 diffuse large B cell lymphomas. In HIV negative patients, 28 cases of diffuse large $B$ cell lymphomas were selected. Two of these patients were recipients of solid organ allograft transplantation (renal and cardiac). In 6 additional patients with DLBCL, the HIV status was unknown. Overall, the total number of cases of DLBCL was 52 .

All cases were diagnosed between January 2004 and December 2007, allowing for a mean follow up of 27 months from the time of diagnosis. 


\subsection{Immunohistochemistry}

Formalin-fixed, paraffin-embedded tissue blocks for each of the selected cases were retrieved from the departmental archives. A panel of immunohistochemical stains was performed, at times augmenting those done at initial histopathologic work-up and diagnosis.

A total of eleven, 3-4 micron, sections were cut from each representative block, floated onto silanised slides, heat fixed at $75^{\circ} \mathrm{C}$ for 30 minutes and then stored at room temperature until immunohistochemistry $(\mathrm{IHC})$ was performed. Silanised slides are those which are coated with organosilane and baked for approximately 30 minutes at temperatures of 55-60 degrees Celsius to ensure optimal adhesion of tissue sections. All immunohistochemistry was performed on a Dako Autostainer (Universal Staining System) using the Envision Detection System. Sections were dewaxed in xylene, taken down to water through graded alcohols and subjected to antigen retrieval. Heat induced epitope retrieval, HIER, was performed in a Tedelex Pressure cooker using either $10 \mathrm{mM}$ Citric Acid at $\mathrm{pH} 6$ or $1 \mathrm{mM}$ EDTA at $\mathrm{pH} 8$. Buffers were brought to boiling point, slides were immersed in the boiling buffer and full pressure was maintained for 2 minutes. Thereafter slides were immediately immersed in running tap water. The staining protocol included blocking for endogenous peroxidase with an aqueous $2 \% \mathrm{H}_{2} \mathrm{O}_{2}$ solution for five minutes; blocking for non-specific binding with 5\% normal goat serum (Dako X0907) in phosphate buffered saline (PBS, IHC washing buffer) for five minutes; incubation with the primary antibody (as specified in the table 8) for 45 minutes and incubation with the secondary antibody (Envision K4001) for 30 minutes. The chromogenic substrate (Dako K3466) was applied for 5 minutes. All rinse steps were done with PBS/Tween. Positive and negative controls were included in each run. PBS/Tween or non-immune serum replaced primary antibodies for the negative controls. 


\begin{tabular}{|lllll|}
\hline Antibody & Clone & Dilution (PBS) & Antigen Retrieval & Control \\
\hline CD10 & 56 C6 & $1: 30$ & $10 \mathrm{mM}$ Citrate & Tonsil \\
CD38 & SPC32 & $1: 60$ & $1 \mathrm{mM}$ EDTA & Tonsil \\
CD138 & Ml 15 & $1: 50$ & $1 \mathrm{mM}$ EDTA & Appendix \\
Bcl-2 & 124 & $1: 20$ & $10 \mathrm{mM}$ Citrate & Appendix \\
Bcl-6 & PG-B6p & $1: 20$ & $1 \mathrm{mM}$ EDTA & Appendix \\
Mib-1 & Ki-67 & $1: 50$ & $10 \mathrm{mM}$ Citrate & Appendix \\
EBV & LMP-1 & $1: 200$ & $1 \mathrm{mM}$ EDTA & Positive lymph node \\
MUM-1 & MUM 1p & $1: 50$ & $1 \mathrm{mM}$ EDTA & Appendix \\
Plasma Cell & VS38C & $1: 30$ & $1 \mathrm{mM}$ EDTA & Tonsil \\
\hline
\end{tabular}

Table 7 Antibodies used in the study

\section{RESULTS}

\subsection{Morphologic features}

The morphologic features of the selected tumours were assessed by light microscopy using haematoxylin and eosin (H\&E) stained sections.

Within nodal and extranodal locations, the diffuse large B cell lymphomas displayed diffusely destructive and widely permeative growth patterns. Necrosis and apoptotic debris were prominent features in some cases, particularly in DLBCL occurring with the HIV positive patients in keeping with the high grade nature of these tumours. The individual tumour cells displayed large nuclei which were generally larger than those of histiocytes. The nuclei were predominantly round and occasionally indented. The nucleoli varied from single, centrally located prominent nucleoli to multiple smaller peripherally located nucleoli. Moderate amounts of eosinophilic to pale amphophilic cytoplasm were present. The vast majority of the diffuse large B cell lymphomas displayed mixed centroblastic and immunoblastic morphologic features. 


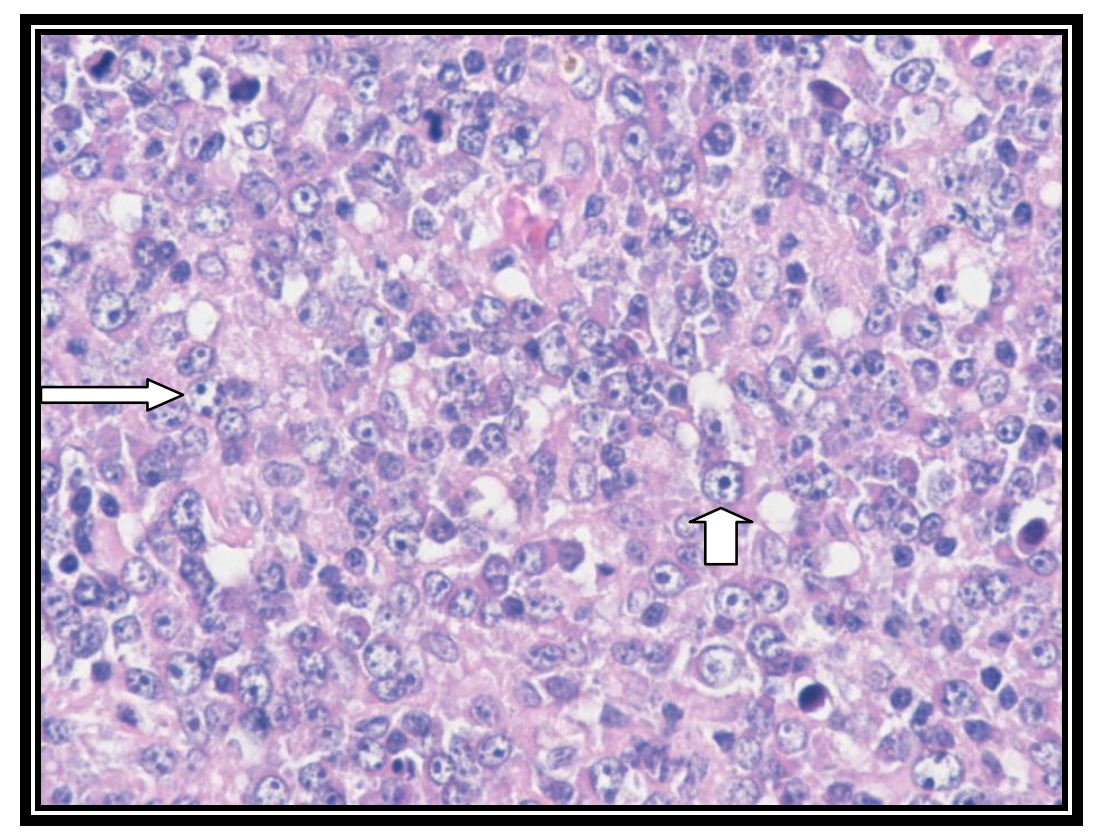

Figure 7 H\&E stained section (X200 magnification) of DLBCL displaying mixed centroblastic (longer arrow) and immunoblastic (shorter arrow) features.

Prominent immunoblastic morphology was evident in DLBCL occurring within the small intestine of an HIV negative patient with previous solid organ (renal) allograft transplantation (Figure 8). EBV LMP1 immunohistochemistry was positive in these tumour cells.

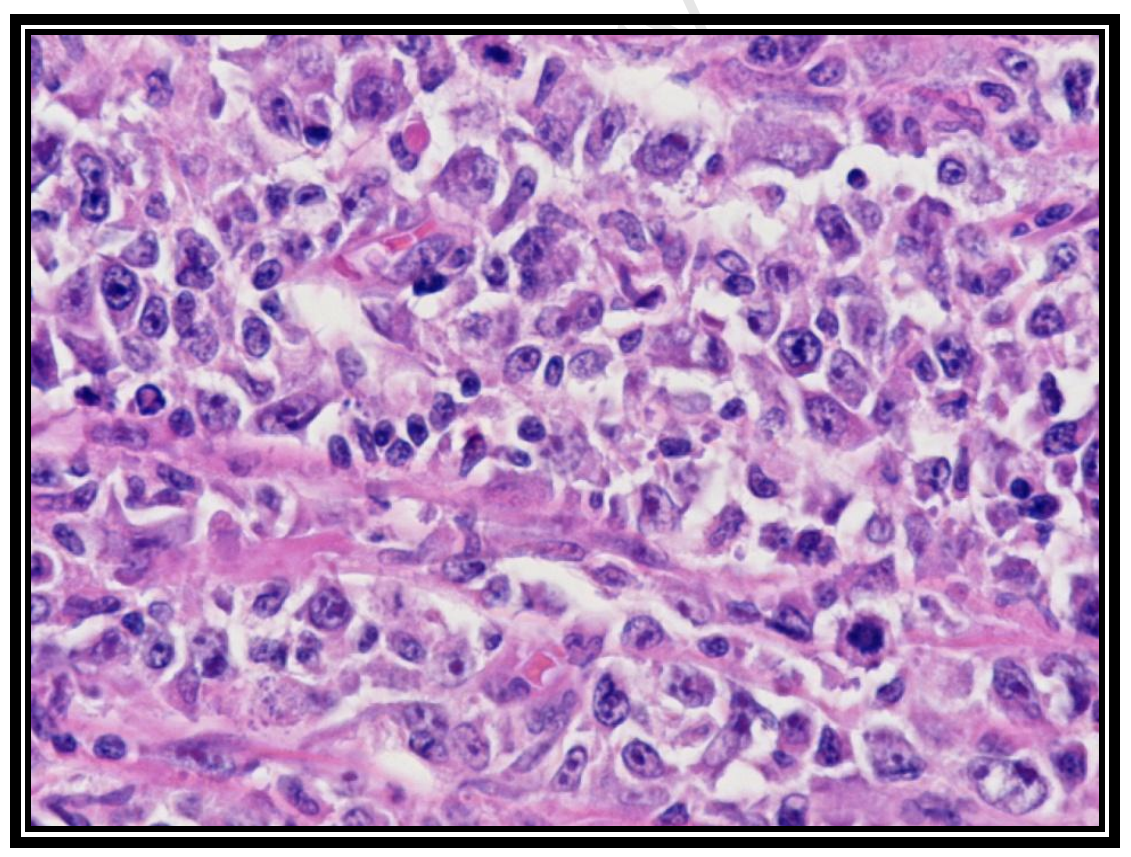

Figure 8 H\&E stained section (X200 magnification) of DLBCL with immunoblastic morphology. 
The plasmablastic lymphomas displayed features of high grade tumours with sheetlike growth patterns and interspersed tingible body macrophages which imparted a starry-sky appearance to the tumour (Figure 9). The individual tumour cells displayed blast-like cytomorphologic characteristics (Figure 10). There was abundant amphophilic to basophilic cytoplasm and eccentrically displaced large round vesicular nuclei within which were prominent nucleoli. The number of nucleoli varied from a single prominent nucleolus to several distinctly prominent nucleoli. Significant mitotic activity and apoptotic debris were often present.

Isolated cases of extra-oral plasmablastic lymphomas showed variable, intermittently subtle, degrees of plasmacytic differentiation (Figure 11) combined with prominent immunoblastic and plasmablastic morphologic features.

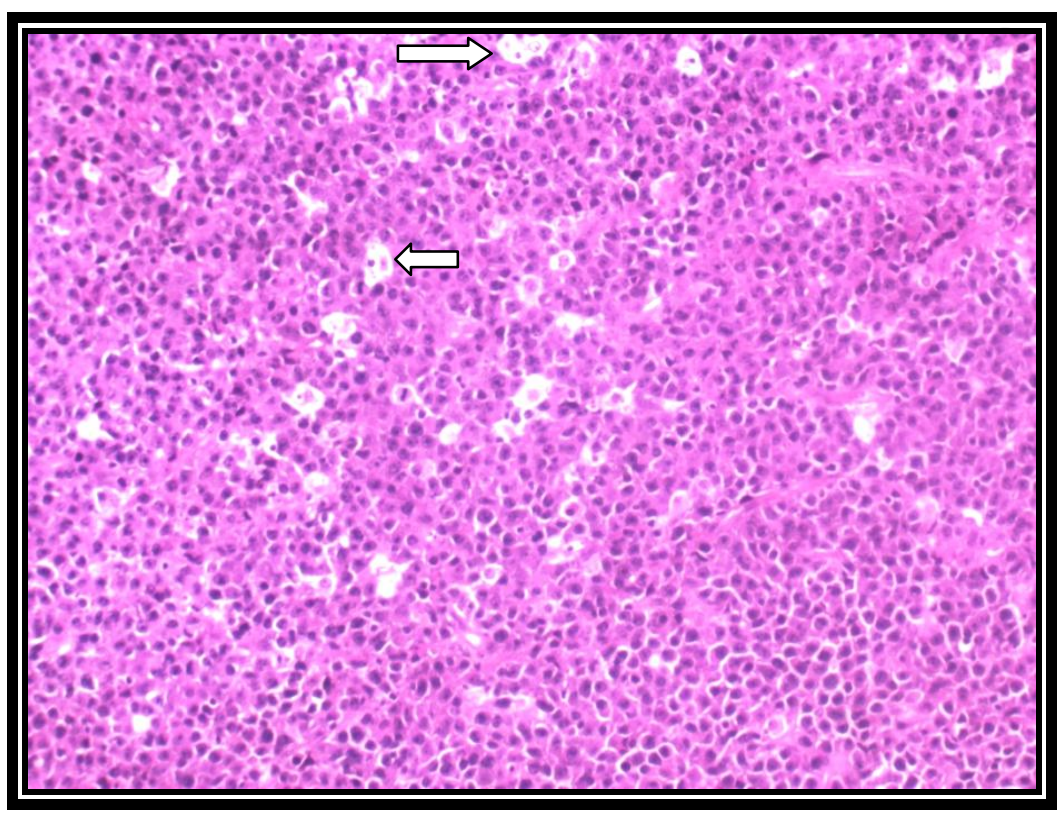

Figure 9 H\&E stained section (X100 magnification) depicting plasmablastic lymphoma with a starry-sky appearance imparted by interspersed tingible body macrophages (arrows) 


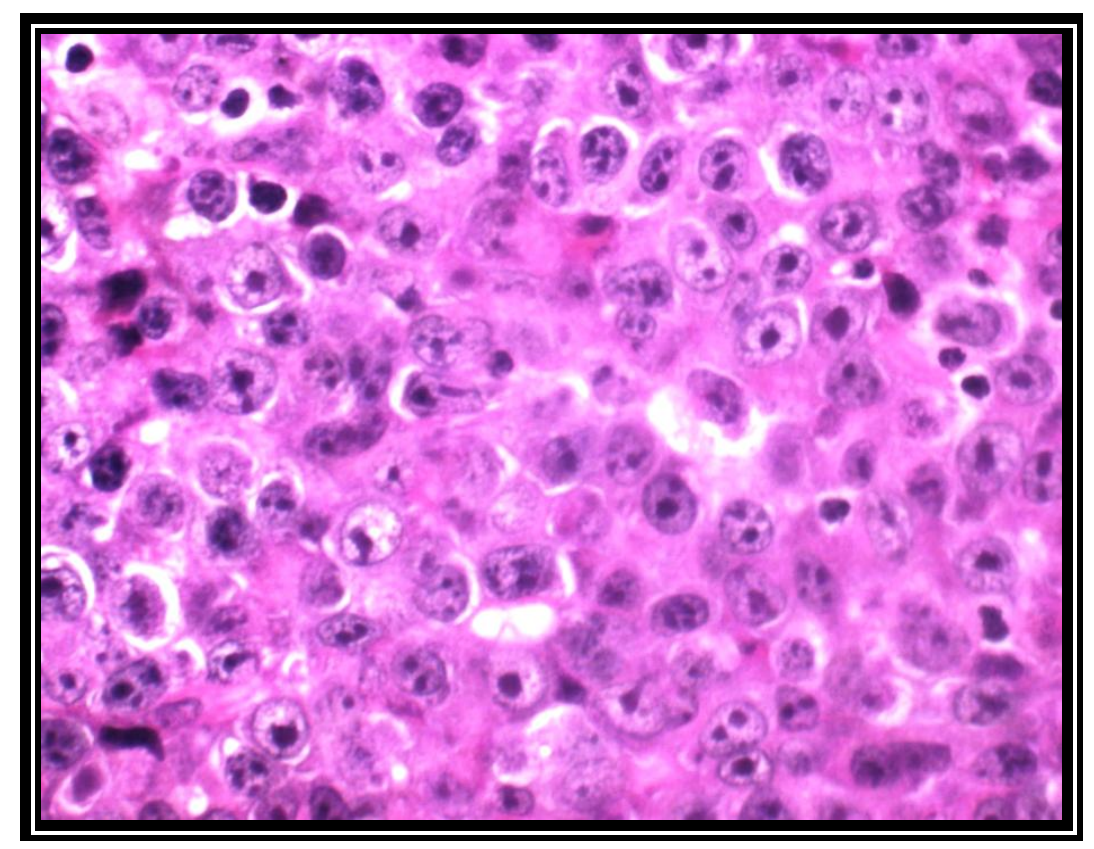

Figure 10 H\&E stained section (X400 magnification) of plasmablastic lymphoma with distinct blastic morphology

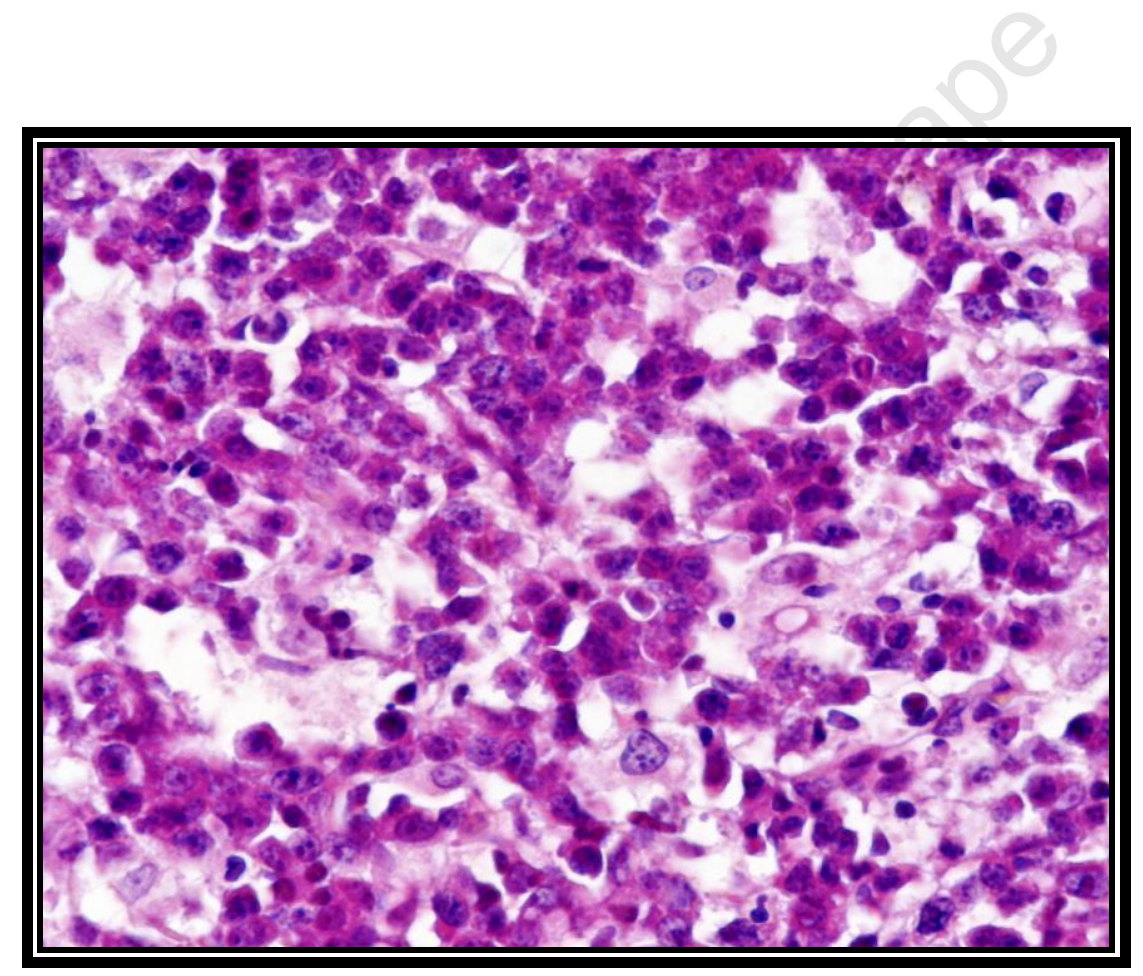

Figure 11 H\&E stained section (X200 magnification) of plasmablastic lymphoma depicting greater degree of plasmacytic differentiation. 


\subsection{Immunohistochemistry}

Immunohistochemistry was interpreted with the aid of a scoring system in which scores of 0-4 were allocated in relation to the percentage of positively staining tumour cells. Scores of 0-5 were used when assessing the proliferation index (Ki67).

Score $\quad \%$ of tumour cells displaying positive staining

$\begin{array}{lll}0 & - & \text { negative } \\ 1 & - & 1-25 \\ 2 & - & 26-50 \\ 3 & - & 51-75 \\ 4 & - & 76-100\end{array}$

Table 8 IHC scoring system

The cut-off level for interpreting CD10, Bcl- 6 and $\mathrm{Bcl}-2$ as positive was $>25 \%$ tumour cell staining which is equivalent to a score of at least 2 .

Immunohistochemistry was interpreted as positive when the following staining patterns occurred with respective antibodies:

MUM1 - nuclear staining

CD20, CD3, CD38 - cell membrane staining

CD10 - cell membrane and cytoplasmic staining

Bcl-6 - nuclear staining

Bcl-2 - cytoplasmic staining

VS38C - cell membrane and cytoplasmic staining

CD138 - cell membrane and cytoplasmic staining

EBV LMP1 - cell membrane and cytoplasmic staining 


\begin{tabular}{|ccc|}
\hline Ki67 score - & \% of tumour cells displaying positive nuclear staining \\
\hline 0 & - & negative \\
1 & - & $1-25$ \\
2 & - & $26-50$ \\
3 & - & $51-75$ \\
4 & - & $76-95$ \\
5 & - & $>95$ \\
\hline
\end{tabular}

Table 9 Scoring of Ki67

All the cases of DLBCL displayed diffuse expression of CD20 (Figure A). There were high proliferation indices which occasionally exceeded $95 \%$ in HIV positive and negative groups (Figure D). CD10 expression, involving at least $25 \%$ of tumour cells (score $\geq 2$ ), was found in $38 \%$ (23/52) of DLBCL cases. Similarly, Bcl-6 expression was established in $60 \%$ (31/52) while MUM1 expression occurred in $88 \%(46 / 52)$ of cases. CD38 expression (Figure C) was found in 98\% (51/52) of DLBCL in this study and EBV LMP1 expression occurred in 5/52 cases. 


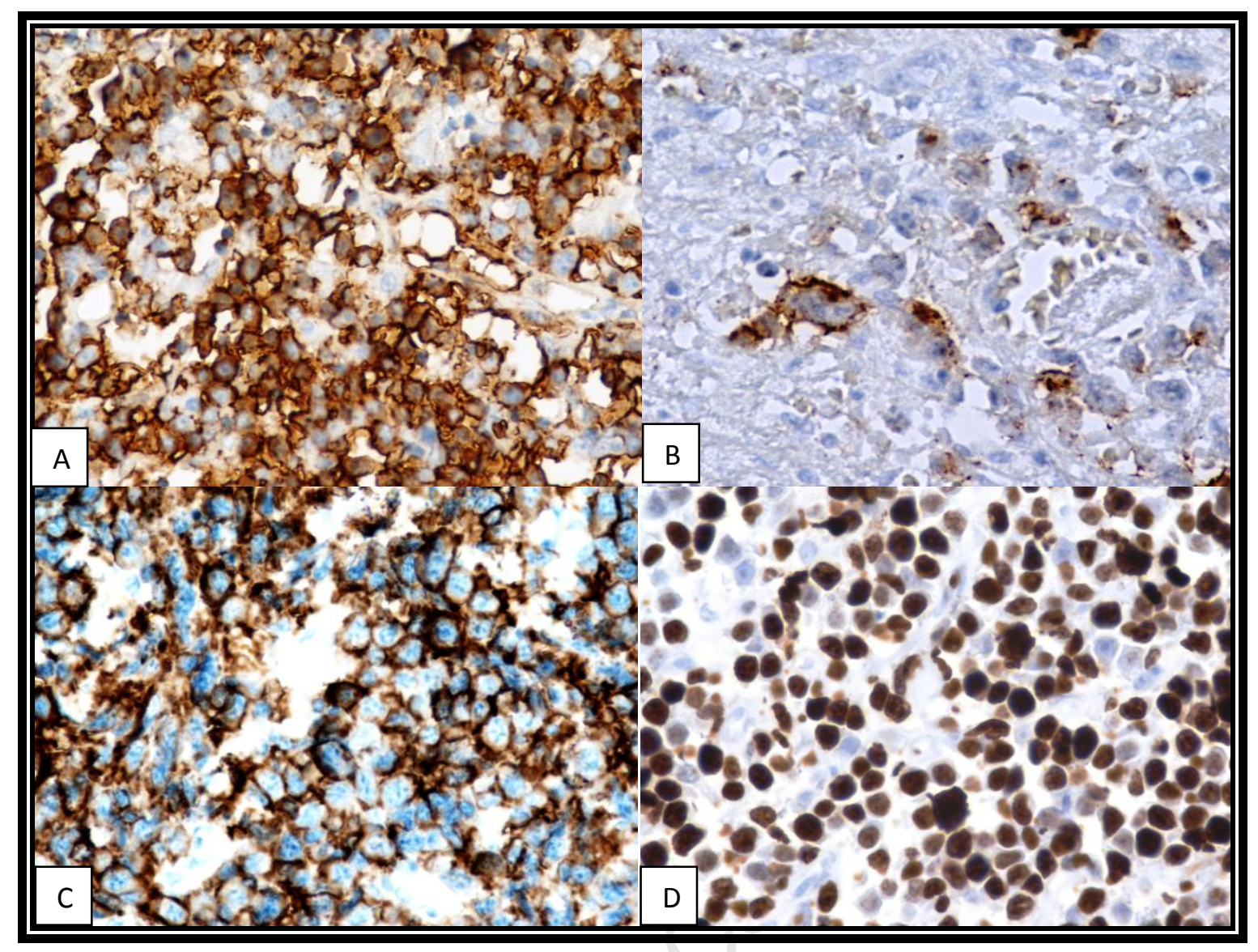

Figure A DLBCL with membrane immunoreactivity for CD20

Figure B DLBCL with EBV LMP1 immunoreactivity. This tumour displayed immunoblastic morphologic features.

Figure C DLBCL with diffuse CD38 immunoreactivity

Figure D High proliferation index in DLBCL demonstrated by Ki-67 immunohistochemistry

All cases of PBL in our study lacked CD20 expression (Figure F) and 8/9 cases displayed MUM1 immuno-expression (Figure E) which involved 76-100\% of tumour cells. In the single case which lacked MUM1 expression, VS38C, CD138 and CD38 immunoexpression was found to occur in 76-100\% of tumour cells. Interestingly, of all our PBL cases, the MUM1-negative case showed the highest level of EBV-LMP1 expression which involved $51-75 \%$ of tumour cells. Overall, EBV LMP1 immunoexpression was detected in 3/9 PBL cases. VS38C, CD38 and CD138 expression was found in all cases of PBL. The proliferation index in all cases of PBL was high and ranged from 76 to $>95 \%$. 


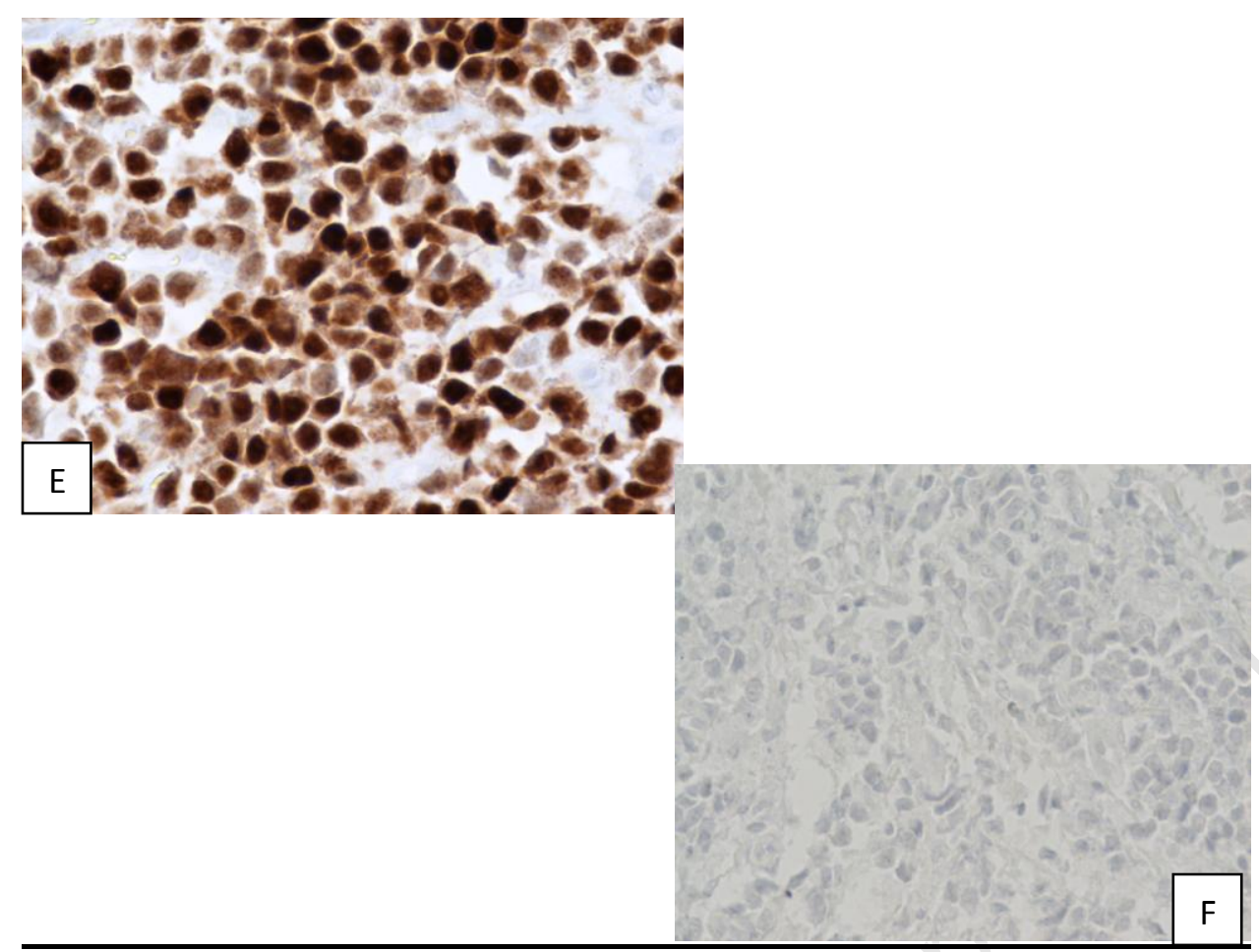

Figure $\mathrm{E}-\mathrm{PBL}$ displaying diffuse nuclear immunoreactivity for MUM1

Figure $\mathrm{F}-\mathrm{PBL}$ displaying an absence of CD20 immunoreactivity

\subsection{Statistical interpretation}

The data generated from this scoring system was captured in an Excel-spread sheet (Tables 10 and 11). Information regarding several prognostic factors such as age, CD4 count, IPI score, highly active anti-retroviral therapy (HAART), chemotherapy $(\mathrm{CHOP})$ and radiation treatment was obtained by close collaboration with a senior radiation oncologist at Groote Schuur Hospital. All the information obtained, was incorporated into the data spread sheet.

Statistical analysis of the gathered data was conducted by the researcher and a statistician using computer programme SPSS version13. Kaplan Meier curves for survival, log rank test and the Cox regression model were used.

The Cox model was used for analysis of survival data by simultaneously exploring the effects of various prognostic factors, which included immunohistochemical 
variables, on survival. Overall, the Cox regression model essentially allowed the researcher to assess the effect of several prognostic variables at a time on survival. It allowed for the estimation of the hazard/risk of death for individual patients in light of the status of their prognostic variables.

In this study the survival time refers to the time to death. Survival time was censored indicating that at the end of the study period, there were surviving patients. From the obtained set of survival times, it is possible to estimate the proportion of the population of patients with DLBCL and PBL who are likely to survive a given length of time under similar circumstances.

Kaplan-Meier estimation of the survivor function allowed for a table, specifically a life table, and a graph or survival curve to be produced. In this study, the comparison of the survival curves between two groups was assessed by means of the log-rank test. The log-rank test essentially tested the null hypothesis that each of the groups in this study had the same force of mortality. This contrasted the Cox regression model which allowed the researcher to estimate the risk of death for a patient, given the respective prognostic variables. $P$ values less than 0.05 were indicative of statistical significance. 


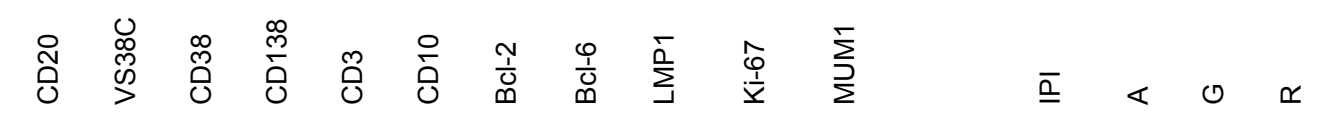

\begin{tabular}{|c|c|c|c|c|c|c|c|c|c|c|c|c|c|c|c|}
\hline 1 & 4 & 3 & 4 & 0 & 3 & 0 & 4 & 2 & 0 & 4 & 4 & DLBL & 3 & 39 & $F$ \\
\hline 2 & 4 & 2 & 3 & 0 & 2 & 0 & 4 & 0 & 0 & 2 & 4 & DLBL & 1 & 67 & M \\
\hline 3 & 4 & 2 & 2 & 0 & 3 & 2 & 1 & 4 & 0 & 4 & 1 & DLBL & - & 69 & $\mathrm{~F}$ \\
\hline 4 & 4 & 3 & 2 & 0 & 2 & 0 & 3 & 3 & 0 & 4 & 4 & DLBL & 0 & 64 & M \\
\hline 5 & 4 & 0 & 1 & 0 & 2 & 4 & 3 & 4 & 0 & 1 & 0 & DLBL & 4 & 67 & $\mathrm{~F}$ \\
\hline 6 & 4 & 1 & 2 & 0 & 1 & 2 & 3 & 4 & 0 & 3 & 1 & DLBL & - & 49 & M \\
\hline 7 & 4 & 1 & 4 & 0 & 1 & 4 & 4 & 4 & 0 & 5 & 0 & DLBL & 3 & 53 & $\mathrm{~F}$ \\
\hline 8 & 4 & 4 & 4 & 0 & 3 & 0 & 4 & 4 & 0 & 4 & 4 & DLBL & 2 & 61 & $\mathrm{~F}$ \\
\hline 9 & 4 & 0 & 3 & 0 & 3 & 0 & 3 & 3 & 0 & 4 & 4 & DLBL & 3 & 51 & $M$ \\
\hline 10 & 4 & 0 & 4 & 0 & 2 & 0 & 4 & 4 & 0 & 4 & 4 & DLBL & - & 33 & $\mathrm{~F}$ \\
\hline 11 & 4 & 4 & 4 & 0 & 3 & 0 & 4 & 3 & 0 & 3 & 4 & DLBL & 3 & 54 & $M$ \\
\hline 12 & 4 & 4 & 3 & 0 & 3 & 0 & 4 & 4 & 0 & 5 & 4 & DLBL & 1 & 34 & $\mathrm{~F}$ \\
\hline 13 & 4 & 1 & 3 & 1 & 1 & 0 & 2 & 4 & 0 & 4 & 4 & DLBL & - & 71 & $M$ \\
\hline 14 & 4 & 4 & 2 & 0 & 3 & 0 & 4 & 0 & 1 & 4 & 0 & DLBL & 2 & 43 & M \\
\hline 15 & 4 & 2 & 3 & 1 & 1 & 4 & 4 & 4 & 0 & 3 & 4 & DLBL & 4 & 67 & $F$ \\
\hline 16 & 4 & 2 & 1 & 0 & 2 & 0 & 2 & 0 & 0 & 4 & 4 & DLBL & 4 & 50 & $\mathrm{~F}$ \\
\hline 17 & 4 & 3 & 3 & 0 & 2 & 0 & 3 & 1 & 0 & 4 & 4 & DLBL & - & 44 & $\mathrm{~F}$ \\
\hline 18 & 1 & 1 & 4 & 0 & 3 & 0 & 0 & 0 & 0 & 4 & 1 & DLBL & 2 & 36 & M \\
\hline 19 & 4 & 1 & 1 & 0 & 3 & 0 & 4 & 1 & 0 & 3 & 1 & DLBL & 3 & 45 & M \\
\hline 20 & 4 & 2 & 1 & 0 & 2 & 0 & 4 & 1 & 0 & 4 & 4 & DLBL & 2 & 45 & $\mathrm{~F}$ \\
\hline 21 & 4 & 2 & 2 & 0 & 3 & 0 & 1 & 2 & 0 & 4 & 3 & DLBL & 4 & 60 & M \\
\hline 22 & 3 & 3 & 3 & 1 & 2 & 3 & 4 & 1 & 0 & 4 & 4 & DLBL & 3 & 59 & $\mathrm{~F}$ \\
\hline 23 & 4 & 2 & 2 & 0 & 1 & 0 & 3 & 3 & 0 & 4 & 3 & DLBL & 5 & 86 & $\mathrm{~F}$ \\
\hline 24 & 4 & 4 & & 0 & 3 & 0 & 1 & 0 & 0 & 3 & 2 & DLBL & 3 & 20 & $F$ \\
\hline 25 & 4 & 0 & 2 & 0 & 2 & 0 & 2 & 2 & 0 & 2 & 1 & DLBL & - & 70 & $F$ \\
\hline 26 & 4 & 1 & 1 & 0 & 2 & 0 & 3 & 0 & 0 & 2 & 1 & DLBL & 3 & 57 & $M$ \\
\hline 27 & 4 & 1 & 1 & 1 & 2 & 0 & 2 & 2 & 0 & 4 & 1 & DLBL & 0 & 60 & $M$ \\
\hline 28 & 2 & 3 & 3 & 0 & 2 & 1 & 4 & 0 & 0 & 4 & 2 & DLBL & 4 & 23 & M \\
\hline 29 & 4 & 1 & 2 & 0 & 3 & 3 & 2 & 0 & 0 & 3 & 1 & DLBL & 4 & 76 & $\mathrm{~F}$ \\
\hline 30 & 1 & 1 & 2 & 0 & 3 & 0 & 1 & 0 & 0 & 1 & 1 & DLBL & - & 68 & $\mathrm{~F}$ \\
\hline 31 & 4 & 3 & 1 & 0 & 3 & 3 & 0 & 3 & 0 & 3 & 2 & DLBL & 3 & 58 & $F$ \\
\hline 32 & 4 & 3 & 4 & 0 & 1 & 3 & 4 & 1 & 0 & 3 & 4 & DLBL & 0 & 76 & $M$ \\
\hline 33 & 4 & 1 & 4 & 0 & 2 & 1 & 0 & 2 & 0 & 3 & 1 & DLBL & - & 35 & $M$ \\
\hline 34 & 4 & 2 & 2 & 0 & 3 & 4 & 4 & 4 & 0 & 3 & 2 & DLBL & 5 & 80 & $\mathrm{~F}$ \\
\hline
\end{tabular}

\footnotetext{
A - Age

G - Gender

R - Retroviral status (- negative; + positive, / unknown)

DLBL- Diffuse large B cell lymphoma
}

CD3 - Background reactive T lymphocytes in the tumour 
Table 11 Data sheet (B)

กิ๊

CD4

\begin{tabular}{|c|c|c|c|c|c|c|c|c|c|c|c|c|c|c|c|c|c|}
\hline 35 & 4 & 1 & 2 & 0 & 2 & 0 & 0 & 1 & 0 & 5 & 1 & DLBL & 2 & 33 & $F$ & + & 77 \\
\hline 36 & 4 & 1 & 3 & 1 & 2 & 1 & 0 & 4 & 0 & 4 & 1 & DLBL & 1 & 36 & $\mathrm{~F}$ & + & 50 \\
\hline 37 & 3 & 3 & 4 & 0 & 3 & 3 & 1 & 0 & 3 & 3 & 3 & DLBL & 1 & 67 & $M$ & + & 67 \\
\hline 38 & 4 & 1 & 4 & 0 & 2 & 0 & 4 & 0 & 1 & 5 & 4 & DLBL & - & 38 & $M$ & + & 131 \\
\hline 39 & 4 & 2 & 4 & 3 & 2 & 0 & 0 & 0 & 0 & 3 & 3 & DLBL & 4 & 30 & $\mathrm{~F}$ & + & 152 \\
\hline 40 & 0 & 3 & 4 & 4 & 1 & 0 & 0 & 0 & 0 & 4 & 4 & PBL & 4 & 32 & $\mathrm{~F}$ & + & 54 \\
\hline 41 & 4 & 3 & 2 & 2 & 3 & 3 & 0 & 4 & 0 & 4 & 4 & DLBL & 3 & 34 & $\mathrm{~F}$ & + & 92 \\
\hline 42 & 4 & 1 & 4 & 2 & 1 & 3 & 0 & 2 & 0 & 3 & 1 & DLBL & 5 & 41 & $M$ & + & - \\
\hline 43 & 0 & 4 & 4 & 4 & 1 & 3 & 2 & 0 & 0 & 4 & 4 & PBL & 1 & 36 & $\mathrm{~F}$ & + & 69 \\
\hline 44 & 4 & 0 & 2 & 0 & 2 & 0 & 4 & 3 & 0 & 4 & 2 & DLBL & 2 & 67 & $M$ & + & 180 \\
\hline 45 & 0 & 4 & 4 & 4 & 3 & 4 & 0 & 2 & 0 & 5 & 4 & PBL & 2 & 35 & $M$ & + & 23 \\
\hline 46 & 0 & 4 & 4 & 1 & 2 & 0 & 1 & 1 & 0 & 4 & 4 & PBL & 0 & 34 & $M$ & + & 42 \\
\hline 47 & 3 & 0 & 4 & 0 & 2 & 0 & 0 & 1 & 2 & 3 & 4 & DLBL & 0 & 40 & $\mathrm{~F}$ & + & 23 \\
\hline 48 & 4 & 3 & 4 & 0 & 3 & 3 & 4 & 3 & 0 & 4 & 4 & DLBL & 3 & 58 & $\mathrm{~F}$ & + & 438 \\
\hline 49 & 4 & 2 & 4 & 0 & 3 & 2 & 4 & 4 & 0 & 4 & 3 & DLBL & 3 & 53 & $M$ & + & 145 \\
\hline 50 & 4 & 1 & 4 & 0 & 2 & 2 & 0 & 3 & 0 & 2 & 0 & DLBL & 0 & 34 & $M$ & + & 200 \\
\hline 51 & 4 & 4 & 4 & 0 & 2 & 4 & 0 & 0 & 0 & 3 & 0 & DLBL & 4 & 29 & $M$ & + & 434 \\
\hline 52 & 0 & 4 & 4 & 4 & 1 & 4 & 2 & 0 & 0 & 4 & 4 & PBL & 1 & 42 & $\mathrm{~F}$ & + & 27 \\
\hline 53 & 4 & 2 & 0 & 0 & 2 & 0 & 0 & 0 & 0 & 1 & 1 & DLBL & 3 & 32 & $M$ & + & 41 \\
\hline 54 & 0 & 4 & 1 & 4 & 3 & 1 & 0 & 0 & 1 & 4 & 4 & PBL & 2 & 32 & $\mathrm{~F}$ & + & 114 \\
\hline 55 & 0 & 4 & 4 & 4 & 1 & 0 & 0 & 0 & 3 & 0 & 0 & PBL & 3 & 35 & $\mathrm{~F}$ & + & 28 \\
\hline 56 & 4 & 1 & 3 & 3 & 0 & 0 & 0 & 3 & 0 & 4 & 4 & DLBL & 2 & 46 & $M$ & + & 138 \\
\hline 57 & 4 & 1 & 3 & 1 & 3 & 0 & 3 & 0 & 2 & 4 & 3 & DLBL & 1 & 49 & $\mathrm{~F}$ & + & 114 \\
\hline 58 & 0 & 4 & 4 & 0 & 3 & 0 & 0 & 0 & 1 & 4 & 4 & PBL & 0 & 35 & $M$ & + & 166 \\
\hline 59 & 0 & 4 & 4 & 3 & 2 & 4 & 0 & 0 & 0 & 5 & 4 & PBL & 2 & 44 & $M$ & + & 29 \\
\hline 60 & 4 & 1 & 4 & 0 & 1 & 4 & 0 & 4 & 0 & 5 & 1 & DLBL & 2 & 48 & $F$ & + & 130 \\
\hline 61 & 2 & 2 & 3 & 0 & 1 & 2 & 1 & 4 & 0 & 5 & 0 & DLBL & 2 & 42 & $M$ & + & 108 \\
\hline
\end{tabular}

A - Age

G - Gender

R - Retroviral status (- negative; + positive, / unknown)

DLBL- Diffuse large $B$ cell lymphoma

PBL- Plasmablastic lymphoma

CD3 - Background reactive T lymphocytes in the tumour 


\section{$\underline{8.4 \text { Statistical results }}$}

The mean age of patients with DLBCL in the HIV negative group was 54 years. However, in the HIV positive group, the overall mean age of patients was 43 years. Further assessment revealed that the mean age of HIV positive patients with DLBCL and PBL was 48 and 36 years, respectively.

In the HIV positive group there were 11 males and 10 females with DLBCL. Five cases were diagnosed on lymph node biopsies and 16 cases were diagnosed on biopsies of extranodal topographic sites. The extranodal sites included liver (3 cases), nasopharynx (7), soft tissue, kidney, pancreas, spleen (2) and adrenal gland.

In the HIV negative group, DLBCL was diagnosed in 18 females and 16 male patients. 15 cases were diagnosed on biopsies of lymph nodes and 18 cases were diagnosed on biopsies of extranodal sites. In one additional case, the distinction between nodal and extranodal involvement was uncertain as the incisional biopsy originated from the retroperitoneum. The extranodal sites included skin, kidney, testis (2 cases), nasopharynx (3), tonsil (2), adenoids (2), central nervous system (2), small intestine, spleen, bone (vertebra and clavicle) and breast.

Plasmablastic lymphoma was diagnosed in 4 male and 5 female patients, all of whom had HIV infection. 2 cases were diagnosed on biopsies originating from the oral cavity (gingiva and floor of mouth) and 7 cases were diagnosed on biopsies from extra-oral sites. The extra-oral sites included bone (1 case; clavicle), rectum, anus, skin, extradural T8 spinal region, scalp and suprasternal region.

In this study, the researcher established that the overall mean CD4 count in patients with HIV infection was $121 \mathrm{cells} / \mathrm{mm}^{3}$. This was further stratified revealing a mean CD4 count of 151 cells $/ \mathrm{mm}^{3}$ in HIV positive patients with DLBCL and mean CD4 count of 61 cells $/ \mathrm{mm}^{3}$ in patients with PBL.

In the absence of HIV infection, the overall survival of patients with DLBCL was significantly better than DLBCL occurring in patients with HIV infection. The log-rank test confirmed the presence of a statistically significant $p$ value $<0.0001$. 
Table 12: Predictive value of individual and combined immunohistochemical markers in $D L B C L$

\begin{tabular}{|c|c|c|c|c|}
\hline Characteristics & Number & OS (\%) & $\begin{array}{c}\text { Median } \\
\text { survival time } \\
\text { (months) }\end{array}$ & P-value \\
\hline
\end{tabular}

Hans' algorithm

$\begin{array}{lllll}\text { GCB } & 25 & 43 & 27 & 0.188 \\ \text { Non GCB } & 27 & 22 & 11 & \end{array}$

Muris' algorithm

$\begin{array}{lllll}\text { Group 1 } & 27 & 39 & 21 & 0.399 \\ \text { Group 2 } & 25 & 24 & 11 & \end{array}$

HIV

$\begin{array}{lllll}\text { Negative } & 28 & 40 & 16 & <0.001 \\ \text { Positive } & 18 & 11 & 7 & \end{array}$

CD10

$\begin{array}{lllll}\text { Negative } & 30 & 33 & 11 & 0.442 \\ \text { Positive } & 22 & 26 & 10 & \end{array}$

Bcl- 6

$\begin{array}{lllll}\text { Negative } & 19 & 13 & 16 & 0.487 \\ \text { Positive } & 33 & 39 & 18 & \end{array}$

MUM 1

$\begin{array}{lllll}\text { Negative } & 23 & 37 & 13 & 0.124 \\ \text { Positive } & 29 & 28 & 11 & \end{array}$




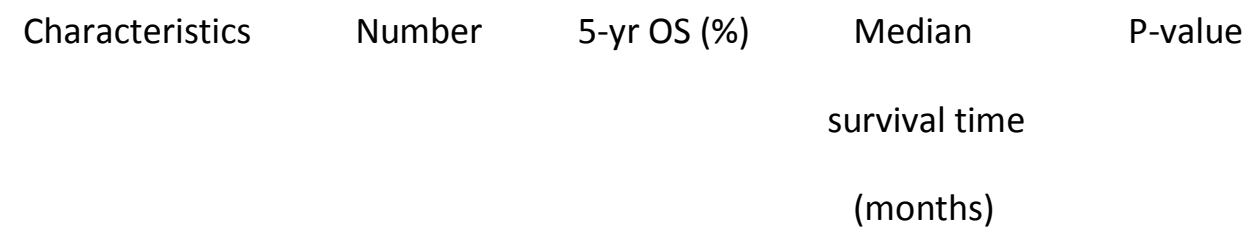

Bcl- 2

$\begin{array}{lcccc}\text { Negative } & 20 & 18 & 9 & 0.371 \\ \text { Positive } & 32 & 38 & 16 & \\ \text { CD } 38 & & & & \\ \text { Negative } & 1 & 14 & 11 & 0.769 \\ \text { Positive } & 51 & 33 & 13 & \end{array}$

$\mathrm{BCl}-2$ in $\mathrm{GCB}$

$\begin{array}{llllll}\text { Negative } & 10 & 20 & 7 & 0.007 \\ \text { Positive } & 15 & 64 & 27 & \end{array}$

$\mathrm{BCl}-2$ in non-GCB

$\begin{array}{lllll}\text { Negative } & 7 & 14 & 21 & 0.268 \\ \text { Positive } & 20 & 25 & 11 & \end{array}$

IPI

$\begin{array}{lllll}\text { Low risk: } 0-2 & 31 & 38 & 13 & 0.794 \\ \text { High risk: } 3-5 & 21 & 24 & 16 & \end{array}$

CD4

$\begin{array}{ccccc}<200 & 24 & & 0 & 0.750 \\ \geq 200 & 3 & & 14 & \\ \text { Ki-67 } & & & & \\ <4 & 21 & 39 & 21 & 0.079 \\ \geq 4 & 31 & 26 & 9 & \end{array}$

Diagnosis

$\begin{array}{lrrrr}\text { PBL } & 9 & 0 & 6 & 0.002 \\ \text { DLBCL } & 52 & 33 & 18 & \end{array}$


Graph 1 Kaplan Meier curves for overall survival: DLBCL occurring in HIV negative and HIV positive patients

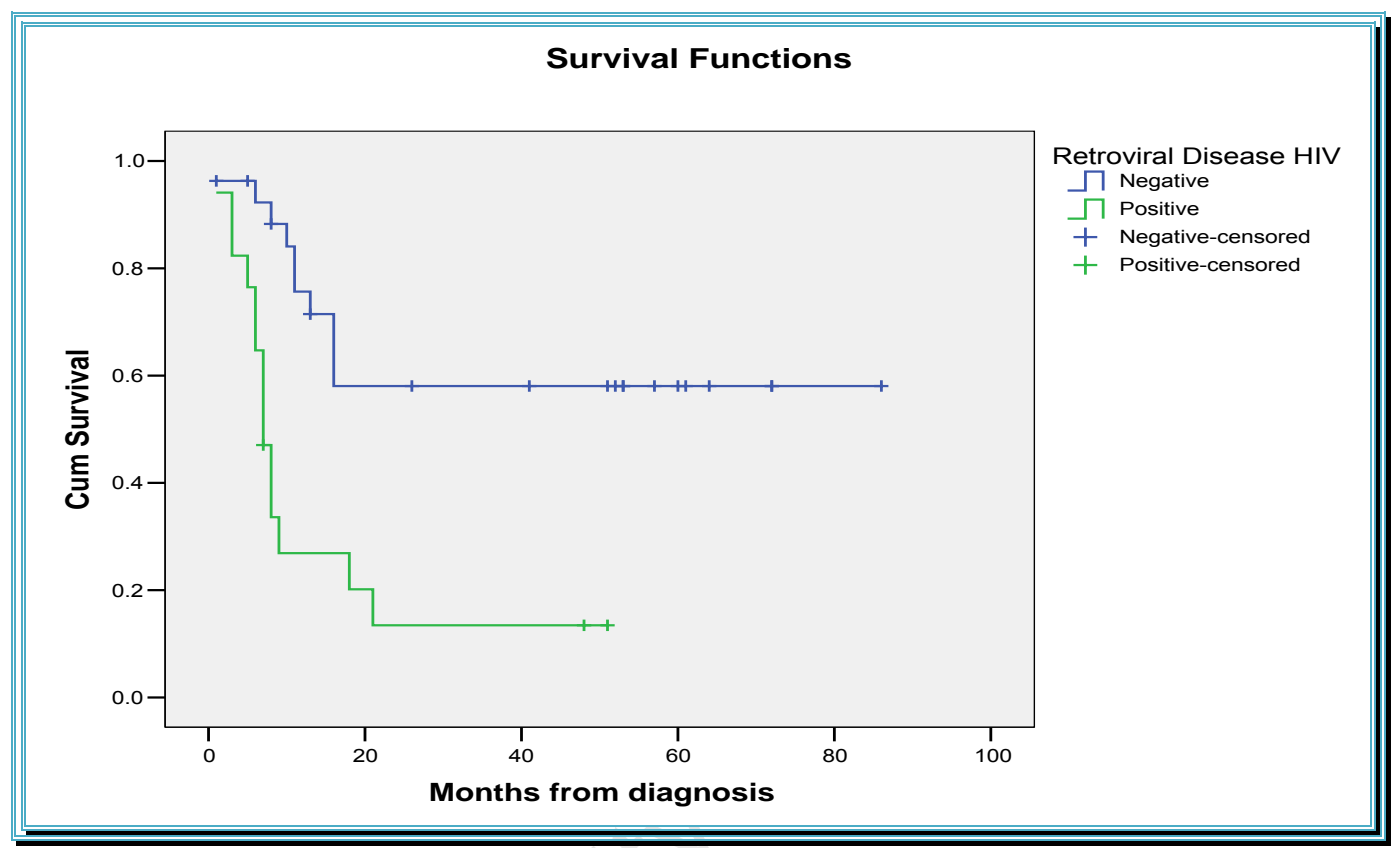

Despite antiretroviral therapy, the overall survival of HIV-positive patients with DLBCL was significantly poorer than that of HIV-negative patients. Log-rank test confirmed statistically significant $p$ value of $<0.001$. 
Graph 2 Kaplan Meier curves for overall survival in patients with plasmablastic lymphoma and DLBCL

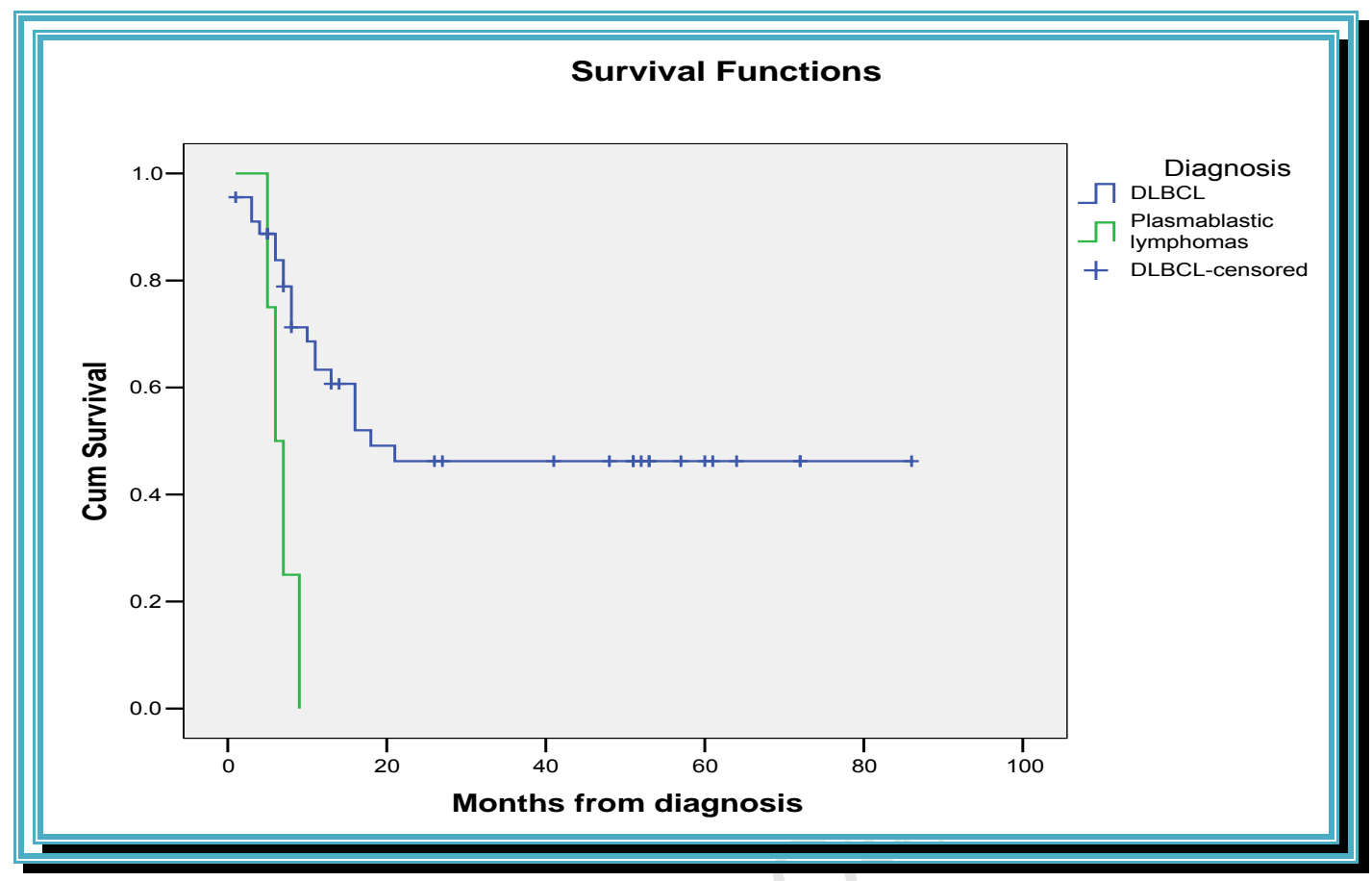

The study revealed that the overall survival of patients with plasmablastic lymphoma was poorer than that of DLBCL. Log-rank test confirmed a statistically significant $p$ value of 0.002 . 
Graph 3 Kaplan Meier curves for overall survival in GCB and non-GCB DLBCL using the Hans' algorithm

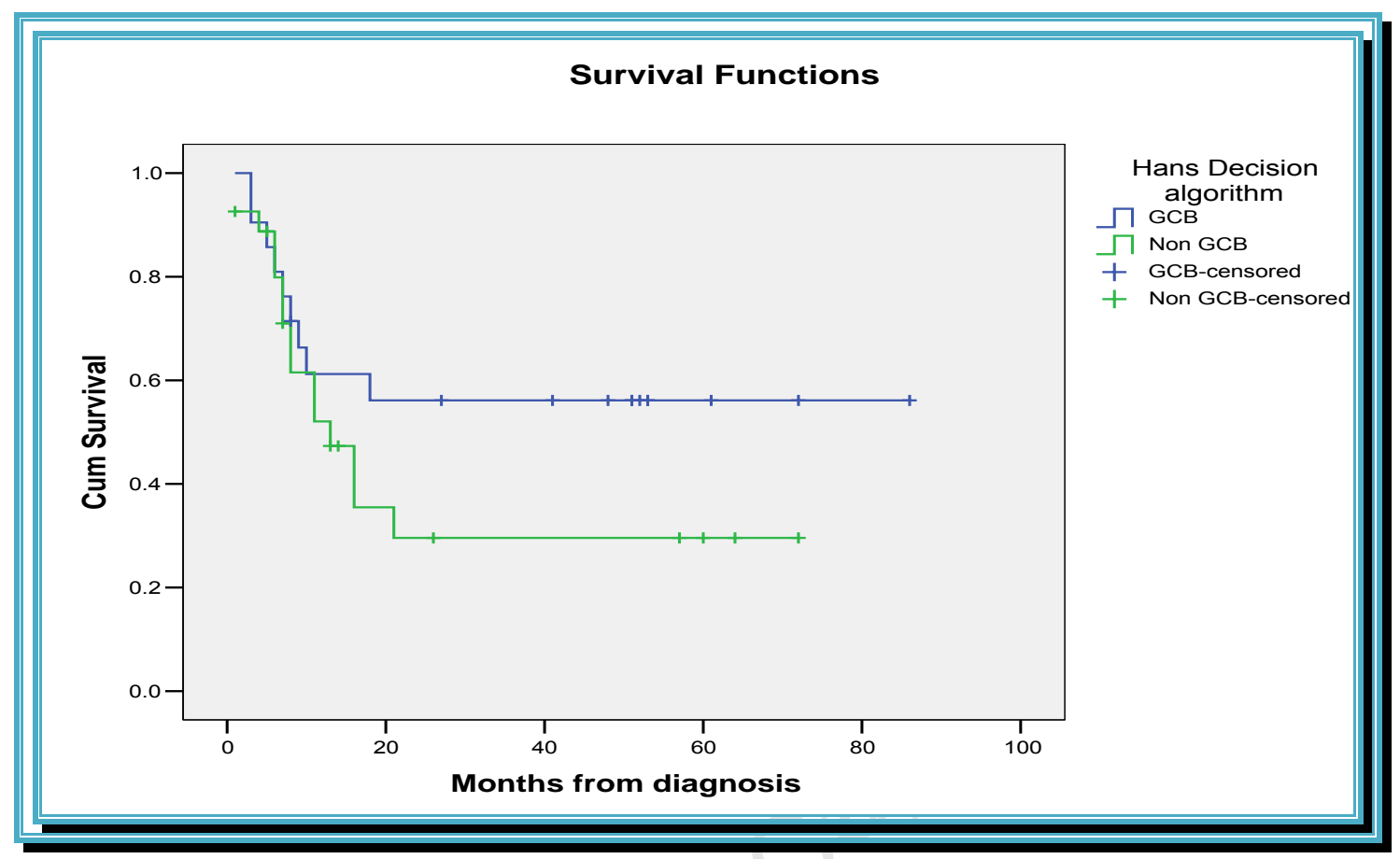

When Hans' algorithm was used to stratify cases of DLBCL, the overall survival of patients with GC-subtype DLBCL was better than that of non-GC subtypes.

However, the difference in survival was not statistically significant as the log-rank $p$ value was 0.188 .

Similarly, when Muris' algorithm was used to stratify cases of DLBCL, the overall survival of patients with group 1-type DLBCL was better than that of group 2-type DLBCL. However, once again there was no statistical significance as the log rank $p$ value was 0.399 . 
Graph 4 Kaplan Meier curves for overall survival in Group 1 and Group 2 DLBCL using Muris' algorithm

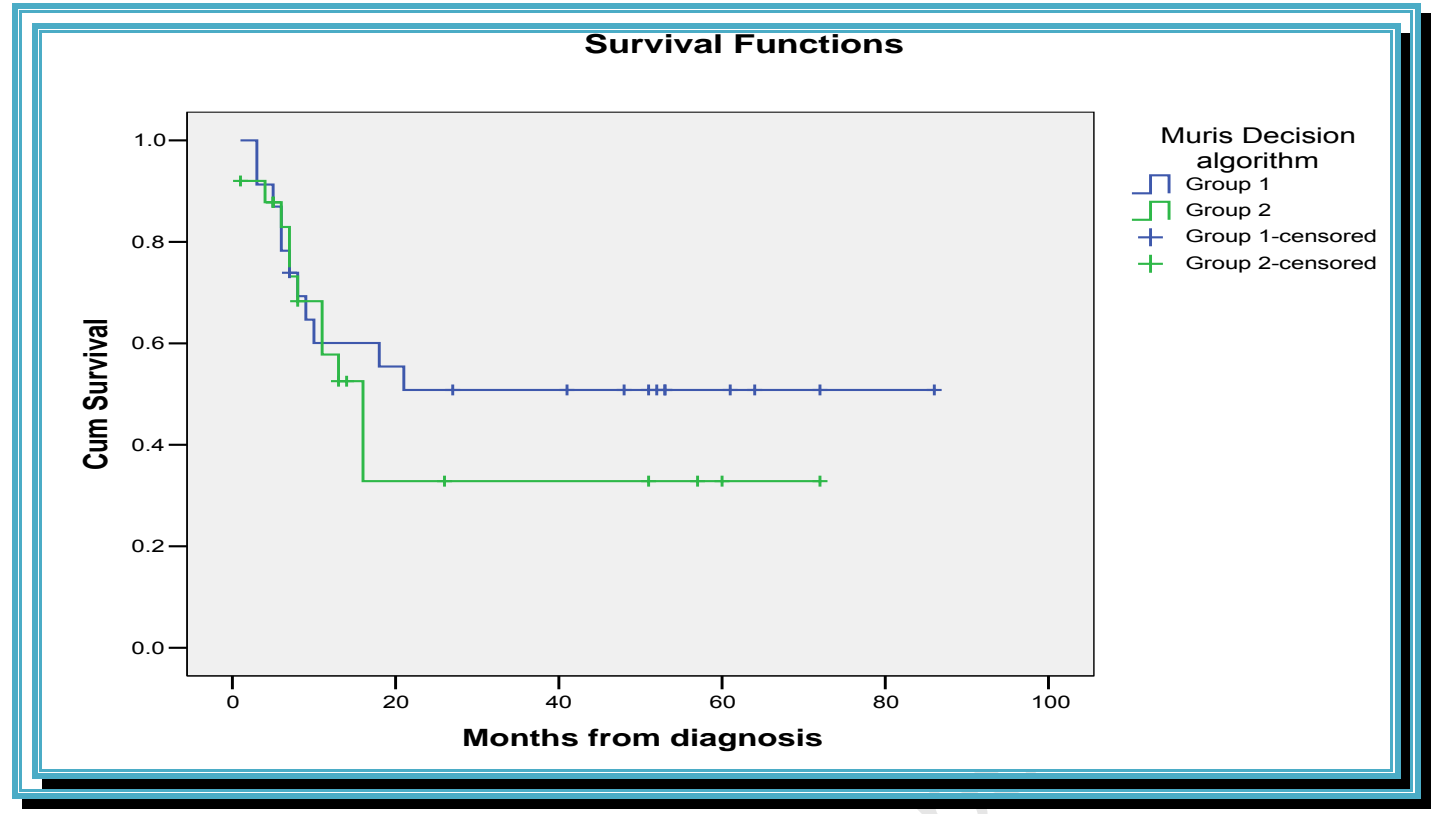

Graph 5 Kaplan Meier curves for overall survival using CD10 expression in DLBCL

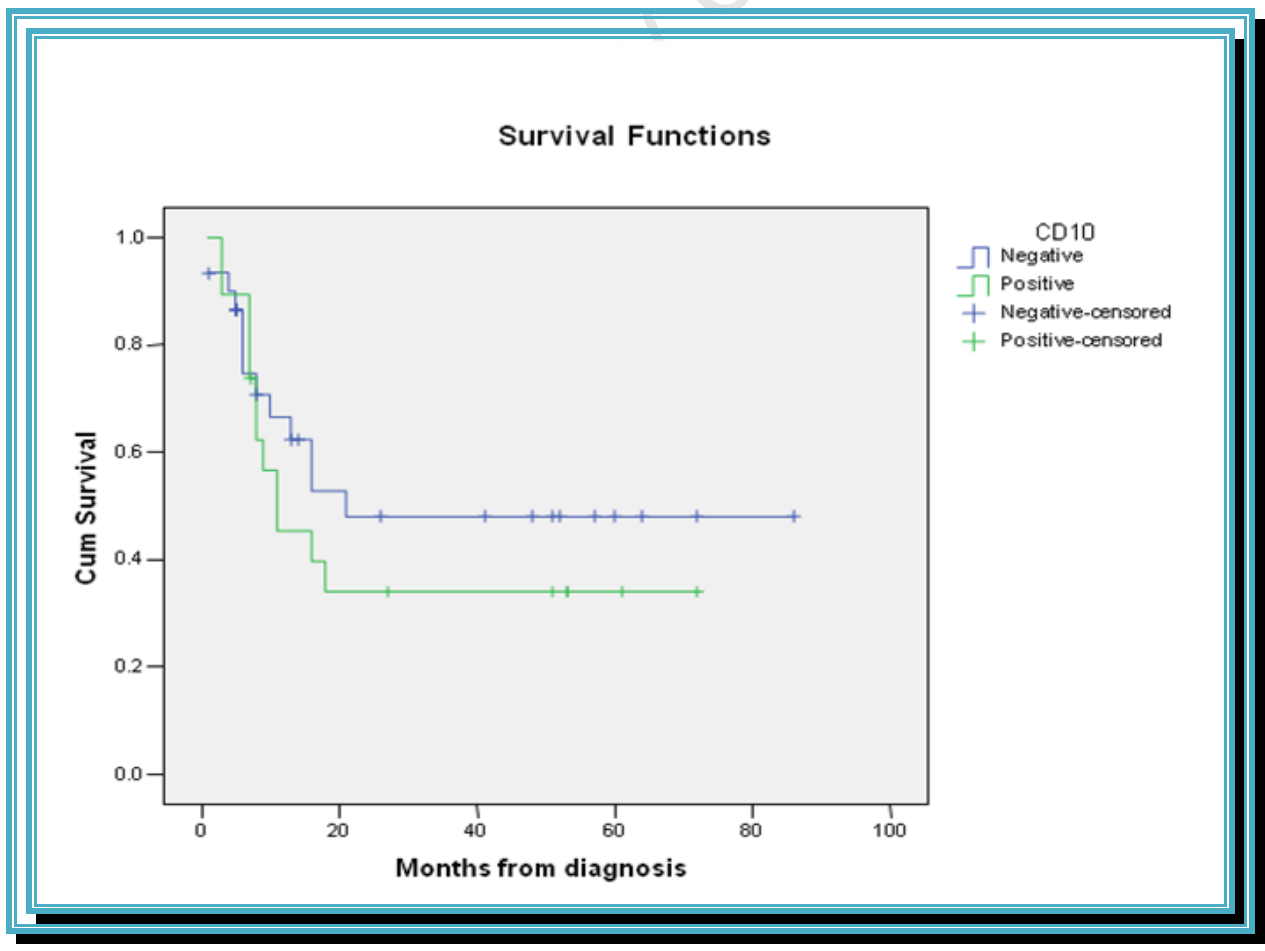


Independent assessment of CD10 expression in DLBCL revealed no statistical significance as the log-rank $p$ value was 0.442 .

Graph 6 Kaplan Meier curves for overall survival in DLBCL using Bcl-6

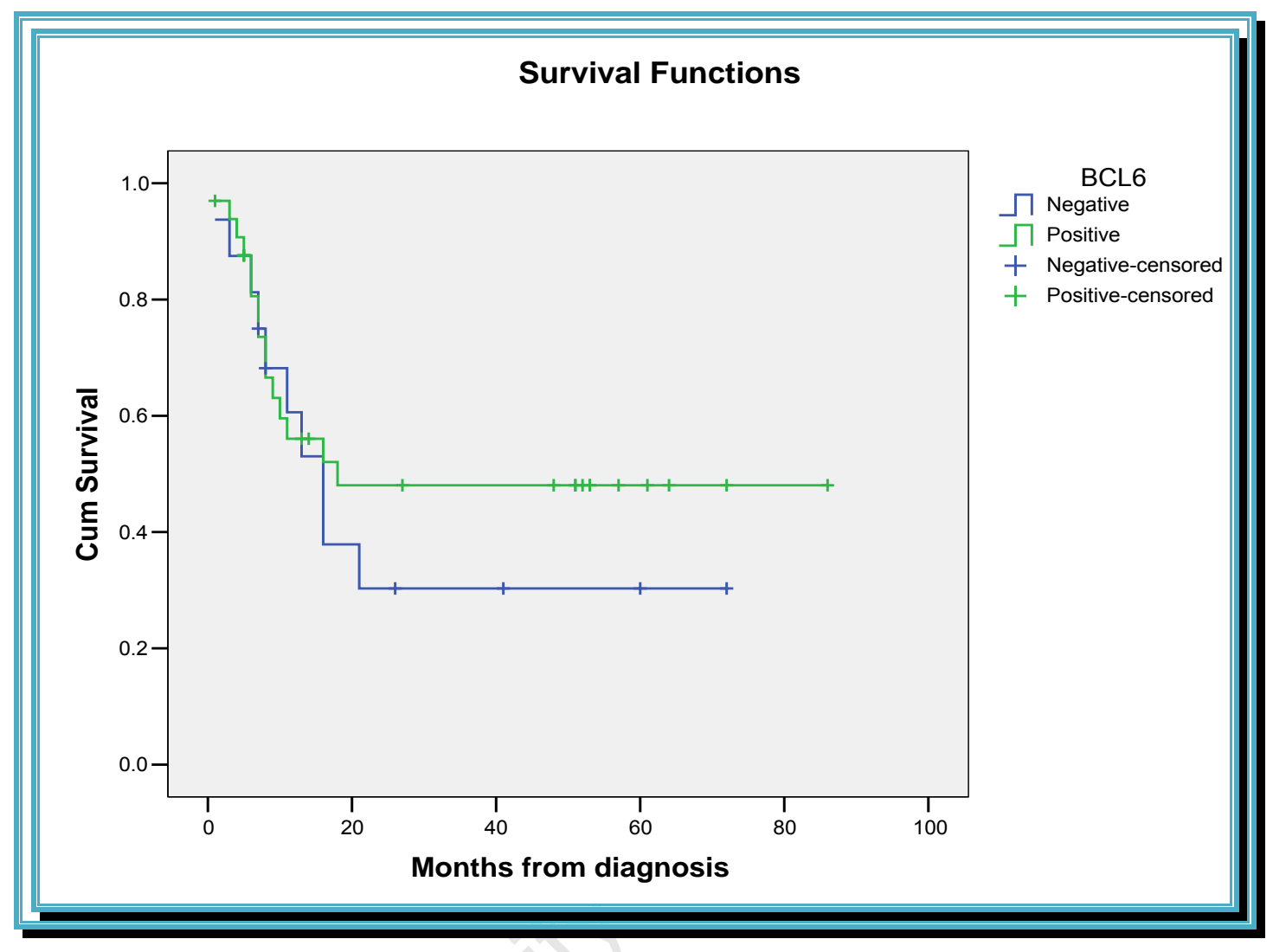

Bcl-6 expression in DLBCL was found to be associated with improved overall survival. However, this was also not found to be statistically significant as the $p$ value was 0.487 . 
Graph 7 Kaplan Meier curves for overall survival in DLBCL using MUM 1 expression

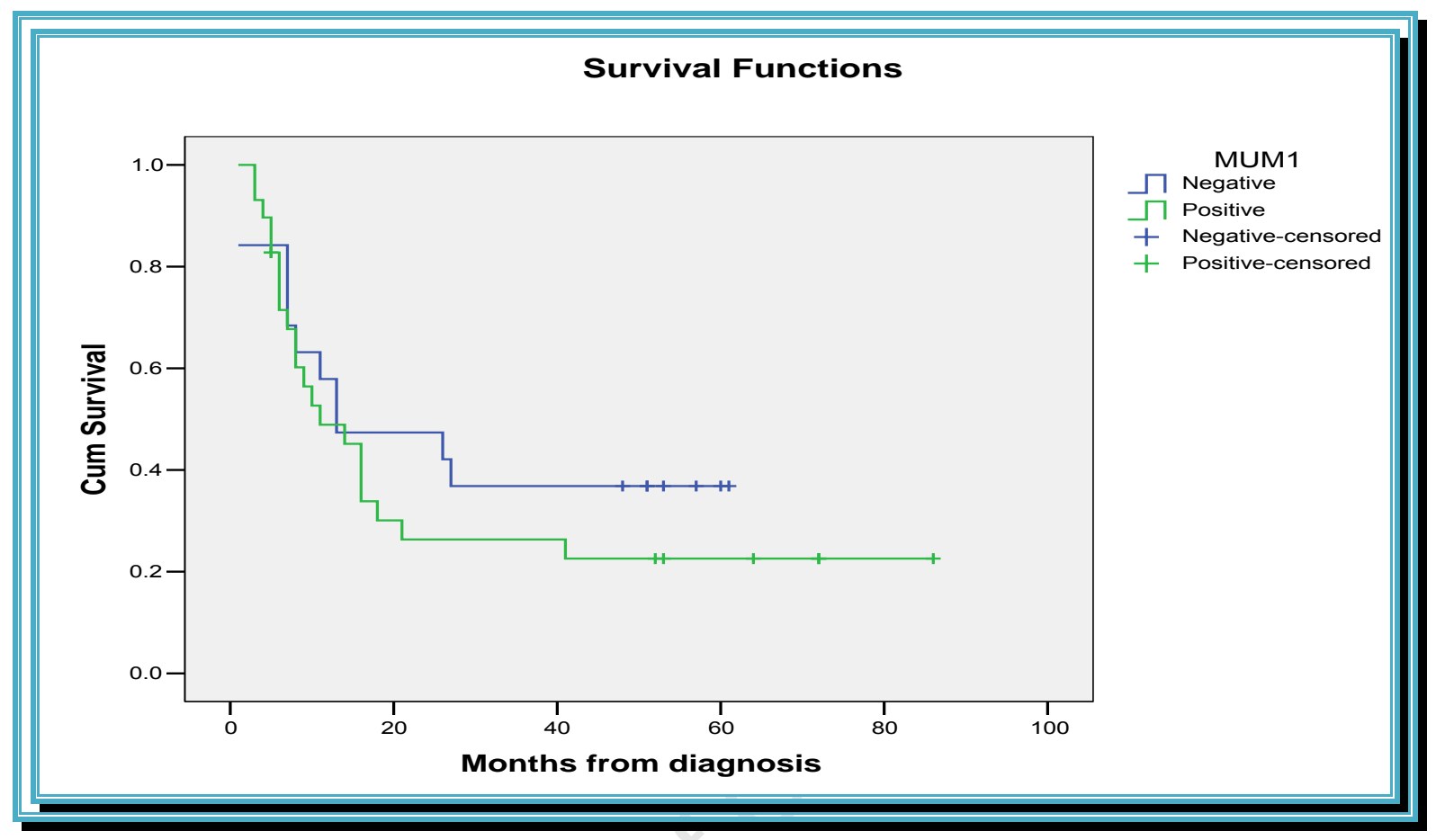

MUM1 expression in DLBCL was associated with lower overall survival. However, there was no statistical significance ( $p$ value 0.124 ). 
Graph 8 Kaplan Meier curves for overall survival in DLBCL when Bcl-2 expression occurred in the Hans-defined GCB group

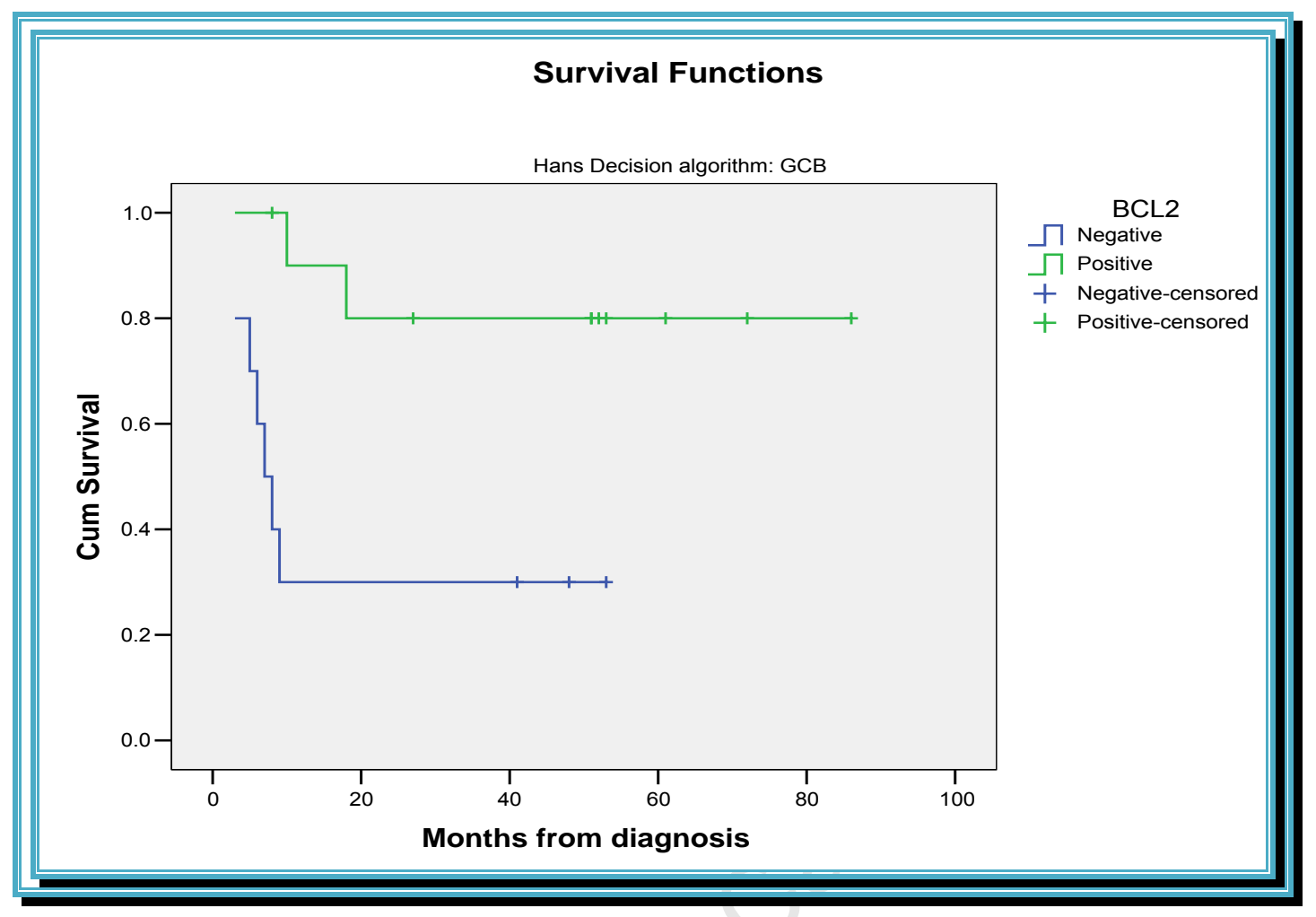

No statistical significance was found when $\mathrm{Bcl}-2$ expression was assessed independently of the IPI score, CD10, Bcl-6 and MUM1 expression ( $p$ value 0.371 )

However, an interesting finding was established when $\mathrm{Bcl}-2$ expression occurred in germinal center-type DLBCL, using the Hans algorithmic stratification, in that improved survival was conferred by the germinal center phenotype. The accompanying statistically significant $p$ value was 0.007 . 
The overall survival of patients with low risk IPI scores (0-2) was better than those with high risk IPI scores. However, this difference was not statistically significant as the $p$ value was 0.794 .

Graph 9 Kaplan Meier curves for overall survival with low risk and high risk IPI scores

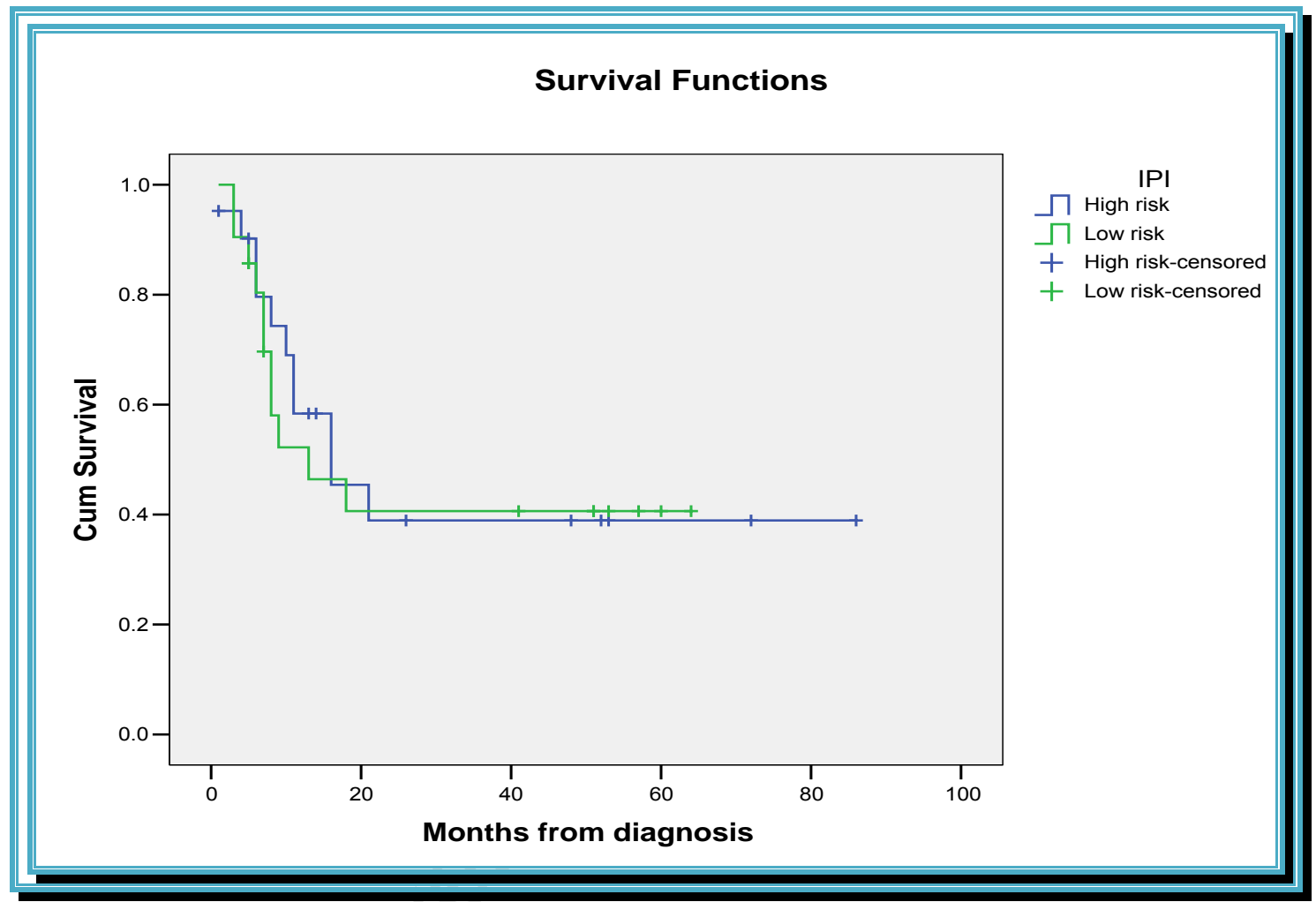


When the proliferation index in DLBCL was such that $\geq 76 \%$ of tumour cells (score $\geq 4$ ) displayed nuclear staining using Ki67 immunohistochemistry, the overall survival was poorer than that which occurred when the proliferative index was $<4$. The logrank $p$ value was 0.079 .

Graph 10 Kaplan Meier curves for overall survival in DLBCL using Ki67 $<4$ and $\geq 4$

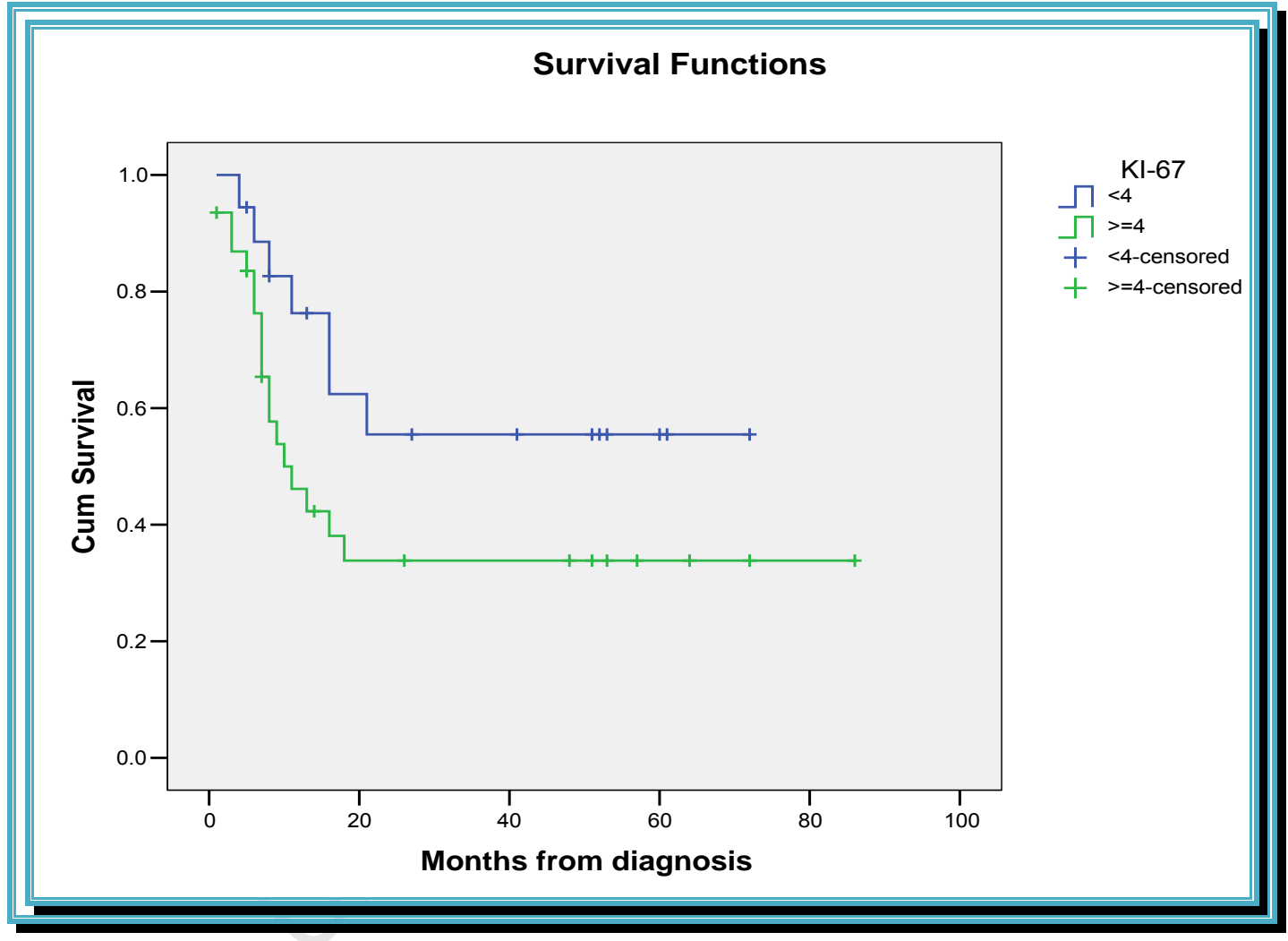

Statistic observation revealed that CD138 expression in $>25 \%$ of tumour cells (score $\geq 2$ ), occurred only in the HIV positive group and was associated with shorter survival time. However no statistic significance was evident ( $p$ 0.402).

Poorer survival outcome was demonstrated in the HIV group when the CD4 count was less than 200 cells $/ \mathrm{mm}^{3}$ in contrast to that which occurred when the CD4 count was greater than $200 \mathrm{celll} / \mathrm{mm}^{3}$. However, the survival difference was not statistically significant as the $p$ value was 0.750 . 
EBV LMP1 expression was found in 3/9 cases of PBL and 5/52 cases of DLBCL. In the latter group, 4/5 EBV LMP1-positive DLBCL occurred in patients with HIV infection.

Table 13 Number of PBL and DLBCL expressing EBV LMP1

\begin{tabular}{|l|l|l|l|r|}
\hline & & EBV & & Count \\
\hline \multirow{4}{*}{ Diagnosis } & DLBCL & \multirow{2}{*}{ LMP1 } & Negative & 47 \\
\cline { 2 - 5 } & & & Positive & 5 \\
\cline { 2 - 5 } & Plasmablastic lymphomas & LMP1 & Negative & 6 \\
& & & Positive & 3 \\
\hline
\end{tabular}

CD38 expression occurred in all cases of DLBCL in the HIV negative group and 16 cases of DLBCL in the HIV positive group; there was no associated statistical significance.

\section{TREATMENT}

All patients with DLBCL were treated with CHOP therapy (cyclophosphamide, vincristine, doxorubicin/adriamycin and prednisone). Intrathecal chemotherapy was used prophylactically in patients with nasopharyngeal or extradural involvement and in patients with central nervous system (CNS) disease. Prophylactic treatment is generally used in patients with non-Hodgkin's lymphoma due to the likelihood of more aggressive disease and high rates of CNS relapse. The use of intrathecal chemotherapy is advocated in all HIV positive patients with NHL. At our institute, 
five cycles of intrathecal chemotherapy is given as prophylaxis in combination with intravenous chemotherapy. If patients are found to have malignant cells in cerebrospinal fluid, therapy is administered until the CSF is clear of tumour cells. Two additional doses are given thereafter.

The patients in our study also received varying therapeutic combinations which included dose-reduced chemotherapy, palliative radiotherapy, involved field radiotherapy and intrathecal chemotherapy.

Patients with PBL were treated with CHOP therapy and involved field/ radiotherapy. Frequent loss of follow up of patients was a limiting factor.

All patients in the HIV positive group received highly active antiretroviral therapy (HAART). Some patients received HAART prior to the diagnosis of lymphoma while others commenced HAART at the time of lymphoma diagnosis.

\subsection{Co-morbidities occurring during the course of the study}

Opportunistic infections frequently complicate the outcome and survival of patients with lymphomas, particularly in the setting of background HIV infection. During the period of our study (2004 - 2007), 11 patients in the HIV positive group were diagnosed with tuberculosis and 1 patient was diagnosed with Kaposi's sarcoma. However, deaths which occurred in the HIV positive group were clinically and radiologically attributed to lymphoma rather than overwhelming opportunistic infection.

\section{DISCUSSION}

Diffuse large B cell lymphoma is an aggressive malignancy which represents 20$30 \%$ of $\mathrm{NHL}$ in Western countries. ${ }^{50}$ The occurrence of DLBCL in African countries is amplified by confounding co-morbidity of immunosuppression due to HIV infection, a well established risk factor for the development of DLBCL.

Cote et al. ${ }^{50}$ demonstrated a phenomenal 165 -fold increase in the relative risk of developing lymphoma within three years of an AIDS diagnosis compared with 
patients unaffected by AIDS. AIDS-associated lymphomas which encompass DLBCL, PBL, BL and PEL, represent one of the commonest AIDS defining illnesses. These occur with increased frequency in patients infected with HIV and are exacerbated by low CD4 counts. The literature abounds with reported studies of various prognostic factors proven to successfully predict outcome in DLBCL. While synchronously providing a South African perspective, this study builds on and contributes to an elaboration of prognostic factors in DLBCL and PBL. These prognostic factors are inclusive of the long-standing, internationally accepted IPI which combines several clinical parameters to stratify patients into (low, intermediate and high risk) prognostic groups. In congruence with the literature, the present study confirmed that low risk IPI indices (scores 0-2) were associated with improved overall survival relative to high risk IPI indices (scores 3-5). ${ }^{55,56,58}$ However, this finding was not statistically significant as the $p$ value was 0.794 .

Assessment of the mean age at presentation revealed that HIV positive patients were significantly younger (greater than a decade) compared to the age at presentation of DLBCL in HIV negative patients (HIV positive - mean age 43 years; HIV negative - mean age 54 years).

In the HIV positive group, the mean CD4 count at diagnosis was $121 \mathrm{cells} / \mathrm{mm}^{3}$. Patients with PBL had a significantly lower mean CD4 count of $61 \mathrm{cells} / \mathrm{mm}^{3}$ in contrast to the mean CD4 count of 151 cells $/ \mathrm{mm}^{3}$ which occurred in patients with DLBCL. Poorer survival outcome was demonstrated in the HIV group when the CD4 count was less than 200 cells $/ \mathrm{mm}^{3}$ in contrast to that which occurred when the CD4 count was greater than $200 \mathrm{cells} / \mathrm{mm}^{3}$. However, the survival difference was not statistically significant as the $p$ value was 0.750 .

In the HIV positive group, DLBCL was diagnosed three times more frequently on biopsies of extranodal topographic sites than lymph node biopsies. In contrast, in the HIV negative group, DLBCL was diagnosed in relatively equal proportion on biopsies of nodal and extranodal sites.

In 2004, the South African National Antiretroviral Treatment Guidelines stipulated specific criteria for the initiation of antiviral therapy in patients infected with HIV. These criteria included CD4 $<200$ cells $/ \mathrm{mm}^{3}$ irrespective of the WHO-defined 
disease stage or WHO stage IV AIDS-defining illness (which included lymphoma) irrespective of the CD4 count. An accompanying essential criterion was that of patient willingness and readiness to take antiviral therapy adherently. ${ }^{99}$

In 2010, the South African National guidelines were amended to include initiation of ART when CD4 counts less than 350 cells $/ \mathrm{mm}^{3}$ occurred in patients with TB and HIV co-infection and in pregnant women. In addition, the criterion for the presence of drug-resistant tuberculosis (MDR/XDR), irrespective of the CD4 count, was included. 100 During the period of this study, the 2004 national ART guidelines were in place. As such, all HIV positive patients in the study received HAART, either prior to the diagnosis of lymphoma or at the time of lymphoma diagnosis. A statistically significant finding in this study was that the overall survival of patients with DLBCL and HIV infection was significantly poorer than that of patients with DLBCL in the absence of HIV infection ( $p$ value $<0.001$ ). This finding contrasts that of several studies in which higher remission and improved survival rates have been established in NHL occurring in HIV positive patients receiving HAART. ${ }^{94,}$ 96, 148, 149

Factors contributing to the disparate survival outcome in our HIV positive group includes severe immunosuppression (mean CD4 121cells $/ \mathrm{mm}^{3}$ ), delayed initiation of antiviral therapy until an advanced stage of HIV infection in combination with limiting issues such as ARV non-compliance and the dreaded possibility of ARV treatment failure. During the course of the study, opportunistic diseases such as tuberculosis occurred in 11 HIV positive patients and Kaposi's sarcoma was documented in 1 additional patient. However, deaths occurring in the HIV positive group were clinically and radiologically attributed to lymphoma rather than tuberculosis.

The researcher hopes that recent amendments to the national ARV policy will contribute to an improvement in the overall survival of HIV positive patients with $\mathrm{NHL}$, such that future studies we will be able to demonstrate improved survival rates in parallel with those reported at present in Western countries. For this to occur, additional amendments to the national ARV policy in terms of implementing a significantly lower threshold for initiating ARV treatment may be required to optimise antiviral treatment at less advanced stages of HIV infection. 
Bcl-2 is known to be an inhibitor of apoptosis. It is likely that the presence of high levels of $\mathrm{Bcl}-2$ protein promotes survival of tumour cells by reducing apoptosis and conferring resistance to therapeutic agents. ${ }^{150,151,152}$ Several studies (Hans et al. ${ }^{58}$, Muris et al. ${ }^{66}$, Obermann et al. ${ }^{81}$, Hermine et al. ${ }^{82}$, Gascoyne et al. ${ }^{83}$ and Barrans et al. ${ }^{84}$ ) have showed that $\mathrm{Bcl}-2$ expression is associated with poor prognosis. In the present study, Bcl-2 expression occurring in non-germinal centre DLBCL was not associated with prognostic significance and no statistic significance was found when Bcl-2 expression was assessed by univariate analysis, independent of the IPI score, CD10, Bcl-6 and MUM1 expression.

Interestingly, when the occurrence of $\mathrm{Bcl}-2$ expression in germinal center-type DLBCL was assessed using the Hans algorithmic stratification, improved overall survival was conferred by the germinal center phenotype. The accompanying statistically significant $p$ value was 0.007 . This study hereby provides additional support of the previously established finding by Barrans et al. ${ }^{84}$ in that the GC phenotype was associated with an improved survival in both $\mathrm{Bcl}-2$ positive and negative groups. ${ }^{78}$

In addition, Muris et al ${ }^{66}$ found that $\mathrm{Bcl}-2$ - positive cases which concomitantly expressed CD10 were found to have significantly better outcome than CD10negative cases. This finding suggested that Bcl-2 expression alone may be insufficient to fully inhibit chemotherapy-induced apoptosis.

There is corroborative evidence supportive of the understanding that CD10expressing lymphoid cells, both neoplastic and non-neoplastic, are inclined to become increasingly prone to apoptosis. Often there is associated c-myc upregulation within these cells with resultant cellular induction into the cell cycle. This process creates the potential for improved response to apoptosis-inducing therapy in CD10-expressing DLBCL and may well account for a significant survival advantage. ${ }^{67-71}$

Several researchers have reiterated the positive prognostic influence associated with Bcl-6 immunoexpression in DLBCL (Lossos et al. ${ }^{64}$, Winter et al. ${ }^{65}$, Amen at al. ${ }^{63}$ ). In further support thereof, this study demonstrated that Bcl-6 expression in DLBCL 
was associated with longer overall survival. However, the survival advantage was not found to be statistically significant ( $p$ value 0.487 ).

Hoffman et al. ${ }^{49}$ established that CD138 expression was associated with poor overall survival in AIDS-related B-cell lymphomas. ${ }^{52}$ In contrast, Tumwine et al. ${ }^{62}$ found that activated germinal center DLBCL, defined as those expressing CD10, Bcl6, MUM1 and CD138, was associated with superior survival outcome. In the present study, statistic observation revealed that CD138 expression in $>25 \%$ of tumour cells (score $\geq 2$ ), occurred only in the HIV positive group and was associated with shorter survival time. However, no statistical significance was evident ( $p$ 0.402). Further investigation of the significance of CD138 expression in larger studies is required as expression thereof is likely to be associated with poorer prognosis in light of plasma cell and/or post-follicular differentiation (i.e. activated B cell phenotype).

Plasmablastic lymphoma occurs predominantly in immunocompromised patients and is estimated to account for $2.6 \%$ of all AIDS- associated non-Hodgkin lymphomas. 113, 116 PBL may also occur in HIV-negative patients as confirmed in rare case reports ${ }^{119-121} \mathrm{PBL}$ is known to be a very aggressive NHL with poor outcome as the estimated survival is usually less than one year. ${ }^{15}$ The present study included 9 cases of de novo PBL occurring in HIV positive patients. Analysis of the age at presentation showed that HIV positive patients with PBL were significantly younger (greater than a decade) than those with DLBCL (HIV/PBL - mean age 36 years; HIV/DLBCL - mean age 48 years). A difference of 18 years was found between the mean age at presentation of HIV positive patients with PBL and HIV negative patients with DLBCL.

In this study the researcher established that patients with PBL had a significantly lower mean CD4 count (61cells $\left./ \mathrm{mm}^{3}\right)$ in contrast to the mean CD4 count of 151 cells $/ \mathrm{mm}^{3}$ in patients with DLBCL. The mean CD4 count in patients with PBL in our study is in-keeping with that quoted by Castillo et al. ${ }^{153}\left(<200 / \mathrm{mm}^{3}\right)$ and lower than the CD4 count of $300 / \mathrm{mm}^{3}$ reported in a case study by Flaitz et al. 153154

Two cases of PBL occurred in the oral cavity and seven were diagnosed at extra-oral and extranodal topographic sites. While classic blast-like morphology was evident in the tumours occurring in the oral cavity, morphologic features of plasmacytic 
differentiation, which at times appeared subtle, were evident in some PBL cases occurring in extra-oral sites. All cases of PBL in our study lacked CD20 expression and 8/9 cases displayed MUM1 immuno-expression in $76-100 \%$ of tumour cells. The single case of PBL which lacked MUM1 expression occurred in an extra-oral location and displayed VS38C, CD138 and CD38 immunoexpression in $76-100 \%$ of tumour cells. Interestingly, of all our PBL cases, the MUM1-negative case showed the highest level of EBV-LMP1 expression which involved $51-75 \%$ of tumour cells. Overall, EBV LMP1 immunoexpression was detected in 3/9 PBL cases.

In keeping with the literature, the proliferation index in all our cases of PBL was high, ranging from 76 to $>95 \%$. A statistically significant difference in survival was established in that the overall survival of patients with PBL was poorer than that of DLBCL ( $p$ value 0.002). The mean survival of patients with PBL was found to be 16 months from initial diagnosis. This mean value may over-score the true mean value for survival in this group as 4 of the patients in this group were lost to follow-up. The scenario of "lost to follow-up" was a significant limiting factor in this group of patients. In the South African milieu, loss of follow up may be attributed to low socio-economic status resulting in frequent logistic and financial difficulties in accessing medical treatment, poor nutritional status, undiagnosed opportunistic diseases and the unfortunate reality of death occurring in non-hospitalised patients.

\section{CONCLUSION}

This study confirms that diffuse large B cell lymphoma and plasmablastic lymphoma are high-grade tumours with significant potential for aggressive behaviour and poor outcome in the setting of profound immunosuppression due to HIV infection. The HIV positive patients were found to be of strikingly younger age at presentation with greater likelihood of extranodal disease at diagnosis. A statistically significant finding in this study was that the overall survival of patients with DLBCL and HIV infection was significantly poorer than that of patients with DLBCL in the absence of HIV infection ( $p$ value $<0.001$ ). When Bcl-2 expression in germinal center-type DLBCL was assessed using the Hans algorithmic stratification, improved overall survival was conferred by the germinal center phenotype. The accompanying statistically 
significant $p$ value was 0.007 . In addition, statistical observation revealed that CD138 expression in DLBCL involving $>25 \%$ of tumour cells (score $\geq 2$ ), occurred only in the HIV positive group and was associated with shorter survival time. However, no statistical significance was evident ( $p$ 0.402). Further investigation of the prognostic significance of CD138 expression in DLBCL in larger studies is required as expression thereof is likely to be associated with poorer prognosis in light of plasma cell and/or post-follicular differentiation (i.e. activated B cell phenotype.

This study established a statistically significant difference in survival regarding DLBCL and PBL in that the overall survival of patients with PBL was poorer than that of DLBCL. Furthermore, this study showed that at the time of initial presentation of lymphoma, patients with PBL had a significantly lower mean CD4 count $\left(61 \mathrm{cells} / \mathrm{mm}^{3}\right)$ in contrast to the mean CD4 count of 151 cells $/ \mathrm{mm}^{3}$ in patients with DLBCL.

The recent amendment of the South African National Antiretroviral Treatment Guidelines has created the potential for improved survival in patients with AIDSrelated malignancies. Further studies are required to assess the effect of these amendments in combination with the role of targeted-immunotherapy on survival in patients with AIDS-related lymphomas. In DLBCL specifically, the combined analysis of gene expression profiles by cDNA microarray and protein expression by immunohistochemistry will contribute to more accurate subclassification, hereby offering tremendous potential for prognostic stratification. However, in many histopathology laboratories, routine cDNA microarray analysis of DLBCL may not be feasible due to constraints associated with cost, time and availability of interpretative skills. This study has demonstrated that in the South African setting, the combination of clinical and biochemical prognostic parameters coupled with thorough morphologic assessment and immunohistochemical analysis of DLBCL and PBL has proven to yield prognostically useful information. In future, this may facilitate the consideration of management stratification of HIV positive patients with DLBCL or PBL. 


\section{REFERENCES}

${ }^{1}$ Dawson PJ. The original illustrations of Hodgkin's disease. Ann Diagn Pathol. 1999; 3(6):386-393.

2 Jaffe ES, Harris NL, Stein H, Isaacson PG. Classification of lymphoid neoplasms: the microscope as a tool for disease discovery. Blood 2008; 112(12):4384-4399.

${ }^{3}$ Trumper LH, Brittinger G, Diehl V, Harris NL. Non-Hodgkin's lymphoma: a history of classification and clinical observations. In: Mauch PM, Armitage JO, Coiffier B, DallaFavera R, Harris NL, (Eds). Non-Hodgkin's Lymphomas. Philadelphia, PA:

Lippincott, Williams and Wilkins; 2004: 3-19.

${ }^{4}$ Gatter K, Pezzella F. Diffuse large B cell lymphoma. Diagn Histopathol 2010; 16 (2):69-81.

${ }^{5}$ Jaffe ES, Harris NL, Diebold J, Muller-Hermelink HK. World Health Organization Classification of neoplastic diseases of the hematopoietic and lymphoid tissues. A progress report. Am J Clin Pathol. 1999;111(Suppl 1):S8-12.

${ }^{6}$ Papermaster BW, Good RA. Relative contributions of the thymus and the bursa of Fabricius to the maturation of the lymphoreticur system and immunological potential in the chicken. Nature 1962; 196: 838-840.

7 Cooper MD, Peterson RD, Good RA. Delineation of the thymic and bursal lymphoid systems in the chicken. Nature 1965; 205: 143-146.

8 Shevach EM, Jaffe ES, Green I. Receptors for complement and immunoglobulin on human and animal lymphoid cells. Transplant Rev. 1973;16:3-28.

9 Jaffe ES, Braylan RC, Nanba K, Frank MM, Berard CW. Functional markers: a new perspective on malignant lymphomas. Cancer Treat Rep. 1977; 61: 953-962.

${ }^{10}$ Good DJ, Gascoyne RD. Classification of Non-Hodgkin's Lymphoma. Hematol Oncol Clin N. 2008; 22(5): 781-805.

${ }^{11}$ Anonymous. A Clinical Evaluation of the International Lymphoma Study Group classification of Non-Hodgkin's Lymphoma. Blood. 1997; 89(11): 3909-3918.

${ }^{12}$ Harris NL, Jaffe ES, Diebold J, Flandrin G, Muller-Hermelink HK, Vardiman J. Lymphoma classification - from controversy to consensus: The R.E.A.L. and WHO Classification of lymphoid neoplasms. Ann Oncol. 2000; 11(Suppl. I): S3-10.

${ }^{13}$ Armitage JO, Weisenburger DD. New approach to classifying non-Hodgkin's lymphomas: Clinical features of the major histologic subtypes. J Clin Oncol. 1998; 16(8): 2780-95.

14 Weisenburger D. The International Lymphoma Study Group Classification of nonHodgkin's lymphoma (NHL): Pathology findings from a large multi-center study. Mod Pathol. 1997;10: 136A. 
${ }^{15}$ Stein H, Harris NL, Campo E. Plasmablastic lymphoma. In Swerdlow SH, Campo E, Harris NL, Jaffe ES, Pileri SA, Thiele J, Vardiman JW (Eds): World Health Organisation classification of tumours of haematopoietic and lymphoid tissues. $4^{\text {th }}$ ed. IARC Press Lyon 2008, 256-257.

${ }^{16}$ Lossos IS, Okada CY, Tibshirani, Warnke R, Vose JM, Greiner TC, Levy R. Molecular analysis of immunoglobulin genes in diffuse large B-cell lymphomas. Blood 2000; 95(5): 1797-1803.

${ }_{17}$ Jaffe ES, Harris NL, Stein H, Campo E, Pileri SA, Swerdlow SH. Introduction and overview of the classification of the lymphoid neoplasms. In: Swerdlow SH, Campo E, Harris NL, Jaffe ES, Pileri SA, Stein H, Thiele J, Vardiman JW, eds. World Health Organisation classification of tumours of haematopoietic and lymphoid tissues. $4^{\text {th }}$ ed. IARC: Lyon 2008; 158-166.

${ }^{18}$ Klein UIF, Goossens T, Fischer M, Kanzler M, Braeuninger H, Rajewsky A, Kuppers K. Somatic hypermutation in normal and transformed human B cells. Immunol Rev.1998; 162(1): 261-280.

${ }^{19}$ Carbone A, Gloghini A, Capello D, Gaidano G. Genetic pathways and histogenetic models of AIDS-related lymphomas. Eur J Cancer. 2001; 37(10): 1270-1275.

${ }^{20}$ Saito M, Gao J, Basso K, Kitagawa Y, Smith PM, Bhagat G, Pernis A, Pasqualucci $L$, Dalla-Favera R. A signaling pathway mediating downregulation of $B C L 6$ in germinal center B cells is blocked by BCL6 gene alterations in B cell lymphoma. Cancer Cell 2007;12(3): 280-292.

${ }^{21} \mathrm{Ye} \mathrm{BH}$. BCL-6 in the pathogenesis of non-Hodgkin's lymphoma. Cancer Invest. 2000;18(4): 356-365.

${ }^{22}$ Offit K, Coco FL, Louie DC, Parsa NZ, Leung D, Portlock C, Ye BH, Lista F, Filippa DA, Rosenbaum A, Ladanyi M, Jhanwar S, Dalla-Favera R, Chaganti RSK. Rearrangement of the blc- 6 gene as a prognostic marker in diffuse large $B$ cell lymphoma. N Engl J Med. 1994; 331(2): 74-80.

${ }^{23}$ Nakaura Y. Internal deletions within the BCL6 gene in B-cell non-Hodgkin's lymphoma. Leuk Lymphoma 2000; 38(5-6): 505-512.

${ }^{24}$ Pezzella F, Tse AG, Cordell JL, Pulford KA, Gatter KC, Mason DY. Expression of the $\mathrm{Bcl}-2$ oncogene protein is not specific for the 14;18 chromosomal translocation. Am J Pathol 1990; 137(2): 225-232.

${ }^{25}$ Kusenda J. Bcl2 family proteins and leukaemia. Minireview. Neoplasma 1998; 45(3): 117-122.

${ }^{26}$ Yang E, Korsmeyer SJ. Molecular thanantopsis: A discourse on the BCL-2 family and cell death. Blood 1996; 88(2): 386-401. 
${ }^{27}$ Mittrucker HW, Matsuyama T, Grossman A, Kündig TM, Potter J, Shahinian A, Wakeham A, Patterson B, Ohashi PS, Mak TW. Requirement for the transcription factor LSIRF/IRF4 for mature B and T lymphocyte function. Science 1997; 275(5299): 540-543.

28 Falini B, Fizzotti M, Pucciarini A, Bigerna B, Marafioti T, Gambacorta M, Pacini R, Alunni C, Natali-Tanci L, Ugolini B, Sebastiani C, Cattoretti G, Pileri S, Dalla-Favera $\mathrm{R}$, Stein $\mathrm{H}$. A monoclonal antibody (MUM1p) detects expression of the MUM1/IRF4 protein in a subset of germinal center $B$ cells, plasma cells and activated T cells. Blood 2000; 95(6): 2084-2092.

${ }^{29}$ lida S, Rao PH, Butler M, Corradini P, Boccadoro M, Klein B, Chaganti RS, DallaFavera R. Deregulation of MUM1/IRF4 by chromosomal translocation in multiple myeloma. Nat Genet. 1997; 17: 226-230.

${ }^{30}$ Nutkunam Y, Warnke RA, Montgomery K, Falini B, van De Rijn M. Analysis of MUM1/IRF4 protein expression using tissue microarrays and immunohistochemistry. Mod Pathol 2001; 14(7): 686-694.

${ }^{31}$ Lund F, Solvason N, Grimaldi JC, Parkhouse RME, Howard M. Murine CD38: an immunoregulatory ectoenzyme. Immunol Today 1995; 16: 469-473.

${ }^{32}$ Vallario A, Chilosi M, Adami F, Montagna L, Deaglio S, Malavasi F, CaligarisCappio F. Human myeloma cells express the CD38 ligand CD31. Brit J Haematol 1999; 105: 441-4.

${ }^{33}$ Reiland J, Ott VL, Lebakken CS, Yeaman C, McCarthy J. Pervanadate activation of intracellular kinases leads to tyrosine phosphorylation and shedding of syndecan-1. Biochem J. 1996; 319: 39-47.

${ }^{34}$ Konigh A, Menzel T, Lynen S, Wrazel L, Rosén A, Al-Katib A, Raveche E, Gabrilove JL. Basic fibroblast growth factor (bFGF) upregulates the expression of bcl-2 in B cell chronic lymphocytic leukaemia cell lines resulting in delaying apoptosis. Leukemia 1997; 11: 258-265.

35 Jourdan M, Ferlin M, Legouffe E, Horvathova M, Liautard J, Rossi JF, Wijdenes J, Brochier J, Klein B. The myeloma cell antigen syndecan-1 is lost by apoptotic myeloma cells. Br J Haematol. 1998; 100: 637-46.

${ }^{36}$ Sebestyén A, Berczi L, Mihalik R, Paku S, Matolcsy A, Kopper L. Syndecan-1 (CD138) expression in human non-Hodgkin lymphomas. Br J Haematol 1999; 104: 412-419.

${ }^{37}$ Carbone A, Gaidano G, Gloghini A, Larocca LM, Capello D, Canzonieri V, Antinori A, Tirelli U, Falini B, Dalla-Favera R. Differential expression of BCL-6, CD138/Syndecan-1, and Epstein-Barr Virus-encoded latent membrane protein-1 identifies distinct histogenetic subsets of Acquired Immunodeficiency Syndromerelated non-Hodgkin's lymphomas. Blood 1998; 91: 747-755. 
${ }^{38}$ Wijdenes J, Clément C, Klein B, Dore JM. New B-cell CD antigens. BC29: CD138 (syndecan-1) workshop panel report. In: Kishimoto T, Kikutani H, von dem Borne AEG, Goyert SM, Mason DY, Miyasaka M. (eds). Leucocyte typing VI. White cell differentiation antigens. Proceedings of the 6th International Workshop and Conference; 1996 Nov 10-14; Kobe, Japan. London: Garland Publishing Inc; 1997: 249-52.

${ }^{39}$ McIntosh GG, Lodge AJ, Watson P, Hall AG, Wood K, Anderson JJ, Angus B, Horne $\mathrm{CH}$, Milton ID. NCL-CD10-270: a new monoclonal antibody recognizing CD10 in paraffin-embedded tissue. Am J Pathol. 1999; 154: 77-82.

${ }^{40}$ de Leon ED, Alkan S, Huang J, Hsi ED. Usefulness of an immunohistochemical panel in paraffin-embedded tissues for the differentiation of B-cell non-Hodgkin's lymphomas of small lymphocytes. Modern Pathol. 1998; 11: 1046-1051.

${ }^{41}$ Turley H, Jones M, Erber W, Mayne K, de Waele M, Gatter K. VS38: a new monoclonal antibody for detecting plasma cell differentiation in routine sections. J Clin Pathol. 1994; 47: 418-22.

${ }^{42}$ Banerjee SS, Shanks JH, Hasleton PS. VS38 immunostaining in neuroendocrine tumours. Histopathology 1997; 230: 256-9.

${ }^{43}$ Shanks JH, Banerjee SS. VS38 immunostaining in melanocytic lesions. J Clin Pathol. 1996: 49; 205-7.

${ }^{44}$ Gerdes J, Lemke H, Baisch H, Wacker HH, Schwab U, Stein H. Cell cycle analysis of a cell proliferation-associated human nuclear antigen defined by the monoclonal antibody Ki-67. J Immunol. 1984; 133: 1710-5.

${ }^{45}$ Key G, Kubbutat MH, Gerdes J. Assessment of cell proliferation by means of an enzyme-linked immunosorbent assay based on the detection of the Ki-67 protein. J Immunol Methods 1994; 177: 113-7.

${ }^{46}$ Scholzen T, Gerdes J. The Ki-67 protein: from the known and the unknown. Review. J Cell Physiol. 2000; 182: 311-22.

${ }^{47}$ Stein H, Warnke RA, Chan WC, Jaffe ES, Chan JKC, Gatter KC, Campo E. Diffuse large B cell lymphoma, not otherwise specified. In Swerdlow SH, Campo E, Harris NL, Jaffe ES, Pileri SA, Thiele J, Vardiman JW (Eds): World Health Organisation classification of tumours of haematopoietic and lymphoid tissues. $4^{\text {th }}$ ed. IARC Press Lyon 2008, 233-237.

${ }^{48}$ Coiffier B. Diffuse large cell lymphoma. Curr Opin Oncol. 2001; 13: 325-334.

${ }^{49}$ Hoffmann C, Tieman M, Schrader C, Janssen D, Wolf E, Vierbuchen M, Parwaresch R, Ernestus K, Plettenberg A, Stoehr A, Fatkenheuer G, Wyen C, Oette $\mathrm{M}$, Horst HA. AIDS-related B-cell lymphoma (ARL): correlation of prognosis with differentiation profiles assessed by immunophenotyping. Blood 2005, 106: 17621769. 
${ }^{50}$ Cote TR, Biggar RJ, Rosenberg PS, Devesa SS, Percy C, Yellin FJ, Lemp G, Hardy C, Geodert JJ, Blattner WA. Non-Hodgkin's lymphoma among people with AIDS: incidence, presentation and public health burden. AIDS/Cancer Study Group. Int J Cancer. 1997; 73: 645- 650.

${ }^{51}$ Colomo L, Loong F, Rives S, Pittaluga S, Martínez A, López-Guillermo A, Ojanguren J, Romagosa V, Jaffe ES, Campo E. Diffuse Large B-cell Lymphomas with plasmablastic differentiation represent a heterogeneous group of disease entities. Am J Surg Pathol. 2004; 28: 736-747.

${ }^{52}$ Chan JKC. Tumors of the lymphoreticular system -part A: the lymph node. In Fletcher CDM (Ed). Diagnostic Histopathology of Tumors Vol 2. $3^{\text {rd }}$ ed ChurchillLivingstone Elsevier London 2007: 1139-1288.

${ }^{53}$ Pileri SA, Dirnhofer S, Went PH, Ascani S, Sabattini E, Marafioti T, Tzankov A, Leoncini L, Falini B, Zinzani PL. Diffuse large B-cell lymphoma: one or more entities? Present controversies and possible tools for its subclassification. Histopathology 2002; 41: 482-509.

${ }^{54}$ Engelhard M, Brittinger G, Huhn D, Gerhartz HH, Meusers P, Siegert W, Thiel E, Wilmanns W, Aydemir U, Bierwolf S, Griesser H, Tiemann M, Lennert K. Subclassification of diffuse large $B$ cell lymphomas according to the Kiel classification: distinction of centroblastic and immunoblastic lymphomas is a significant prognostic risk factor. Blood 1997; 89: 2291-2297.

${ }^{55}$ Warnke RA, Strauchen JA, Burke JS, Hoppe RT, Campbell BA, Dorfman RF. Morphologic types of diffuse large B-cell lymphoma. Cancer 1982; 50: 690-695.

${ }^{56}$ Ambinder RF. Epstein-Barr virus associated lymphoproliferations in the AIDS setting. Eur J Cancer 2001; 10: 1209 -1216

${ }^{57}$ Lim ST, Levine AM. Recent Advances in Acquired Immunodeficiency Syndrome (AIDS)-related lymphoma. CA Cancer J Clin 2005; 55; 229-241.

${ }^{58}$ Hans CP, Weisenburger DD, Greiner TC, Gascoyne RD, Delabie J, Ott G, MüllerHermelink HK, Campo E, Braziel RM, Jaffe ES, Pan Z, Farinha P, Smith LM, Falini B, Banham AH, Rosenwald A, Staudt LM, Connors JM, Armitage JO, Chan WC. Confirmation of the molecular classification of diffuse large B-cell lymphoma by immunohistochemistry using a tissue microarray. Blood 2004, 103; 1: 275-282.

59 Chang CC, McClintock S, Cleveland RP, Trzpuc T, Vesole DH, Logan B, Kajdacsy-Balla A, Perkins SL. Immunohistochemical expression patterns of germinal center and activation B-cell markers correlate with prognosis in diffuse large B-cell lymphoma. Am J Surg Pathol. 2004; 28: 464-470.

${ }^{60}$ Madan R, Gormley R, Dulau A, Xu D, Walsh D, Ramesh KH, Cannizaro L, Tamas EF, Kumar P, Sparano J, LeValley A, Xue X, Bhattacharyya PK, loachim HL, Ratech $\mathrm{H}$. AIDS and non-AIDS diffuse large B-cell lymphomas express different antigen profiles. Mod Pathol. 2006; 19: 438-446. 
${ }^{61}$ Carbone A, Gaidano G, Gloghini A, Larocca LM, Capello D, Canzonieri V, Antinori A, Tirelli U, Falini B, Dalla-Favera R. Differential expression of BCL-6, CD138/Syndecan-1, and Epstein-Barr Virus-encoded latent membrane protein-1 identifies distinct histogenetic subsets of Acquired Immunodeficiency Syndromerelated non-Hodgkin's lymphomas. Blood 1998; 91: 747-755.

${ }^{62}$ Tumwine LK, Agostinelli C, Campidelli C, Othieno E, Wabinga H, Righi S, Falini B, Piccaluga PP, Byarugaba W, Pileri SA. Immunohistochemical and other prognostic factors in B cell non Hodgkin lymphoma patients, Kampala, Uganda. BMC Clin Pathol. 2009; 9 : 1-7.

${ }^{63}$ Amen F, Horncastle D, Elderfield K, Banham AH, Bower M, Macdonald D, Kanfer $\mathrm{E}$, Naresh KN. Absence of cyclin-D2 and Bcl-2 expression within the germinal centre type of diffuse large B-cell lymphoma identifies a very good prognostic subgroup of patients. Histopathology 2007; 51: 70-79.

${ }^{64}$ Lossos IS, Jones CD, Warnke R, Natkunam Y, Kaizer H, Zehnder JL, Tibshirani R, Levy R. Expression of a single gene, BCL-6, strongly predicts survival in patients with diffuse large B-cell lymphoma. Blood 2001; 98: 945-951.

${ }^{65}$ Winter JN, Weller EA, Horning SJ, Krajewska M, Variakojis D, Habermann TM, Fisher RI, Kurtin PJ, Macon WR, Chhanabhai M, Felgar RE, Hsi ED, Medeiros LJ, Weick JK, Reed JC, Gascoyne RD. Prognostic significance of Bcl-6 protein expression in DLBCL treated with CHOP or R-CHOP: a prospective correlative study. Blood 2006; 107: 4207-4213.

${ }^{66}$ Muris JJF, Meijer CJLM, Vos W, van Krieken JH, Jiwa NM, Ossenkoppele GJ, Oudejans JJ. Immunohistochemical profiling based on Bcl-2, CD10 and MUM1 expression improves risk stratification in patients with primary nodal diffuse large $B$ cell lymphoma. J Pathol. 2006; 208: 714-723.

${ }^{67}$ Ohshima K, Kawasaki C, Muta H, Muta K, Deyev V, Haraoka S, Suzumiya J, Podack ER, Kikuchi M. CD10 and Bcl10 expression in diffuse large B-cell lymphoma: CD10 is a marker of improved prognosis. Histopathology 2001; 39(2): 156-162.

${ }^{68}$ Liu YJ, Johnson GD, Gordon J, Maclennan IC. Germinal centres in T-celldependent antibody responses. Immunol Today. 1992;13:17-21.

${ }^{69}$ Cutrona G, Dono M, Pastorino S, Ulivi M, Burgio VL, Zupo S, Roncella S, Ferrarini $M$. The propensity tp apoptosis of centrocytes and centroblasts correlates with elevated levels of intracellular myc protein. Eur J Immunol. 1997;27:234-238.

${ }^{70}$ Cutrona G, Leanza N, Ulivi M, Melioli G, Burgio VL, Mazzarello G, Gabutti G. Expression of CD10 by human T cells that undergo apoptosis both in vitro and in vivo. Blood 1999; 94(9): 3067-3076.

${ }^{71}$ Cutrona G, Tasso P, Dono M, Roncella S, Ulivi M, Carpaneto EM, Fontana V, Comis M, Morabito F, Spinelli M, Frascella E, Boffa LC, Basso G, Pistoia, Ferrarini 
M. CD10 is a marker for cycling cells with propensity to apoptosis in childhood ALL. Br J Cancer 2002; 86(11): 1776-1785.

72 Morabito F, Mangiola M, Rapezzi D, Zupo S, Oliva BM, Ferraris AM, Spriano M, Rossi E, Stelitano C, Callea V, Cutrona G, Ferrarini M. Expression of CD10 by Bchronic lymphocytic leukemia cells undergoing apoptosis in vivo and in vitro. Haematologica 2003; 88(8): 864-873.

${ }^{73}$ Sjo LD, Poulsen CB, Hansen M, Møller MB, Ralfkiaer E. Profiling of diffuse large B-cell lymphoma by immunohistochemistry: identification of prognostic subgroups. Eur J Haematol. 2007; 79: 501-507.

${ }^{74}$ Xu Y, McKenna RW, Molberg KH, Kroft SH. Clinicopathologic analysis of CD10+ and CD10- diffuse large B-cell lymphoma: identification of a high-risk subset with coexpression of CD10 and bcl-2. Am J Clin Pathol. 2001;116: 183-190.

${ }^{75}$ Uherova P, Ross CW, Schnitzer B, Singleton TP, Finn WG. The clinical significance of CD10 antigen expression in diffuse large B-cell lymphoma. Am J Clin Pathol. 2001;115: 582-588.

${ }^{76}$ Fabiani B, Delmer A, Lepage E, Guettier C, Petrella T, Brière J, Penny AM, Copin MC, Diebold J, Reyes F, Gaulard P, Molina TJ; Groupe d'Etudes des Lymphomes de l'Adulte. CD10 expression in diffuse large B-cell lymphomas does not influence survival. Virchows Arch. 2004; 445: 545-551.

${ }^{77}$ Chini C, Cergnul M, Uccella S et al. Limitation of immunohistochemisty in predicting the outcome of patients treated for germinal center diffuse large B-cell lymphoma. J Clin Oncol 2008; 26 (ASCO annual meeting abstract), May 20 suppl; abstract 8604 .

${ }^{78}$ Choi WW, Weisenburger DD, Greiner TC, Piris MA, Banham AH, Delabie J, Braziel RM, Geng H, Iqbal J, Lenz G, Vose JM, Hans CP, Fu K, Smith LM, Li M, Liu Z, Gascoyne RD, Rosenwald A, Ott G, Rimsza LM, Campo E, Jaffe ES, Jaye DL, Staudt LM, Chan WC. A new immunostain algorithm classifies diffuse large B-cell lymphoma into molecular subtypes with high accuracy. Clin Cancer Res. 2009; 15: 5494-502.

79 Kramer MH, Hermans J, Parker J, Krol AD, Kluin-Nelemans JC, Haak HL, van Groningen K, van Krieken JH, de Jong D, Kluin PM. Clinical significance of bcl2 and p53 protein expression in diffuse large B-cell lymphoma: a population based study. $J$ Clin Oncol. 1996; 14: 2131-2138.

${ }^{80}$ Berglund M, Thunberg U, Amini RA, Book M, Roos G, Erlanson M, Linderoth J, Dictor M, Jerkeman M, Cavallin-Ståhl E, Sundström C, Rehn-Eriksson S, Backlin C, Hagberg H, Rosenquist R, Enblad $\mathrm{G}$. Evaluation of immunophenotype in diffuse large B-cell lymphoma and its impact on prognosis. Modern Pathol. 2005;18: 11131120. 
${ }^{81}$ Obermann EC, Csato M, Dirnhofer S, Tzankov A. BCL2 gene aberration as an IPIindependent marker for poor outcome in non-germinal-centre diffuse large $B$ cell lymphoma. J Clin Pathol. 2009; 62: 903-907.

${ }^{82}$ Hermine O, Haioun C, Lepage E, d'Agay MF, Briere J, Lavignac C, Fillet G, Salles G, Marolleau JP, Diebold J, Reyas F, Gaulard P. Prognostic significance of bcl-2 protein expression in aggressive non-Hodgkin's lymphoma. Blood 1996; 87: 265272.

${ }^{83}$ Gascoyne R, Adomat S, Krajewski S, Krajewska M, Horsman DE, Tolcher AW, O'Reilly SE, Hoskins P, Coldman AJ, Reed JC, Connors JM. Prognostic significance of bcl-2 protein expression and $\mathrm{Bcl}-2$ gene rearrangement in diffuse aggressive nonHodgkin's lymphoma. Blood 1997; 90: 244-251.

${ }^{84}$ Barrans SL, Carter I, Owen RG, Davies FE, Patmore RD, Haynes AP, Morgan GJ, Jack AS. Germinal center phenotype and bcl-2 expression combined with the International Prognostic Index improves patient risk stratification in diffuse large Bcell lymphoma. Blood 2002, 99: 1136-1143.

${ }^{85}$ Nyman H, Jerkeman M, Karjalainen-Lindsberg ML, Banham AH, Leppä S. Bcl-2 but not FOXP1, is an adverse risk factor in immunochemotherapy-treated nongerminal center diffuse large B-cell lymphomas. Eur J Haematol. 2009, 82: 364-372.

${ }^{86}$ Little RF, Pittaluga S, Grant N, Steinberg SM, Kavlick MF, Mitsuya H, Franchini G, Gutierrez M, Raffeld M, Jaffe ES, Shearer G, Yarchoan R, Wilson WH. Highly effective treatment of acquired immunodeficiency syndrome-related lymphoma with dose-adjusted EPOCH: Impact of antiretroviral therapy suspension and tumor biology. Blood 2003; 101: 4653-4659.

${ }^{87}$ Sanchez E, Chacon I, Plaza MM, Muñoz E, Cruz MA, Martinez B, Lopez L, Martinez-Montero JC, Orradre JL, Saez AI, Garcia JF, Piris MA. Clinical outcome in diffuse large B-cell lymphoma is dependent on the relationship between different cell-cycle regulator proteins. J Clin Oncol. 1998; 16: 1931-1939.

${ }^{88}$ Miller TP, Grogan TM, Dahlberg S, Spier CM, Braziel RM, Banks PM, Foucar K, Kjeldsberg CR, Levy N, Nathwani BN. Prognostic significance of the Ki67associated proliferation antigen in aggressive non-Hodgkin's lymphomas: a prospective Southwest Oncology Group trial. Blood 1994; 83: 1460-1466.

${ }^{89}$ Chadburn A, Chiu A, Lee JY, Chen X, Hyjek E, Banham AH, Noy A, Kaplan LD, Sparano JA, Bhatia K, Cesarman E. Immunophenotypic analysis of AIDS-related diffuse large B-cell lymphoma and clinical implications in patients from AIDS Malignancies Consortium clinical trials 010 and 034. J Clin Oncol. 2009; 27: 50395048.

${ }^{90}$ Obermann EC, Csato M, Dirnhofer S, Tzankov A. Aberrations of the MYC gene in unselected cases of diffuse large $B$ cell lymphoma are rare and unpredictable by morphological or immunohistochemical assessment. J Clin Pathol. 2009; 62: 754756. 
${ }^{91}$ Rao PH, Houldsworth J, Dyomina K, Parsa NZ, Cigudosa JC, Louie DC, Popplewell L, Offit K, Jhanwar SC, Chaganti RS. Chromosomal and gene amplification in diffuse large B-cell lymphoma. Blood 1998; 92: 234-240.

${ }^{92}$ Chang CC, Liu YC, Cleveland RP, Perkins SL. Expression of c-Myc and p53 correlates with clinical outcome in diffuse large B-cell lymphomas. Am J Clin Pathol. 2000; 113: 512-518.

${ }^{93}$ Sanchez E, Chacon I, Plaza MM, Muñoz E, Cruz MA, Martinez B, Lopez L, Martinez-Montero JC, Orradre JL, Saez AI, Garcia JF, Piris MA. Clinical outcome in diffuse large B-cell lymphoma is dependent on the relationship between different cell-cycle regulator proteins. J Clin Oncol. 1998; 16: 1931-1939.

${ }^{94}$ Antinori A, Cingolani A, Alba L, Ammassari A, Serraino D, Ciancio BC, Palmieri F, De Luca A, Larocca LM, Ruco L, Ippolito G, Cauda R. Better response to chemotherapy and prolonged survival in AIDS-related lymphomas responding to highly active antiretroviral therapy. AIDS 2001; 15: 1483-1491.

${ }_{95}$ Navarro JT, Ribera JM, Oriol A. Influence of highly active antiretroviral therapy on response to treatment and survival in patients with acquired immunodeficiency syndrome-related non-Hodgkin's lymphoma treated with CHOP. Brit J Haematol. 2001; 112: 909-915.

${ }^{96}$ Besson C, Goubar A, Gabarre J. Changes in AIDS-related lymphoma since the era of highly active antiretroviral therapy. Blood 2001 98: 2339-2344.

${ }^{97}$ Matthews GV, Bower M, Mandalia S, Powles T, Nelson MR, Gazzard BG. Changes in acquired immunodeficiency syndrome-related lymphoma since the introduction of highly active antiretroviral therapy. Blood. 2000; 96: 2730-2734.

${ }^{98}$ Ledergerber B, Telenti A, Egger M. Risk of HIV-related Kaposi's sarcoma and nonHodgkin's lymphoma with potent antiretroviral therapy: prospective cohort study. BMJ. 1999; 319: 23-24.

${ }^{99}$ South African National Antiretroviral Treatment Guidelines. National Department of Health South Africa: Jacana; 2004.

100 The South African antiretroviral treatment guidelines 2010.

${ }^{101}$ Cohen JI, Bollard CM, Khanna R, Pittaluga S. Current understanding of the role of Epstein-Barr virus (EBV) in lymphomagenesis and therapeutic approaches to EBV associated lymphomas. Leuk Lymphoma. 2008; 49(Suppl 1): 27-34.

102 Hislop AD, Taylor GS, Sauce D, Rickinson AB. Cellular responses to viral infection in humans: lessons from Epstein-Barr virus. Annu Rev Immunol. 2007; 25: 587-617.

${ }^{103}$ Cohen Jl. Epstein-Barr virus infection. N Engl J Med. 2000; 343: 481-492. 
${ }^{104}$ Kieff, E.; Rickinson, AB. Epstein-Barr virus and its replication. In: Knipe, DM.; Howley, PM. (Eds). Fields Virology. Vol 2. 5th ed. Lippincott: Williams and Wilkins; Philadelphia 2007, 2603-2654.

105 Thorley-Lawson DA. Epstein-Barr virus: exploiting the immune system. Nat Rev Immunol. 2001; 1: 75-82.

106 Johannsen E, Koh E, Mosialos G, Tong X, Kieff E, Grossman SR. Epstein-Barr virus nuclear protein 2 transactivation of the latent membrane protein 1 promoter is mediated by J kappa and PU.1. J Virol. 1995; 69: 253-262.

107 Young LS, Dawson CW, Eliopoulos AG. Epstein-Barr virus and apoptosis: viral mimicry of cellular pathways. Biochem Soc Trans. 1999; 27: 807-812.

${ }^{108}$ Rickinson AB, Kieff E. Epstein-Barr virus. In: Knipe DM, Howley PM. (Eds). Fields Virology.Vol. 2, 5th ed. Lippincott: Williams and Wilkins Philadelphia 2007, 2655-2700.

${ }^{109}$ Siebenlist U, Franzoso G, Brown K. Structure, regulation and function of NF-KB. Annu Rev Cell Biol. 1994; 10: 405-445.

${ }^{110}$ Karin M, Ben-Neriah Y. Phosphorylation meets ubiquitination: the control of NFKB activity. Annu. Rev.Immunol. 2000; 18: 621-663.

${ }^{111}$ Gugasyan R, Grumont R, Grossmann M, Nakamura Y, Pohl T, Nesic D, Gerondakis S. Rel/NF-kB transcription factors: key mediators of B-cell activation. Immunol.Rev. 2000; 176: 134-140.

112 Bonizzi G, Karin M. The two NF-kappa B activation pathways and their role in innate and adaptive immunity. Trends Immunol. 2004; 25: 280-288.

${ }^{113}$ Grumont RJ, Rourke IJ, O'Reilly LA, Strasser A, Miyake K, Sha W, Gerondakis S. $B$ lymphocytes differentially use the Rel and nuclear factor kB1 (NF-kB1)

transcription factors to regulate cell cycle progression and apoptosis in quiescent and mitogen-activated cells. J. Exp. Med. 1998; 187: 663-674.

${ }^{114}$ Grumont RJ, Rourke IJ, Gerondakis S. Rel dependent induction of A1 transcription is required to protect $B$ cells from antigen receptor ligation-induced apoptosis. Genes Dev. 1999; 13: 400-411.

115 Staudt LM. The molecular and cellular origins of Hodgkin's disease. J. Exp. Med. 2000; 191: 207-212.

${ }^{116}$ Alizadeh AA, Eisen MB, Davis RE, Ma C, Lossos IS, Rosenwald A, Boldrick JC, Sabet H, Tran T, Yu X, Powell JI, Yang L, Marti GE, Moore T, Hudson J Jr, Lu L, Lewis DB, Tibshirani R, Sherlock G, Chan WC, Greiner TC, Weisenburger DD, Armitage JO, Warnke R, Levy R, Wilson W, Grever MR, Byrd JC, Botstein D, Brown PO, Staudt LM. Distinct types of diffuse large B-cell lymphoma identified by gene expression profiling. Nature 2000; 403: 503-511. 
${ }^{117}$ Davis RE, Brown KD, Siebenlist U, Staudt LM. Constitutive nuclear factor kappaB activity is required for survival of activated B cell-like diffuse large B cell lymphoma cells. J Exp Med 2001; 194: 1861-1874.

118 Banks PM, Keller RH, Li C-Y, White WL. Case report Malignant lymphoma of plasmablastic identity: A neoplasm with both "immunoblastic" and plasma cellular features. Am J Med. 1978; 64(5): 906-909.

119 Delecluse HJ, Anagnostopoulos I, Dallenbach F, Hummel M, Marafioti T, Schneider U, Huhn D, Schmidt-Westhausen A, Reichart PA, Gross U, Stein H. Plasmablastic lymphomas of the oral cavity: a new entity associated with the human immunodeficiency virus infection. Blood 1997; 89: 1413-1420.

${ }^{120}$ Brown RSD, Campbell C, Lishman SC, Spittle MF, Miller RF. Plasmablastic lymphoma: a new subcategory of human immunodeficiency virus-related nonHodgkin's lymphoma. Clin Oncol. 1998; 10: 327-329.

${ }^{121}$ Carbone A, Gaidano G, Gloghini A, Ferlito A, Rinaldo A, Stein H. AIDS related plasmablastic lymphomas of the oral cavity and jaws: a diagnostic dilemma. Ann Otol Rhinol Laryngol. 1999; 108: 95-99.

${ }^{122}$ Chetty R, Hlatswayo N, Muc R, Sabaratnam R, Gatter K. Plasmablastic lymphoma in HIV+ patients: an expanding spectrum. Histopathology 2003; 42: 605609.

${ }^{123}$ Lin Y, Rodrigues GD, Turner JF, Vasef MA. Plasmablastic Lymphoma of the Lung. Report of a Unique Case and Review of the Literature. Arch Pathol Lab Med. 2001; 125: 282-285.

${ }^{124}$ Gatter K, Warnke R. Diffuse large B-cell lymphoma. In:Jaffe ES, Harris NL, Stein $\mathrm{H}$, Vardiman JW (eds). WHO Pathology and Genetics of Tumours of Haematopoietic and Lymphoid Tissues. $3^{\text {rd }}$ edn. France: IARC Press Lyon; 2001, 171-174 ${ }^{125}$ Levine AM. AIDS-related lymphoma. Semin Oncol Nurs. 2006; 22: 80-9.

${ }^{126}$ Chabay P, De Matteo E, Lorenzetti M, Gutierrez M, Narbaitz M, Aversa L, Preciado MV. Case report: Vulvar plasmablastic lymphoma in a HIV-positive child: a novel extraoral localisation. J Clin Pathol. 2009; 62: 644-646.

${ }^{127}$ Radhakrishnan R, Suhas S, Kumar RV, Krishnanand G, Srinivasan R, Rao NN.. Plasmablastic lymphoma of the oral cavity in an HIV-positive child. Oral Surg Oral Med O. 2005; 100: 725-731.

${ }^{128}$ Scheper MA, Nikitakis NG, Fernandes R, Gocke CD, Ord RA, Sauk JJ. Oral plasmablastic lymphoma in an HIV-negative patient: a case report and review of the literature. Oral Surg Oral Med O. 2005; 100: 198-206. 
${ }^{129}$ Lin F, Zhang K, Quiery AT, Prichard J, Schuerch C. Plasmablastic Lymphoma of the cervical lymph nodes in a Human Immunodeficiency Virus-negative patient. A case report and review of the literature. Arch Pathol Lab Med. 2004; 128: 581-584.

${ }^{130}$ Guan B, Zhang X, Hu W, Rao Q, Wang Y, Zhu Y, Wang H, Ma H, Zhou H, Zhou $X$. Plasmablastic lymphoma of the oral cavity in an HIV-negative patient. Ann Diagn Pathol. Forthcoming.

${ }^{131}$ Teruya-Feldstein J, Chiao E, Filippa DA, Lin O, Comenzo R, Coleman M, Portlock C, Noy A. CD20-negative large-cell lymphoma with plasmablastic features: a clinically heterogenous spectrum in both HIV-positive and -negative patients. Ann Oncol. 2004; 15: 1673-1679.

132 Tavora F, Gonzalez-Cuyar LF, Sun CC, , Burke A, Zhao XF. Extra-oral plasmablastic lymphoma: report of a case and review of literature. Hum Pathol. 2006; 37: 1233- 1236.

${ }^{133}$ Dong HY, Scadden DT, de Leval L, Tang Z, Isaacson PG, Harris NL.

Plasmablastic lymphoma in HIV-positive patients: an aggressive Epstein-Barr virusassociated extramedullary plasmacytic neoplasm. Am J Surg Pathol. 2005; 29: 1633- 1641.

134 Rochford R, Hobbs MV, Garnier JL, Cooper NR, Cannon MJ. Plasmacytoid differentiation of Epstein-Barr virus-transformed B cells in vivo is associated with reduced expression of viral latent genes. Proc Natl Acad Sci USA. 1993; 90: 352356.

${ }^{135}$ Dupin N, Diss TL, Kellam P, Tulliez M, Du MQ, Sicard D, Weiss RA, Isaacson PG, Boshoff C. HHV-8 is associated with a plasmablastic variant of Castleman disease that is linked to HHV-8-positive plasmablastic lymphoma. Blood 2000; 95: 14061412.

${ }^{136}$ Oksenhendler E, Boulanger E, Galicier L, Du MQ, Dupin N, Diss TC, Hamoudi R, Daniel MT, Agbalika F, Boshoff C, Clauvel JP, Isaacson PG, Meignin V. High incidence of Kaposi sarcoma-associated herpesvirus-related non-Hodgkin's lymphoma in patients with HIV infection and multicentric Castleman disease. Blood 2002; 99: 2331-2336.

${ }^{137}$ Cioc AM, Allen C, Kalmer JR, Suster S, Baiocchi R, Nuovo GJ. Oral plasmablastic lymphomas in AIDS patients are associated with human herpesvirus 8. Am J Surg Pathol 2004; 28: 41- 46.

138 Deloose STP, Smit LA, Pals FT, Kersten MJ, van Noesel CJ, Pals ST. High incidence of Kaposi sarcoma-associated herpesvirus infection in HIV-related solid immunoblastic/plasmablastic diffuse large B-cell lymphoma. Leukemia 2005; 19: 851-855.

139 Toure G, Roucayrol A, Meningaud JP, Bertrand JC. Plasmablastic lymphoma: a case report. Quintessence Int. 2007; 38: 161-3. 
${ }^{140}$ Cathomas G, Stalder A, McGandy CE, Mihatsch MJ. Distribution of human herpesvirus 8 DNA in tumorous and nontumorous tissue of patients with acquired immunodeficiency syndrome with and without Kaposi's sarcoma.

Mod Pathol. 1998; 11: 415-420.

${ }^{141}$ Carbone A, Gloghini A, Giadano G. Is plasmablastic lymphoma of the oral cavity an HHV8-associated disease? Am J Surg Pathol. 2004; 28: 1251-1252.

${ }^{142}$ Qing X, Sun N, Chang E, French S, Ji P, Yue C. Plasmablastic lymphoma may occur as a high-grade transformation from plasmacytoma. Exp Molecular Pathol. 2011; 90: 85-90.

${ }^{143}$ Folk GS, Abbondanzo SL, Childers EL, Foss RD. Plasmablastic lymphoma: a clinicopathologic correlation. Ann Diagn Pathol. 2006; 10: 8-12.

${ }^{144}$ Dawson MA, Schwarer AP, McLean C, Oei P, Campbell LJ, Wright E, Shortt J, Street AM. Aids-related plasmablastic lymphoma of the oral cavity associated with an $\mathrm{lgH} / \mathrm{MYC}$ translocation-treatment with autologous stem-cell transplantation in a patient with severe haemophilia-A. Haematologica 2007; 92: 11-12.

${ }^{145}$ Gaidano G, Cerri M, Capello D, Berra E, Deambrogi C, Rossi D, Larocca LM, Campo E, Gloghini A, Tirelli U, Carbone A. Molecular histogenesis of plasmablastic lymphoma of the oral cavity. Br J Haematol. 2002; 119: 622-8.

${ }^{146}$ Chang CC, Zhou X, Taylor JJ, Huang WT, Ren X, Monzon F, Feng Y, Rao PH, Lu $X Y$, Fabio F, Hilsenbeck S, Creighton CJ, Jaffe ES, Lau CC. Genomic profiling of plasmablastic lymphoma using array comparative genomic hybridization (aCGH): revealing significant overlapping genomic lesions with diffuse large B-cell lymphoma. J Hematol Oncol. 2009; 2: 47. doi:10.1186/1756-8722-2-47.

${ }^{147}$ Vega F, Chang CC, Medeiros LJ, Udden MM, Cho-Vega JH, Lau CC, Finch CJ, Vilchez RA, McGregor D, Jorgensen JL. Plasmablastic lymphomas and plasmablastic plasma cell myelomas have nearly identical immunophenotypic profiles. Modern Pathol. 2005; 18: 806-815.

${ }^{148}$ Evison J, Jost J, Ledergerber B, Jost L, Strasser F, Weber R. HIV-associated non-Hodgkin's lymphoma: highly active antiretroviral therapy improves remission rate of chemotherapy. AIDS 1999, 13: 732-734.

${ }^{149}$ Thiessard F, Morlat P, Marimoutou C, Labouyrie E, Ragnaud JM, Pellegrin JL, Dupon M, Dabis F, the Groupe d'Epidémiologie Clinique du SIDA en Aquitaine (GECSA). Prognostic factors after non-Hodgkin's lymphoma in patients infected with the human immunodefciency virus: Aquitaine cohort, France. Cancer 2000; 88: 1696-1702.

${ }^{150}$ Hockenbery D, Nunez G, Milliman C, et al. Bcl-2 is an inner mitochondrial membrane protein that blocks programmed cell death. Nature 1990; 348: 334-336. 
${ }^{151}$ Cory S. Regulation of lymphocyte survival by the bcl-2 gene family.Annu Rev Immunol. 1995; 13: 513-543.

${ }^{152}$ Reed JC. Bcl-2 family proteins: regulators of apoptosis and chemoresistance in hematologic malignancies. Semin Hematol. 1997; 34: 9-19.

${ }^{153}$ Castillo J, Pantanowithz L, Dezube BJ. HIV-associated plasmablastic lymphoma: A literature review of 112 cases. Am J Hematol. 2008; 83: 804-809.

${ }^{154}$ Flaitz CM, Nichols, Walling DM, Hicks MJ. Case report. Plasmablastic lymphoma: an HIV-associated entity with primary oral manifestations. Oral Oncol. 2002; 38: 96102.

155 Valera A, Balagué O, Colomo L, Martínez A, Delabie J, Taddesse-Heath L, Jaffe $\mathrm{ES}$, Campo E. IG/MYC rearrangements are the main cytogenetic alteration in plasmablastic lymphomas. Am J Surg Pathol. 2010; 34: 1686-1694.

156 Hans CP, Weisenburger DD, Greiner, TC, Chan WC, Aoun P, Cochran GT, Pan Z, Smith LM, Lynch JC, Bociek RG, Philip J Bierman PJ, Vose JM, Armitage JO. Expression of PKC-beta or cyclin D2 predicts for inferior survival in diffuse large Bcell lymphoma. Mod Pathol 2005; 18: 1377-1384.

157 Ventura G, Lucia MB, Damiano F, Cauda R, Larocca LM. Multiple myeloma associated with Epstein-Barr virus in an AIDS patient: a case report. Eur J Haematol. 1995; 55: 332-334.

158 Yan B, Tan SY, Yau EX, Ng SB, Petersson F. EBV-Positive Plasmacytoma of the Submandibular Gland-Report of a Rare Case with Molecular Genetic Characterization. Head Neck Pathol. DOI: 10.1007/s12105-011-0257-z. 
Health Sciences Faculty

Research Ethics Committee

Room E52-24 Groote Schuur Hospital Old Main Building
Observatory 7925

Telephone [021] 4066338 • Facsimile [021] 4066411

e-mail: preaward@curie.uct..ac.za

02 June 2006

REC REF: 209/2006

Dr S Pather

Anatomical Pathology

Dear Dr Pather

PROJECT TITLE: LARGE CELL LYMPHOMA:
CORRELATION OF

Thank you for submitting your study to the Research Ethics Committee for review.

It is a pleasure to inform you that the Ethics Committee has formally approved the above-mentioned study.

Please ensure that any potentially identifying information is anonymised (ie. No personal identifying details are collected) or de-identified.

This serves to confirm that the University of Cape Town Research Ethics Committee complies to the Ethics Standards for Clinical Research with a new drug in patients, based on the Medical Research Council (MRCSA), Food and Drug Administration (FDA-USA), International Convention on

Harmonisation Good Clinical Practice (ICH GCP) and Declaration of Helsinki guidelines.

The Research Ethics Committee granting this approval is in compliance with the ICH Harmonised Tripartite Guidelines E6: Note for Guidance on Good Clinical Practice (CPMP/ICH/135/95) and FDA Code Federal Regulation Part 50, 56 and 312.

Please note that the ongoing ethical conduct of the study remains the responsibility of the principal investigator.

Please quote the REC. REF in all your correspondence. 


$$
[
$$

